large intersite ferromagnetic interaction predicted by LSDA is also was shown to be an artifact. Thus, the observed RTFM in MgO cannot be explained by a simple model where magnetic interactions between hole centers, in their ground state, percolate through the sample. But, in 2014 Choudhury's [9] again showed that RTFM is expected to be arising from Mg vacancies which induce spin polarization of $2 p$ electrons of the oxygen atom and result in ferromagnetism. In the next year, Merabet et al. [25] shown that there is a significant polarization energy gain resulting from the oxygen atoms of nearest neighbors of the cation vacancy and making it ferromagnetic. If the authors refer to the results obtained with the LSDA approximation, these defects are responsible for the appearance of localized electronic states may change forbidden bandwidths which give rise to the magnetic moments. In 2018 Khamkongkoe et al. [26] once more confirmed that RTFM in the NPs caused by the induction of magnetic moment from the $2 p$ orbitals of the nearest $\mathrm{O}$ atoms surrounding the $\mathrm{Mg}$ vacancies.

Very attractive conception concerns the presence of divacancies. In 2014 Choudhury's [9] observed that defects play a prominent role in making the $\mathrm{MgO}$ nanoparticle an optically and magnetically active material. In MgO, the oxygen vacancies are present as color centers, or as dimmers of these color centers. These color centers create energy levels in the band gap of $\mathrm{MgO}$ and the trapped electron in these centers undergoes excitation on exposure to UV light. The authors have observed that although oxygen vacancies make $\mathrm{MgO}$ optically active, these vacancies have an opposite effect on the magnetism. In 2017 Pathak et al. [27] performed some positron annihilation lifetime measurements which indicate the presence of divacancy $\left(2 \mathrm{~V}_{\mathrm{Mg}}+2 \mathrm{~V}_{\mathrm{O}}\right)$ cluster along with $\mathrm{Mg}$ vacancies at the low annealing temperature. An EPR study showed that $\mathrm{MgO}$ compound possesses both singly negative charged $\mathrm{Mg}$ vacancies and singly positively charged oxygen vacancies and the spins of both of these vacancies are ferromagnetically coupled. DFT calculation also showed that this dimer form has higher magnetic moment than the monomer.

Thus, both Mg vacancy/divacancy and oxygen vacancy in MgO nanomaterials could promote the RTFM formation, and it is necessary to obtain new experimental data to improve the description of RTFM phenomenon."

Q\#2: In the Graphical abstract, the Authors should add other details, (i.e., BET specific surface), that put in relation the magnetic results to the NPs features.

A: In the Graphical abstract was added some information about BET specific surface areas and MgO contents.

Moreover, there are some specific comments that the authors need to follow before acceptance for publication:

Q1) Page 2: Please, clarify the sentence "The observed ferromagnetism in MgO nanoparticles was a subject of great interest because bulk magnesia is a diamagnetic material, what makes MgO NPs one of the most attractive model materials for the RTFM study"

A1: CORRECTED as: " It is known that bulk magnesium oxide (MgO) exhibits interesting properties, such as high symmetry of rock salt structure, a wide direct band gap of $7.8 \mathrm{eV}$ [4] and the most common defects of $\mathrm{V}$-type centers, which make it one of the most attractive model materials for investigating the RTFM [1]."

Q2) Page 2: Insert a reference related to the following sentence: "It is known, that the main advantage of using nanoparticles (which have the largest specific surface area) over those of films is the more accurate determining of specific magnetization values of the materials."

A2: CORRECTED as: "Nanoparticles, with their large surface-to-volume ratio, can be especially effective in producing various structural defects [3]. This is necessary to take in mind for the adequate comparison of data between samples prepared under different fabrication methods and synthesis conditions [6]." 
3) Page 2: Considering the following sentence: "Experimentally RTFM has been observed in undoped $\mathrm{MgO}$ nanoparticles preferable synthesized by wet chemical routes", complete with: (see Table 1)

A3: CORRECTED.

4) Page 2: Please, explain what the Author mean when they say: "the surface of such nanoparticles was not sufficiently clean"

A4: CORRECTED as: "the surface of such nanoparticles could not sufficiently clean compared with NPs produced by gas-phase methods."

Q5) Page 3: Substitute "metal magnesium" with "metallic magnesium"

A5: "metal" is corrected to "metallic".

6) Page 4: Please, specify better the techniques that are used to evaluate the parameters listed in Table 2 , or move the Table in the "Results and discussion" section

A6: In page 4 the text was corrected as: "Some parameters of the NPs synthesis, including metal feed rates, gases flow rates, and corresponding collection zones are listed in Table 2.

Table 2. Main properties of the Mg-O NPs. $S$ - specific surface area obtained from BET measurements; $<d\rangle$ - mean particle size obtained from SEM micrographs; $y$ - MgO content and $a-\mathrm{MgO}$ lattice parameter obtained from XRD data; $\sigma_{s}-$ maximum specific magnetization (VSM, RT, $10 \mathrm{kOe}$ )."

7) Page 5: As concerns the BET measurements, specify the measurements conditions (i.e., time, temperature, minimum pressure in outgassing procedure)

A7: In the text on page 5 was added the sentence: "No outgassing procedures were applied before the BET measurements."

8) Page 6: Correct: "collected in the main zone" with "collected in the main zones" A8: CORRECTED.

9) Page 6: Considering the sentence: "In Figure 2a, NPs of about $50 \mathrm{~nm}$ in an average size is generally uniform cubes", please specify how the Authors evaluate the average size. From a first visual investigation, only the interval can be estimated.

A9: In the text on page 5 written: "Particle size and morphology were investigated by scanning electron microscopy (SEM) using CARL ZEISS ULTRA PLUS. Electron micrographs were analyzed by Carl Zeiss AxioVision ver. 4.82 image processing software to calculate the average particle size $\langle d\rangle[22] . "$

10) Page 6: Author refer to the "Particle size distribution", but it is not reported. Did the Author evaluate the particles size distribution by SEM images?

A10: Yes, see A12.

11) Page 6: The same consideration reported in point 9), but in relation to the average evaluation of the NPs of Figure $2 b$

A11: See A9.

12) Page 6: Considering the sentence "NPs (M), collected from the most remote zone $(400 \mathrm{~mm})$, has bigger average size with a roughed surface (Figure 2e)": in my opinion, from the SEM images of Figures 2 $c-d-e)$, (having a slight difference in the marker size, too) there is no relevant differences in the NPs dimensions collected from the three different zones.

A12: To clarify this situation the particles size distributions evaluated by SEM images was added as the new Figures $3 d, 3 e$, and $3 f$.

13) Page 7: In the caption of Figure 2, please, report the letter representing the three main zones ( $M, T$ or C) 
A13: The letter representing the three main zones $(\mathrm{M}, \mathrm{T}$ or $\mathrm{C})$ was inserted in the caption of the new Figure 3.

14) Page 8, Fig. 3 and Fig 4: In my opinion, it is better to graph the three XRD patterns not superimposed one each other, in order to see the differences

A14: CORRECTED. 


\title{
Effect of synthesis conditions on room-temperature ferromagnetic properties of $\mathrm{Mg}-\mathrm{O}$ nanoparticles
}

\author{
Iu.G. Morozova, , , S. Sathasivam ${ }^{\mathrm{b}}$, O.V. Belousova ${ }^{\mathrm{a}}$, I.P. Parkin' ${ }^{\mathrm{b}}$, and M.V. Kuznetcov \\ ${ }^{a}$ Institute of Structural Macrokinetics and Materials Science, Russian Academy of Sciences, 8 Academician Osipyan \\ Street, Chernogolovka, Moscow Region, 142432 Russia \\ ${ }^{\mathrm{b}}$ Department of Chemistry, University College London, 20 Gordon Street, London WC1H OAJ UK \\ ${ }^{\mathrm{c}}$ All-Russian Research Institute on Problems of Civil Defense and Emergencies of Emergency Control Ministry of \\ Russia (EMERCOM), 7 Davidkovskaya Street, Moscow, 121352 Russia
}

\begin{abstract}
A B S T R A C T
Cubic, terraced, and spherical Mg-MgO nanoparticles (NPs), ranging in average particle size from 30 up to $80 \mathrm{~nm}$, were prepared through vaporization and condensation of $\mathrm{Mg}$ metal in mix gas flow (argon + air) at conditions of the levitation-jet aerosol synthesis. These NPs were collected in three zones, located at different distances from an evaporator. Scanning electron microscopy (SEM), X-ray diffraction (XRD), BET measurements, UV-Vis, FT-IR, Raman, XPS, and vibrating-sample magnetometry (VSM) were used for characterized of NPs. The results indicated an essential effect of synthesis conditions on the nanoparticle properties. Room temperature ferromagnetism with the maximum magnetization of up to $0.65 \mathrm{emu} / \mathrm{g}$ was found in the nanoparticles. The maximum specific magnetization of the NPs depends on the value of specific surface area multiplied by oxide content in the form of two-peaks function. It was discovered a clear increase in the maximum magnetization of NPs, collected in the different zones, with an increase in the distance of these zones from the evaporator. It was suggested that the observed ferromagnetic ordering may be related to the $\mathrm{Mg}$ deficient defects on the surface of NPs. This suggestion was in agreement with the results of optical experiments, particularly, with an increase in the Raman peak intensities. In addition, XPS studies reveal an oscillating quenching dependence of the maximum magnetization on $\mathrm{Mg} 2 \mathrm{p}$ peak width value. It was also supposed that various values of the maximum magnetization origin from the different fabrication conditions promoting defects propagation on the surface of NPs.
\end{abstract}

Keywords:

Nanoparticles (NPs)

Room temperature ferromagnetism (RTFM)

Levitation-jet generator

Magnesium oxide

NPs optical properties

XPS

\section{Introduction}

Today there is a large number of reports on room temperature (RT) ferromagnetism (RTFM) in metal oxide semiconductors, those open new directions in the research field of such materials [1]. RTFM, reported in certain thin films and nanoparticles (NPs) of non-magnetic oxides, can be explained by the presence of defects on their surfaces [2]. While oxygen vacancy defects are believed to have a main effect on the ferromagnetic order in some oxide semiconductors, the origin of RTFM in insulators, such as MgO, is still unclear [3].

\footnotetext{
* Corresponding author.

E-mail addresses: morozov@ism.ac.ru (Iu.G. Morozov), sanjayan1@gmail.com (S. Sathasivam), belous@ism.ac.ru, i.p.parkin@ucl.ac.uk (I.P.Parkin), maxim1968@mail.ru (M.V. Kuznetcov)
} 
It is known that bulk magnesium oxide $(\mathrm{MgO})$ exhibits interesting properties, such as high symmetry of rock salt structure, a wide direct band gap of $7.8 \mathrm{eV} \mathrm{[4]} \mathrm{and} \mathrm{the} \mathrm{most} \mathrm{common}$ defects of V-type centers, which make it one of the most attractive model materials for investigating the RTFM [1]. Besides, $\mathrm{MgO}$ is one of many advanced engineering materials, that has been investigated intensively in recent years, because of their potential for various applications in medical and pharmaceutical products, toxic waste remediation, electronics industry, etc. [5].

Nanoparticles, with their large surface-to-volume ratio, can be especially effective in producing various structural defects [3]. This is necessary to take in mind for the adequate comparison of data between samples prepared under different fabrication methods and synthesis conditions [6]. Experimentally RTFM has been observed in undoped $\mathrm{MgO}$ nanoparticles preferable synthesized by wet chemical routes (see Table 1). These findings have described a behavior of NPs only in the narrow range of average particle sizes (6-52 nm) with different maximum RT magnetization from 2 to $70 \mathrm{memu} / \mathrm{g}$ (Table 1), wherein, the surface of such nanoparticles could not sufficiently clean compared with NPs produced by gas-phase methods. The other mentioned methods also did not exclude the unwanted contact of nanoparticles with installation details before the synthesis process was finished. Because of that, there was difficult to estimate a role of the original surface in the RTFM evolution of the NPs.

Table 1. Experimental observation of RTFM in undoped Mg-O NPs.

\begin{tabular}{|c|c|c|c|}
\hline Fabrication method & $\begin{array}{l}\text { Average particle } \\
\text { size, } \mathrm{nm}\end{array}$ & $\begin{array}{l}\text { Maximum RT } \\
\text { magnetization, memu/g }\end{array}$ & Refs. \\
\hline \multirow[t]{2}{*}{ Sol-gel } & $6-23$ & 13 & [7] \\
\hline & 24,52 & 33 & {$[8]$} \\
\hline \multirow[t]{6}{*}{ Wet-chemical technology } & 12 & 2.6 & [3] \\
\hline & 13 & 70 & [9] \\
\hline & $17,21,25$ & 8.3 & {$[2]$} \\
\hline & $20-30$ & 50 & {$[10]$} \\
\hline & $22,28,32$ & 2 & {$[11]$} \\
\hline & 35 & 14 & {$[12]$} \\
\hline Microwave-assisted co-precipitation & 20 & 25 & {$[13]$} \\
\hline Thermal decomposition of $\mathrm{Mg}(\mathrm{OH})_{2}$ & 50 (clustered) & 2 & {$[5]$} \\
\hline Polymer pyrolysis & 25 & 35 & {$[14]$} \\
\hline $\begin{array}{l}\text { Vaporization-condensation in a glass balloon under } \\
\text { reduced pressure }\end{array}$ & 15 & 13 & [15] \\
\hline
\end{tabular}

The currently available phenomenological and theoretical considerations related to the origin of RTFM in $\mathrm{MgO}$ nanomaterials are rather inconsistent. 
Some authors suggested that RTFM behavior results from the oxygen vacancies at the surfaces of NPs. In $2011 \mathrm{Maoz}$ et al. [16] studied highly defective nanosheets of $\mathrm{MgO}$ with RTFM. Using EPR experiments, they have confirmed that the material comprised strongly interacting spin clusters, concentrated along extended defects, possibly as unpaired electrons trapped at oxygen vacancies. In 2013 Mishra et al. [17] have established the direct correlation between the oxygen vacancy concentrations and the values of magnetization of MgO NPs. In 2017 Qi et al. [18], using photoluminescence and theoretical analysis, revealed that the single charged oxygen vacancy plays an important role in mediating the RTFM in MgO ceramics. These authors explained ferromagnetic exchange coupling between oxygen vacancies either by direct exchange interactions between oxygen vacancies or by the mediation of conduction electrons. But already in 2009 Wang et al. [19], studying the electronic and magnetic properties of $\mathrm{MgO}$ bulk, thin films, and quantum dots and carrying out calculations by density functional theory, show that oxygen vacancies do not lead to magnetism in $\mathrm{MgO}$ independent of the concentration. In 2013 Rao et al. [13] confirmed that oxygen vacancies do not induce RTFM.

The other authors suggested that RTFM behavior results from Mg vacancies. In 2009 Kumar et al. [11] have observed ferromagnetism in $\mathrm{MgO}$ NPs, which they attributed to $\mathrm{Mg}$ vacancies. In $2013 \mathrm{Li}$ et al. [20] and Mahadeva et al. [21] revealed that there exists a close correlation between the RTFM, the crystallinity, and the Mg vacancy concentrations in the $\mathrm{MgO}$ thin films. In 2017 Guo et al. [22] observed the RTFM in Mg deficiency MgO film and decided that the RTFM should be related to $\mathrm{Mg}$ vacancy defects.

Some researchers reported that though the bulk $\mathrm{MgO}$ was nonmagnetic MgO NPs showed RTFM, which probably originates due to the loss ( $\mathrm{Mg}$ vacancies) of donor charge of $\mathrm{O}$ atoms, which will form the $2 p$ holes at the surface of the nanomaterials (see Ref. [13]). Based on the first-principles calculations, still in 2009 Gao et al. [23] investigated defect induced magnetism in $\mathrm{MgO}$ and suggested that the induced magnetic moment indeed was due to the spinpolarization of $2 p$ electrons of $\mathrm{O}$ atoms near $\mathrm{Mg}$ vacancies. They supposed that the RTFM in $\mathrm{MgO}$ nanomaterial is not only due to the vacancies of $\mathrm{Mg}$ but also the distribution/positions of the vacancies. In the same time, Wang et al. [19] established that spin polarization appears at the top of the valence band when introducing $\mathrm{Mg}$ vacancies so the local magnetic moments mainly arise from the $2 \mathrm{p}$ orbitals of the nearest $\mathrm{O}$ atoms. The formation energy of $\mathrm{Mg}$ vacancy decreases much with the dimension of the system decreasing and a larger concentration of $\mathrm{Mg}$ vacancies expectedly appearing. In the next year, Droghetti et al. [24] have shown that semilocal LSDA/GGA can lead to qualitative failures in their description of hole centers in $\mathrm{MgO}$. Significantly, the large intersite ferromagnetic interaction predicted by LSDA is also was shown to be an artifact. Thus, the observed RTFM in MgO cannot be explained by a simple model 
where magnetic interactions between hole centers, in their ground state, percolate through the sample. But, in 2014 Choudhury's [9] again showed that RTFM is expected to be arising from $\mathrm{Mg}$ vacancies which induce spin polarization of $2 \mathrm{p}$ electrons of the oxygen atom and result in ferromagnetism. In the next year, Merabet et al. [25] shown that there is a significant polarization energy gain resulting from the oxygen atoms of nearest neighbors of the cation vacancy and making it ferromagnetic. If the authors refer to the results obtained with the LSDA approximation, these defects are responsible for the appearance of localized electronic states may change forbidden bandwidths which give rise to the magnetic moments. In 2018 Khamkongkoe et al. [26] once more confirmed that RTFM in the NPs caused by the induction of magnetic moment from the $2 \mathrm{p}$ orbitals of the nearest $\mathrm{O}$ atoms surrounding the $\mathrm{Mg}$ vacancies.

Very attractive conception concerns the presence of divacancies. In 2014 Choudhury's [9] observed that defects play a prominent role in making the $\mathrm{MgO}$ nanoparticle an optically and magnetically active material. In $\mathrm{MgO}$, the oxygen vacancies are present as color centers, or as dimmers of these color centers. These color centers create energy levels in the band gap of $\mathrm{MgO}$ and the trapped electron in these centers undergoes excitation on exposure to UV light. The authors have observed that although oxygen vacancies make $\mathrm{MgO}$ optically active, these vacancies have an opposite effect on the magnetism. In 2017 Pathak et al. [27] performed some positron annihilation lifetime measurements which indicate the presence of divacancy $\left(2 \mathrm{~V}_{\mathrm{Mg}}+\right.$ $2 \mathrm{~V}_{\mathrm{O}}$ ) cluster along with $\mathrm{Mg}$ vacancies at the low annealing temperature. An EPR study showed that $\mathrm{MgO}$ compound possesses both singly negative charged $\mathrm{Mg}$ vacancies and singly positively charged oxygen vacancies and the spins of both of these vacancies are ferromagnetically coupled. DFT calculation also showed that this dimer form has higher magnetic moment than the monomer.

Thus, both $\mathrm{Mg}$ vacancy/divacancy and oxygen vacancy in $\mathrm{MgO}$ nanomaterials could promote the RTFM formation, and it is necessary to obtain new experimental data to improve the description of RTFM phenomenon.

In present work, we focused on the correlations between magnetic, structural, optical properties as well as XPS spectra of the Mg-O NPs. Since RTFM is strongly dependent on the method of NPs production (Table 1) we intended to obtain larger maximum magnetization values in $\mathrm{Mg}-\mathrm{O}$ nanoparticles of the different scale sizes by using the levitation-jet generator [28]. It is operated under controlled gaseous oxidizer in an inert gas flow allows for simultaneous manipulation of size, shape, and composition of nanoparticles, allowing to produce of nanopowders with the clean surface [29]. Such technique offers many variations of synthesis conditions, which affected the maximum magnetization of the NPs and promote search of its 
dependencies on some experimental parameters, which could help to accelerate practical usage of such RTFM materials.

\section{Experimental}

\subsection{Synthesis of NPs}

Mg-O nanoparticles were obtained by using the Gen's levitation-jet generator described in details elsewhere [29, 30], which was modified for the special goals of this research (Figure 1). In this technique, a piece of metallic magnesium (99.99\%) was suspended in an appropriate quartz tube. The levitated piece of metal was heated up by an electromagnetic field, generated using a counter-current inductor until obtained ingot began to vaporize. The vaporizing droplet was blown by an adjustable stream of Ar gas (purity 99.995 at. \%) with simultaneously step-bystep supplying by the $\mathrm{Mg}$ metal $\operatorname{rod}\left(3 \times 3 \mathrm{~mm}^{2}\right.$ ) into this evaporator. The controlled metal oxidation was realized by permanent injection of a definite amount of gaseous air (99.9 at. \%) into the main Ar flow in the combined mode [29]. During the NPs fabrication, appropriate additional measures were undertaken in order to prevent any influence of alien magnetic impurities [31]. After each synthesis was finished, some parts of the installation were demounted and three powdered samples were collected from the different zones, where NPs could be deposited: wall of the quartz-glass tube - NPs (T); center of the non-ferromagnetic metal-made cooler - NPs (C); and the main cloth filter - NPs (M). The distance between the levitating droplet-evaporator to these collection zones was fixed at approximately 100, 200, and $400 \mathrm{~mm}$, respectively. Such approach allowed us to study the properties of NPs, which formation during post-condensation oxidation processes at the zones with different deposition conditions. 


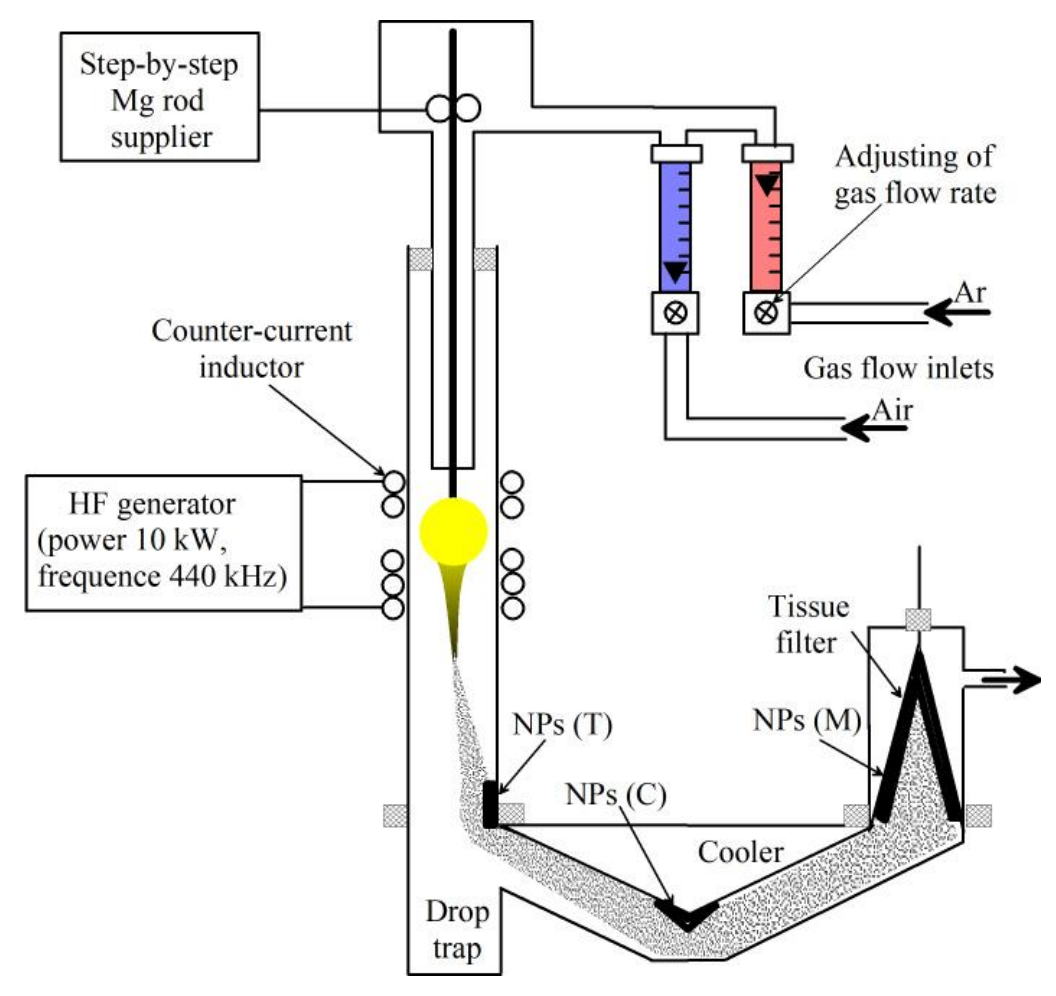

Fig. 1 Schematic representation of the levitation-jet installation for the Mg-O NPs fabrication.

Some parameters of the NPs synthesis, including metal feed rates, gases flow rates, and corresponding collection zones are listed in Table 2.

Table 2. Main properties of the Mg-O NPs. $S$ - specific surface area obtained from BET measurements; $\langle d\rangle$ - mean particle size obtained from SEM micrographs; $y-\mathrm{MgO}$ content and $a-\mathrm{MgO}$ lattice parameter obtained from XRD data; $\sigma_{\mathrm{s}}-$ maximum specific magnetization (VSM, RT, $10 \mathrm{kOe}$ ). 


\begin{tabular}{|c|c|c|c|c|c|c|c|c|c|}
\hline \multirow{2}{*}{$\begin{array}{l}\text { Sample } \\
\text { IDs }\end{array}$} & \multicolumn{3}{|c|}{ Synthesis conditions } & \multirow{2}{*}{$\begin{array}{l}\text { NPs } \\
\text { collection } \\
\text { zone }\end{array}$} & \multirow{2}{*}{$\begin{array}{l}<\mathrm{d}>, \\
\mathrm{nm}\end{array}$} & \multirow[t]{2}{*}{$S, \mathrm{~m}^{2} / \mathrm{g}$} & \multirow[t]{2}{*}{$y$, at.\% } & \multirow[t]{2}{*}{$a, \mathrm{~nm}$} & \multirow{2}{*}{$\begin{array}{l}\sigma_{\mathrm{s}}, \\
\mathrm{memu} / \mathrm{g}\end{array}$} \\
\hline & $\begin{array}{l}\mathrm{Mg}, \\
\mathrm{g} / \mathrm{h}\end{array}$ & $\begin{array}{l}\mathrm{Ar}, \\
\mathrm{l} / \mathrm{h}\end{array}$ & $\begin{array}{l}\text { Air, } \\
1 / \mathrm{h}\end{array}$ & & & & & & \\
\hline$\# 1$ & 8 & 53 & 28 & $\mathrm{M}$ & 42 & $14.57 \pm 0.18$ & 100 & 0.4217 & 650 \\
\hline$\# 2$ & 8 & 53 & 28 & $\mathrm{~T}$ & - & $15.06 \pm 0.34$ & 68.1 & 0.4219 & 7.4 \\
\hline$\# 3$ & 12 & 53 & 14 & $\mathrm{M}$ & 37 & $15.81 \pm 0.52$ & 70.1 & 0.4201 & 217 \\
\hline$\# 4$ & 12 & 53 & 14 & $\mathrm{C}$ & 33 & $16.09 \pm 0.44$ & 66.0 & 0.4205 & 108 \\
\hline$\# 5$ & 12 & 53 & 14 & $\mathrm{~T}$ & 30 & $16.29 \pm 0.58$ & 42.5 & 0.4209 & 9.5 \\
\hline$\# 6$ & 8 & 68 & 55 & $\mathrm{C}$ & - & $21.22 \pm 0.38$ & 99.7 & - & 90.5 \\
\hline$\# 7$ & 8 & 68 & 55 & $\mathrm{~T}$ & - & $22.11 \pm 0.34$ & 99.2 & - & 9.3 \\
\hline$\# 8$ & 6 & 68 & 55 & $\mathrm{M}$ & 80 & $21.63 \pm 0.45$ & 99.9 & 0.4211 & 430 \\
\hline$\# 9$ & 6 & 68 & 55 & $\mathrm{C}$ & 74 & $22.58 \pm 0.36$ & 96.0 & 0.4210 & 65 \\
\hline$\# 10$ & 6 & 68 & 55 & $\mathrm{~T}$ & 59 & $24.01 \pm 0.24$ & 94.3 & 0.4214 & 6 \\
\hline$\# 11$ & 6 & 85 & 40 & $\mathrm{M}$ & - & $24.17 \pm 0.41$ & 99.8 & - & 184 \\
\hline$\# 12$ & 6 & 53 & 30 & $\mathrm{M}$ & - & $22.77 \pm 1.45$ & 99.9 & - & 162 \\
\hline$\# 13$ & 8 & 85 & 50 & $\mathrm{M}$ & 66 & $25.26 \pm 0.08$ & 99.6 & 0.4210 & 75 \\
\hline$\# 14$ & 8 & 85 & 50 & $\mathrm{~T}$ & 60 & $26.89 \pm 0.31$ & 99.3 & 0.4210 & 16 \\
\hline$\# 15$ & 6 & 53 & 14 & $\mathrm{M}$ & 47 & $30.07 \pm 0.99$ & 99.9 & 0.4207 & 610 \\
\hline$\# 16$ & 6 & 53 & 14 & $\mathrm{~T}$ & 45 & $32.52 \pm 0.61$ & 99.1 & 0.4210 & 175 \\
\hline$\# 17$ & 6 & 150 & 55 & $\mathrm{M}$ & 55 & $32.59 \pm 0.23$ & 98.0 & 0.4201 & 280 \\
\hline$\# 18$ & 6 & 150 & 55 & $\mathrm{~T}$ & 52 & $34.69 \pm 0.62$ & 96.2 & 0.4204 & 62 \\
\hline$\# 19$ & 6 & 300 & 40 & $\mathrm{M}$ & 37 & $62.16 \pm 0.51$ & 100 & 0.4207 & 42 \\
\hline$\# 20$ & 6 & 300 & 40 & $\mathrm{~T}$ & 35 & $66.24 \pm 0.56$ & 91.7 & 0.4208 & 41 \\
\hline
\end{tabular}

\subsection{Characterization of NPs}

Particle size and morphology were investigated by scanning electron microscopy (SEM) using CARL ZEISS ULTRA PLUS. Electron micrographs were analyzed by Carl Zeiss AxioVision ver. 4.82 image processing software to calculate the average particle size $\langle d\rangle$ [29]. Specific surface areas of NPs were determined by 4-point nitrogen physical sorption BET measurements using META SORBI-M device. No outgassing procedures were applied before the BET measurements. Crystal structure of NPs was studied by X-ray powder diffractometer DRON-3M ( $\mathrm{Cu} K_{\alpha}$ radiation). Their phase compositions were determined using JCPDS PDF database (release 2011) and Crystallographica SearchMatch ver. 3.102 software. Rietveld analysis (PowderCell for Windows ver. 2.4) of X-ray diffraction patterns was used to evaluate the ratio of crystalline phases in the synthesized NPs. UV-vis spectra were recorded using Lambda950 (Perkin Elmer) with integrated sphere detector in the wavelength range of 200 $1200 \mathrm{~nm}$. Fourier transform infrared (FT-IR) spectra were recorded in solid phase using Tensor 27 spectrometer with attenuated total reflectance accessory (Bruker) in the frequency range of 400-4000 $\mathrm{cm}^{-1}$. Raman spectra were recorded using InVia Raman Renishaw and confocal microscope Leica DMLM apparatus with air-cooled, charge coupled device coupled with Ar laser emitting at $514.5 \mathrm{~nm}$ and $55 \mu \mathrm{W}$. XPS instrument was Thermo Scientific X-ray Photoelectron Spectrometer equipped with monochromated Al $K \alpha(1486.6 \mathrm{eV})$ source running at 
a power of $72 \mathrm{~W}$ with a pass energy of $50 \mathrm{eV}$. For the charges correction, a one-point scale with $\mathrm{C} 1 \mathrm{~s}$ base peak shifted to $284.8 \mathrm{eV}$ was used. Magnetic properties of NPs were measured by EG\&G PARC M4500 vibrating sample magnetometer in applied magnetic fields of up to 10 kOe. We subtracted magnetic moments of samples from the experimental data with respect to the diamagnetic contribution associated with a nylon-made container.

\section{Results and discussion}

\subsection{NPs morphology and BET results}

Figures 2a-b show SEM-micrographs of some NPs, which were obtained under various synthesis conditions and collected in the main zones. In Figure 2a, NPs of about $50 \mathrm{~nm}$ in an average size is generally uniform cubes. Particle size distribution was close to the lognormal one $[28,29]$. Some of the NPs in this Figure looks like terraced ones. Similar structures were observed in the MgO NPs, obtained by the flame metal combustion method [32]. In Figure 2b, NPs with an average size of $35 \mathrm{~nm}$ have a coarsened cubic (rouged spherical) morphology. Such particles were obtained at the same metal feed as previous ones, but with an enhanced flow of argon and diminished air rate.

Figures 3a-c show an effect of the different collection zones on the NPs formation in the same synthesis process. In (T) zone at the distance of $100 \mathrm{~mm}$ from the bottom of the levitated droplet, the most of collected NPs were almost uniform cubes with some terraced signs (Figure 3a). In the second zone, the most of NPs (C) were rouged spherical shapes with an increased average size and some traces of agglomeration (Figure 3b). NPs (M), collected from the most remote zone $(400 \mathrm{~mm})$, has bigger average size with a roughed surface (Figure $3 \mathrm{c}$ ). Such situation has been characteristic one for all studied NPs, which demonstrated a decrease in the value of specific surface area for NPs from M-zones compared with NPs from C- and Tzones (Table 2). Figures 3d-f show particle size distributions of NPs\#\# 8-10, which support above-mentioned considerations.

It is known that crystalline growth, governed only by condensation of $\mathrm{MgO}$ molecules, leads to the formation of cubes [33]. But, oxygen molecules in air flow are rather active participants in NPs surface growth [34]. Such molecules are splitting over the defects on the surfaces of the growing $\mathrm{MgO}$ nanoparticles, thus stimulating the most surface-defective incipient spherical shapes [32] and effect on the RTFM evolution [35]. We suggested that such behavior takes place during some manipulations of the levitation-jet synthesis conditions when an excess amount of the oxidizer gas was presented in the basic gas flow [30]. For the used 
combined mode, initial oxidation of NPs was uncompleted, because of secondary character of this process compared with the primary process of vapor metal condensation and hence a postcondensation intensification of the oxidation process might take place [32]. As it is clear from the above-mentioned Figures, NPs, which formed during post-condensation oxidation processes at the most far away zone (M), possess essentially modified surface. Possibly, it is also related with the use in this zone such gas-filter material, which characterized by minimal contact with NPs surface, compared with the C (cooled metal) and T (heated glass) zones.

In Table 2 specific surface areas (S) of all the NPs, obtained from BET measurements, listed to their increasing values, which has been used as the main characterization parameter of NPs. Average volumed sizes of some NPs $\langle d\rangle$, obtained from the micrographs, accompanied these BET data. In the following sections, we will see how these parameters affected RTFM and the other properties of different NPs.
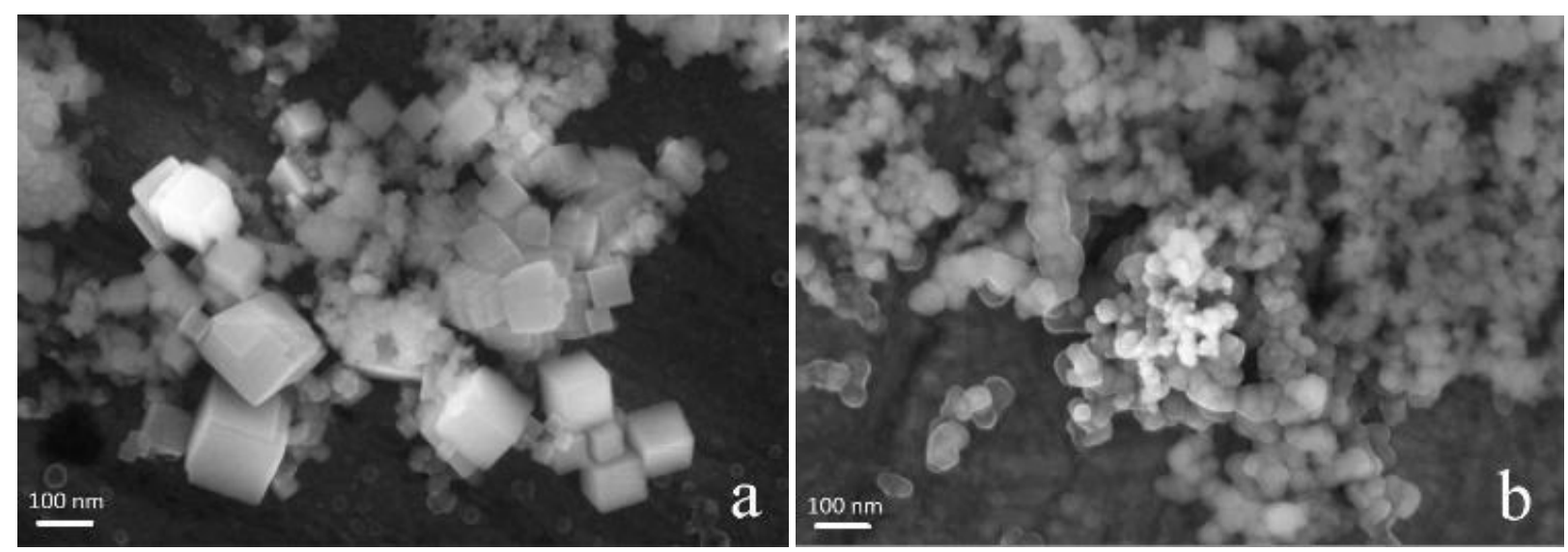

Fig. 2. SEM micrographs of some NPs collected in the main zones and listed in Table 2 : a - \#15, b $\# 19$.
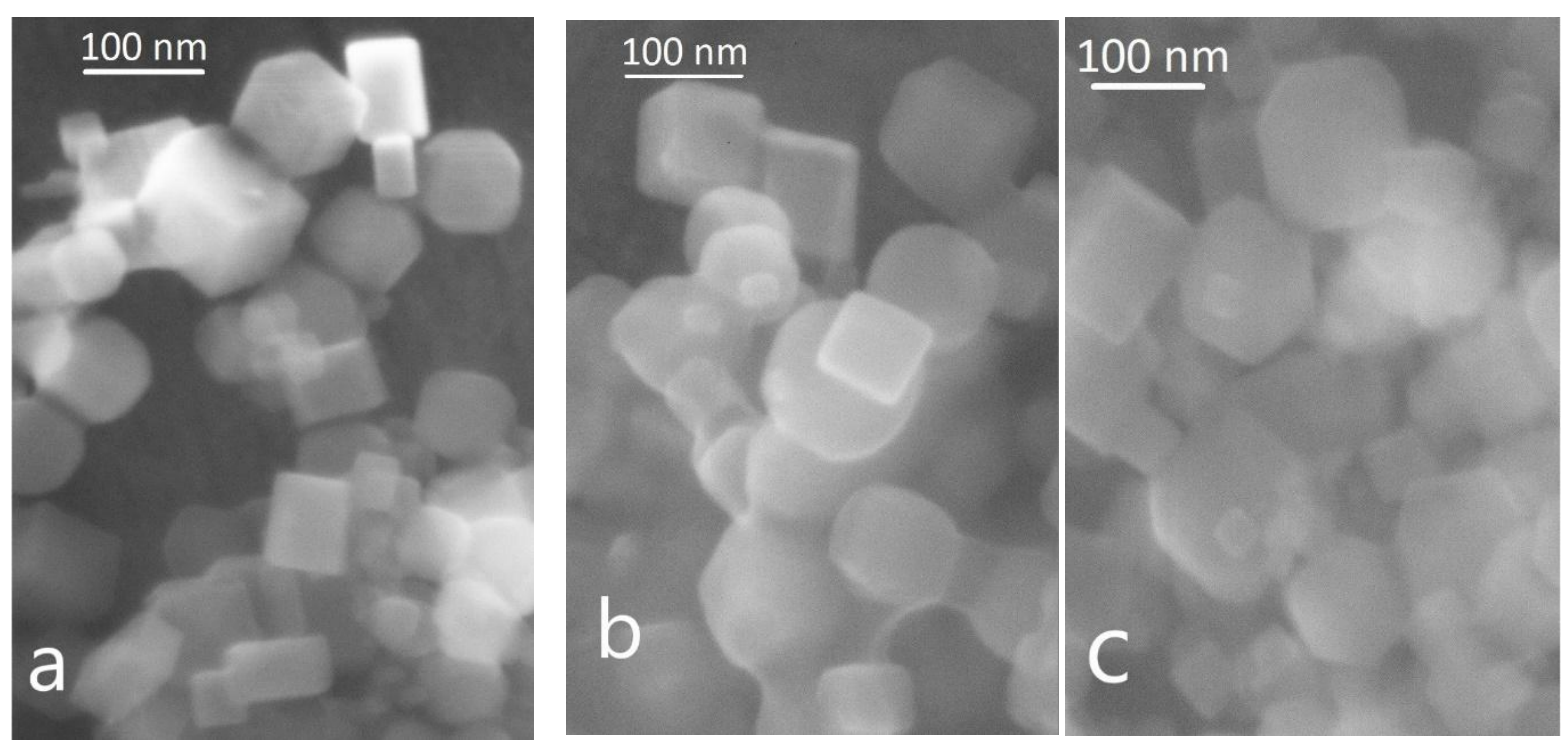

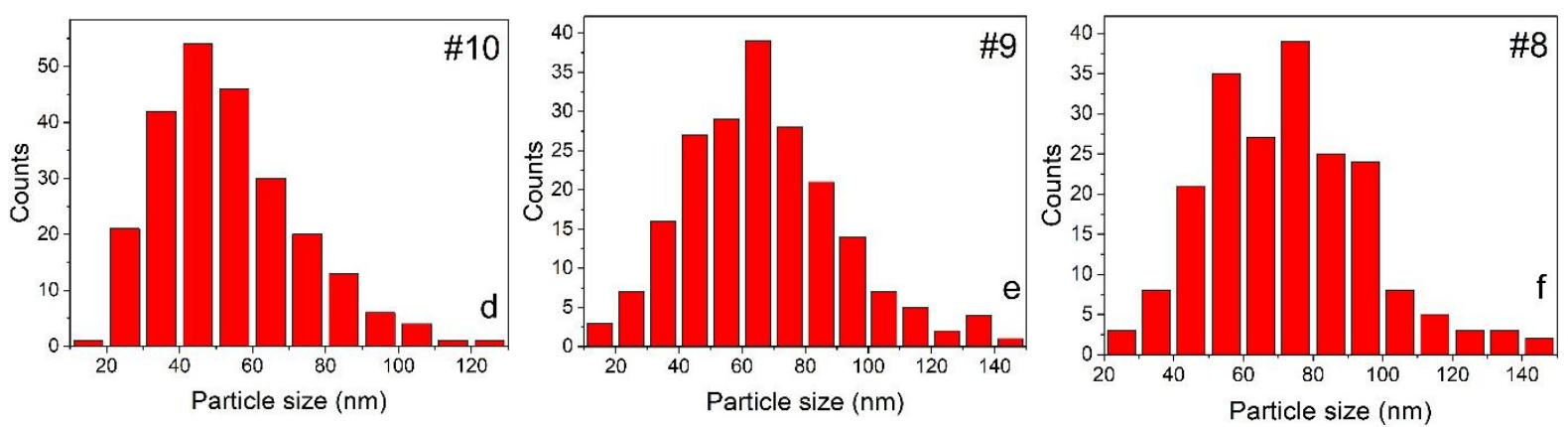

Fig. 3. SEM micrographs of some NPs collected in the different zones and listed in Table 2: a - \#10 (T), $\mathrm{b}-\# 9(\mathrm{C})$, and $\mathrm{c}-\# 8(\mathrm{M})$. d, e, and $\mathrm{f}$ - particle size distributions of these NPs.

\subsection{X-ray diffraction analysis}

XRD patterns of NPs matched the reflections of cubic MgO JCPDS (45-0946) with the unitcell parameter of $a=0.4201-0.4219 \mathrm{~nm}$ (Table 2). The second crystal phase of NPs matched the XRD patterns of hexagonal Mg (JCPDS 35-0821) with unit-cell parameters of $a=0.3174-0.3232$ $\mathrm{nm}$ and $c=0.5224-0.5181 \mathrm{~nm}$. No other crystal phases were found by XRD in our NPs. Figure 4 shows some representative patterns of NPs \#19, \#11, and \#13. Rietveld-refined MgO phase percentage, $y$, and its lattice parameter $a$ for the studied NPs are presented in Table 2. It was seen that magnesia content is growing up with the increase in the collection distance for all the nanoparticles. $\mathrm{MgO}$ lattice parameter, as a rule, decreased (away from the maximum value of the bulk $\mathrm{MgO}-0.4211 \mathrm{~nm}$ ) for NPs, collected at the most remote zone from evaporating droplet, in comparison with the other zones of the NPs collection. In Figure 5, an example of this effect was displayed. Such behavior agrees with the above-mentioned suggestion about the growth of defect structures during the post-synthesis processes, especially, in NPs disposed of in the through gasblown M-zone and possess almost free surface.

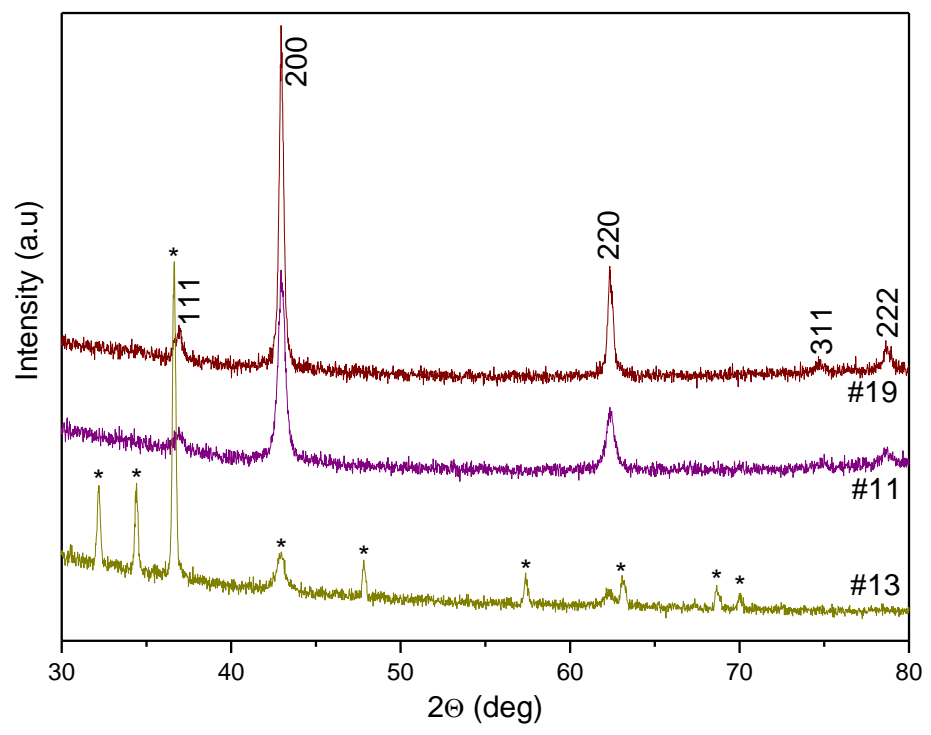


Fig. 4. Representative XRD patterns of some NPs. The numbers of curves correspond to the numbers of NPs in Table 2. Asterisks mark the reflections from Mg (JCPDS 35-0821). Indexed reflections are belonging to $\mathrm{MgO}$ (JCPDS 45-0946).

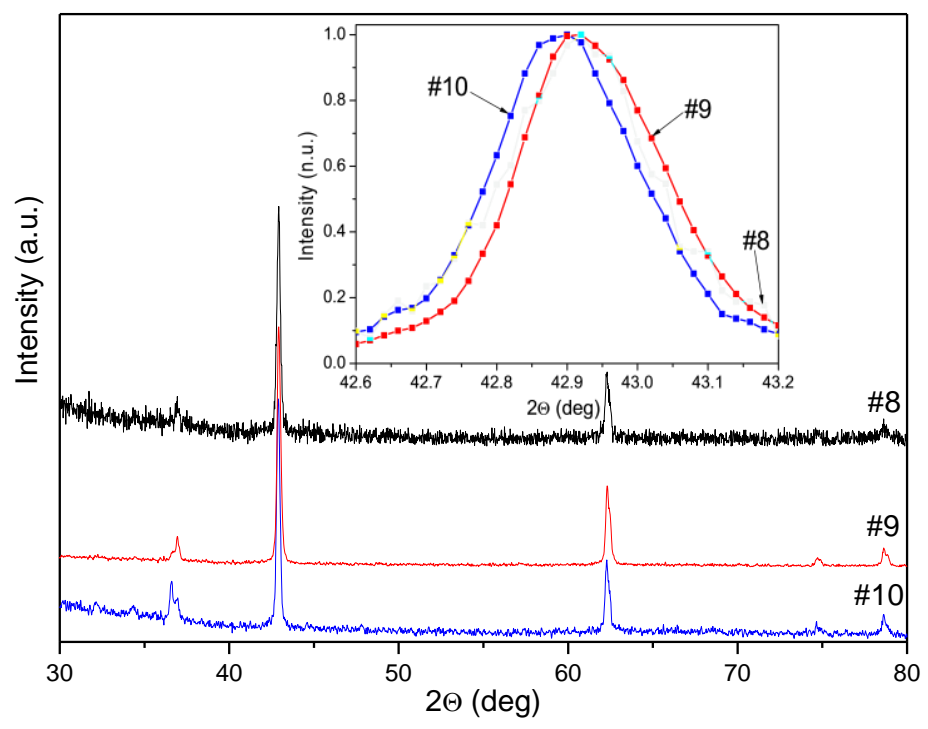

Fig. 5. XRD patterns of NPs, collected in the different zones of levitation-jet installation. The numbers of curves correspond to the numbers of NPs in Table 2.

\subsection{Magnetic measurements}

VSM magnetic measurements showed, that all the NPs had ferromagnetic hysteresis loops at room temperature. Some of the measurement results of specific magnetization $\sigma$ vs. applied magnetic field $H$ are shown in Figure 6. All the loops exhibit soft-magnetic behavior with coercivity ranged within 30-140 Oe. In Table 2, the results of measurements of net maximum specific magnetization $\sigma_{\mathrm{s}}$ (at $H=10 \mathrm{kOe}$ ) are presented. It should be noted, that in Figure 6 and Table 2 there is a progressive increase in $\sigma_{\mathrm{s}}$ for NPs collected in the different zones \#10 (T), \#9 $(\mathrm{C})$, and \#8 (M) with the increase in the zone distance from the evaporator. It is possibly related to above-noted changes in the processes of post-condensation oxidation. 


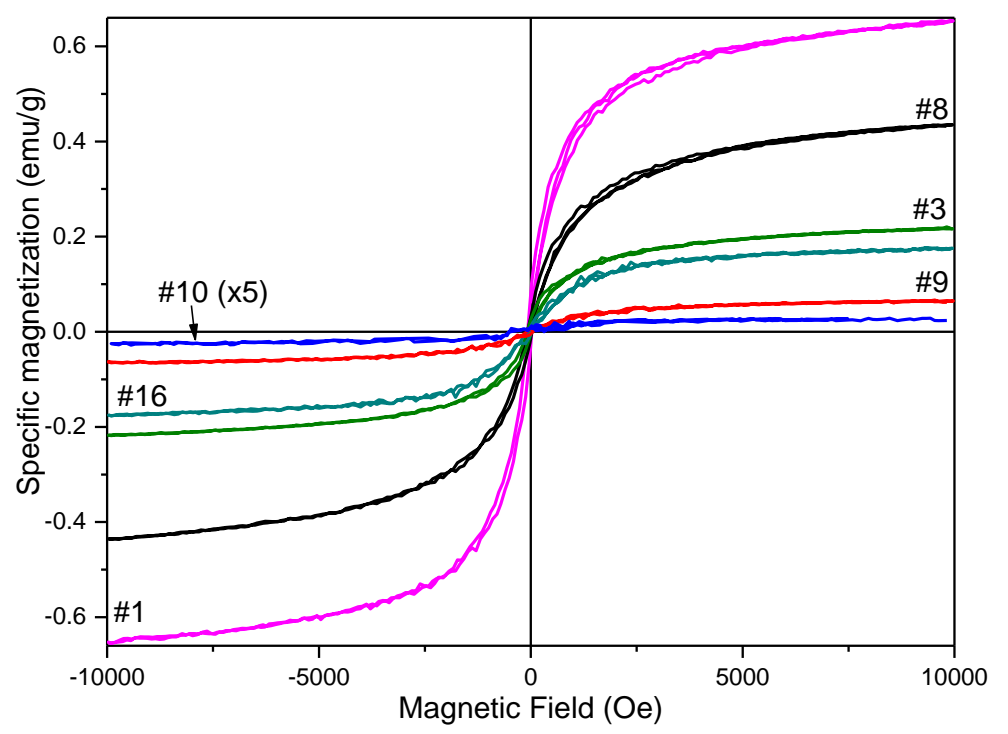

Fig. 6. Ferromagnetic hysteresis loops of some NPs. The numbers of curves correspond to the numbers of NPs in Table 2.

The main task of our study was to find out how the maximum magnetization depends on the other characteristics of the NPs $[6,36,37]$. It is known, that the maximum RTFM magnetization can be achieved for a certain density of vacancies, which is necessary to achieve magnetic order in solids, independently from the crystal structure details or elements, which were represented in the lattice, provided that the vacancies or other defects in the lattice lead to the nearly localized magnetic moments [38]. In Figure 7, we can see a two-peak dependence of the maximum magnetization $v s .(S \cdot y)$-product for some NPs. If it is supposed that the specific surface area is a measure of the roughness of the MgO NPs surface, and metallic magnesium is located in the separate nanoparticles (which do not take part in the RTFM), both measured terms are the real parameters, by which can to characterize the RTFM in our NPs. It is interesting, that the second maximum located at double value of the product relative to the first maximum. It is interesting, that the second maximum located at double value of the product relative to the first maximum position. Such behavior might point to the important role of vacancies and divacancy centers of our spherical/terraced MgO NPs [39] for the origination of RTFM.

A comparison between the data, presented in Tables 1 and 2, it is easy to see, that the maximum specific magnetization value of $0.65 \mathrm{emu} / \mathrm{g}$, achieved in our NPs \#1, is found to be almost one order of magnitude higher compared to the early achieved values for the MgO NPs synthesized by other methods. This difference in the $\sigma_{\mathrm{s}}$ values of the $\mathrm{MgO}$ materials is, probably, origin from the better RTFM NPs synthesis conditions, which promote the $\mathrm{Mg}$ vacancies propagation over the surface of NPs with the formation of various types of their 
configurations [14].

It should be noted following. All NPs studied retained their ferromagnetic properties when stored in air at room temperature for at least several months. However, by elevated temperatures, such behavior will not really. It is very difficult to determine the true "Curie point" of the RTFM NPs in air, inert gas, or vacuum, because of the high mobility of the weakcoupled oxygen during such studies [36].

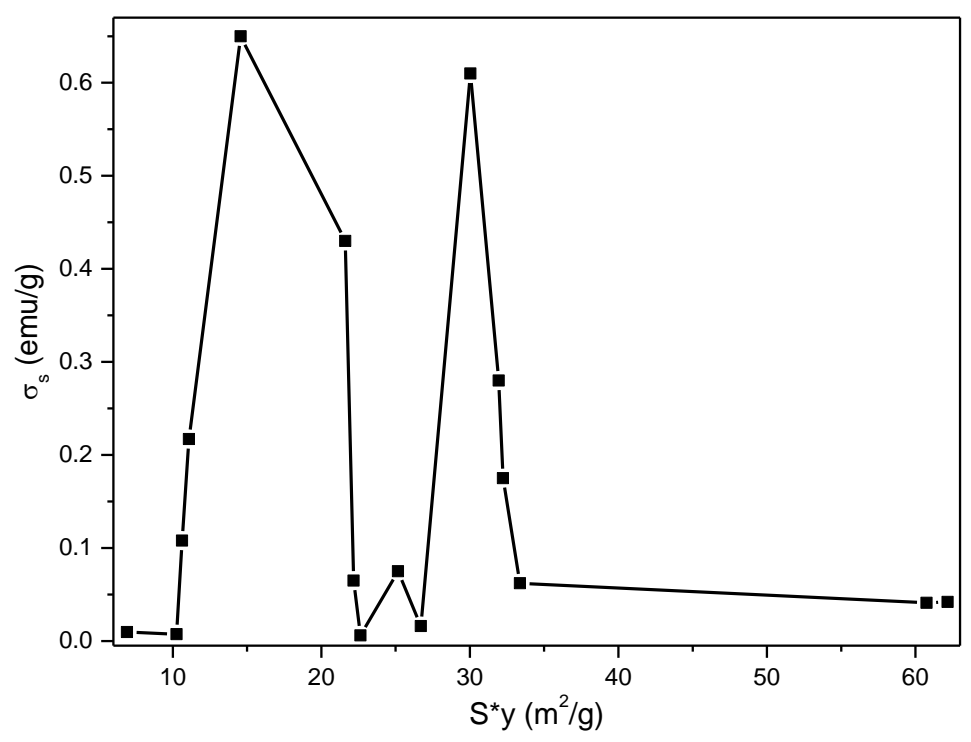

Fig. 7. The maximum specific magnetization of some NPs samples $v s .(S \cdot y)$ product.

We used some spectroscopic techniques in order to find out appropriates relationship between the observed RTFM and vacancy defects on the NPs surface.

\subsection{Optical characterization of NPs}

\subsubsection{UV-vis reflectance spectra}

UV-vis diffuse reflectance spectra (DRS) of some NPs recorded at RT are shown in Figure 8 over the wavelength range of $200-850 \mathrm{~nm}$. DRS of some NPs shows a slight absorption peak in the range of 260 to $280 \mathrm{~nm}$, which is known as a specific one for the MgO NPs [40]. A broad shoulder, observed in the 270-350 nm wavelength region for some NPs (except NPs \#3 and \#5), probably, results from some defect structures [3]. In the NPs with maximum $\sigma_{\mathrm{s}}$, possible, large amounts of charged species are presented at the energy levels of local vacancies. In the DRS, reflection bands of the NPs at 210-220 nm and 280-300 $\mathrm{nm}$ corresponded to the excitation of four-fold and three-fold coordinated $\mathrm{O}^{2-}$ anions, respectively [3]. Large dips in the DRS of NPs \#3 and \#5 may be attributed to the presence of moderate metal $\mathrm{Mg}$ content. We suggested, that 
the higher metal content enables more free electrons, and, because of that, the amount of visible light, reflected from such NPs, increased.

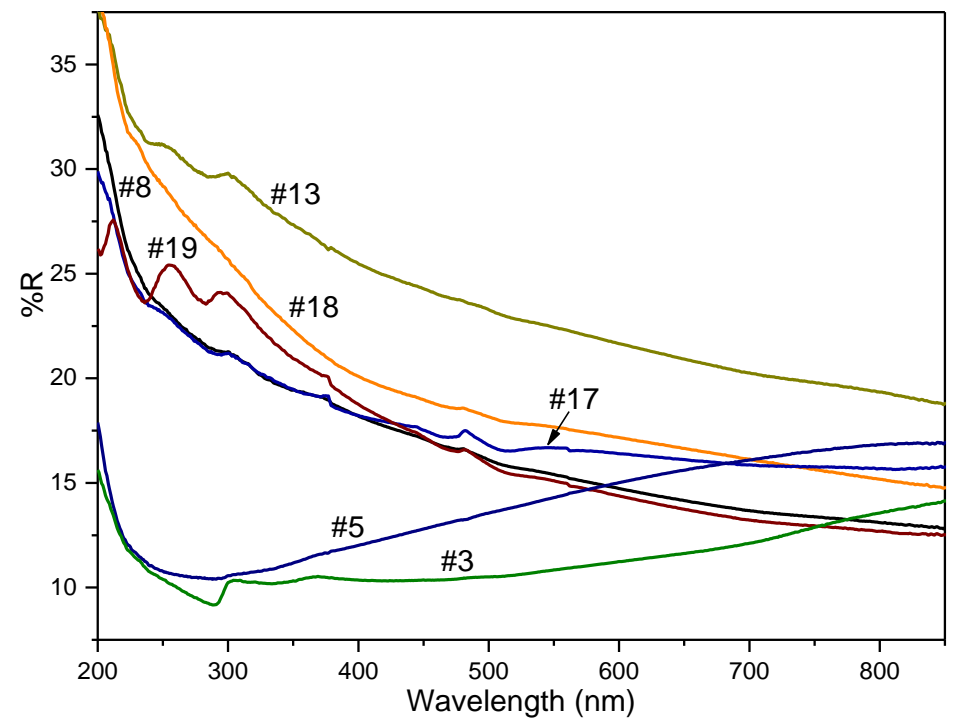

Fig. 8. Room temperature UV-vis diffuse reflectance spectra of some NPs. The numbers of curves correspond to the numbers of NPs in Table 2.

In order to study the energy band gap structures of our NPs, their DRS were analyzed using Kubelka-Munk equation $F(R)$ [41], which is related to the diffuse reflectance as follows:

$$
F(R)=(1-R)^{2} / 2 R .
$$

Here, $R$ is an absolute reflectance and $F$ is an equivalent to the absorption coefficient $\alpha$.

The optical band gap energy $\left(E_{\mathrm{g}}\right)$ may be calculated from $\alpha$ by Tauc's plot using Tauc relation [42]:

$$
\alpha h v=A\left(h v-E_{\mathrm{g}}\right)^{q},
$$

where $A$ is a constant, which depends from the transition probability, $h v$ is an incident photon energy, and $q$ is an index, which characterizes an optical absorption process in semiconductor, $q$ is equal to 0.5 for the direct band gap.

Direct band gap $E_{\mathrm{g}}$ of the NPs was estimated by plotting $(h v \cdot F(R))^{2}$ as a function of light wave energy $h v$ (Figures 9a and 9b). Extrapolation of the straight line gives the value of the energy band gap. The observed energy band gaps for NPs \#3 and \#5 were found to be close to $1.7 \mathrm{eV}$, which has been discovered early for some $\mathrm{MgO}$ nanoparticles [43, 44]. The band gap values of all the NPs are strongly red-shifted down from the standard value of bulk $\mathrm{MgO}$ (7.65 eV) [45]. The redshift of the direct band gaps exhibits, that the NPs morphology is suggesting an existence of various main active sub-surfaces, which response various excitation energy. Because of that, our NPs are having different values of the direct band gap, which also may be attributed to the quantum confinement effect $[44,46]$. 

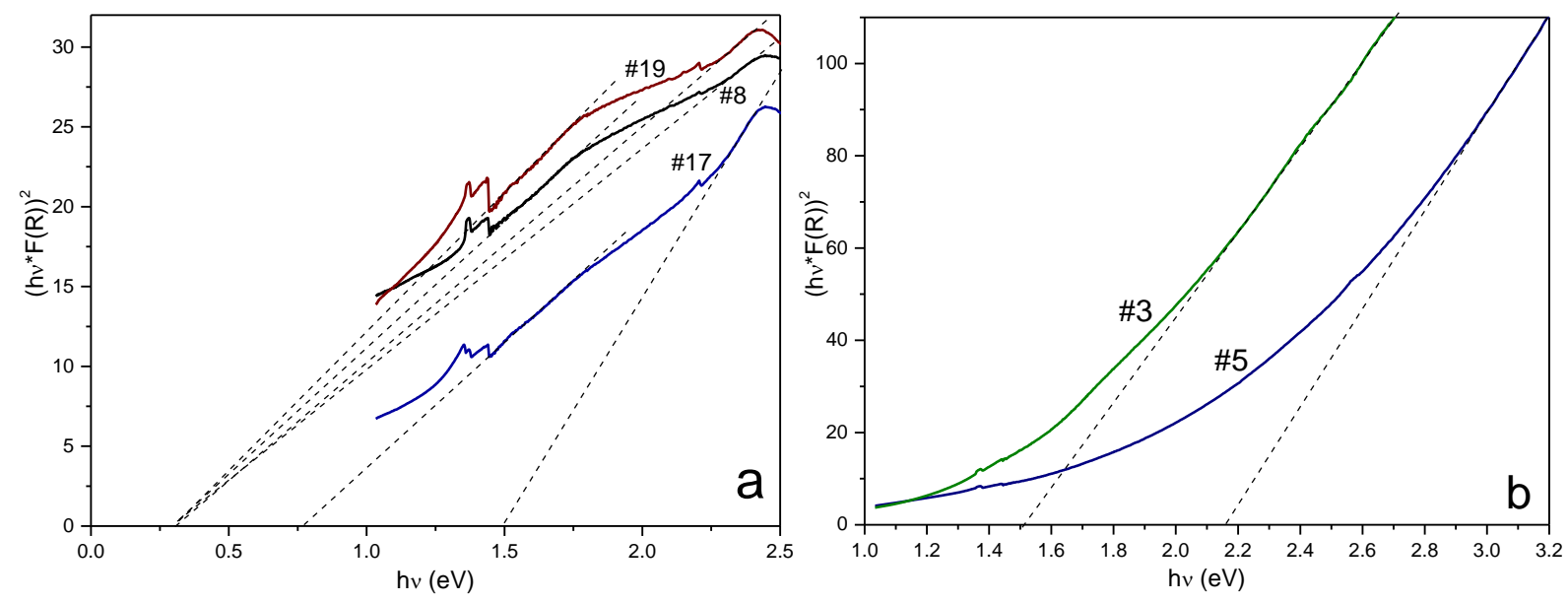

Fig. 9. (a) - Tauc plots of some NPs. (b) - The same plots for the NPs collected at the two different zones (M) and (T). The numbers of curves correspond to the numbers of NPs in Table 2.

\subsubsection{FT-IR spectra}

The typical FT-IR spectra for some NPs in the frequency region of $400-4000 \mathrm{~cm}^{-1}$ are shown in Figure 10a. A broad vibration band may be seen in the wavenumber range of $3000-3700 \mathrm{~cm}^{-1}$ due to the $\mathrm{O}-\mathrm{H}$ stretching vibration of an absorbed water molecule and surface hydroxyl group [47]. This is due to the slight aerial adsorptions of water molecule onto the $\mathrm{MgO}$ surface when it was exposed to the ambient atmosphere. The FT-IR absorption peak, which may be seen at the wavenumber $1420 \mathrm{~cm}^{-1}$, was assigned to the asymmetric stretching of the aerial carbonate ion, $\mathrm{CO}_{3}{ }^{2-}$ species [47-49]. The peaks, presented at 500-860 $\mathrm{cm}^{-1}$, are due to the higher frequency of $\mathrm{MgO}$ stretching [50].

In order to discover the observed changes in the IR bands of the different NPs, measurements in the frequency region of $450-900 \mathrm{~cm}^{-1}$ were undertaken. In Figure $10 \mathrm{~b}$, the characteristic peaks of two bands, centered at about $860 \mathrm{~cm}^{-1}[5,51]$ and $535 \mathrm{~cm}^{-1}[49,50]$, are presented. Inside of the band at $480-730 \mathrm{~cm}^{-1}$ definite changes in the peaks positions and their magnitudes for different NPs are take place. Some correlations between the peaks parameters and $\sigma_{\mathrm{s}}$ were founded, particularly, an increase in the peak magnitudes for the NPs with large maximum magnetizations. 

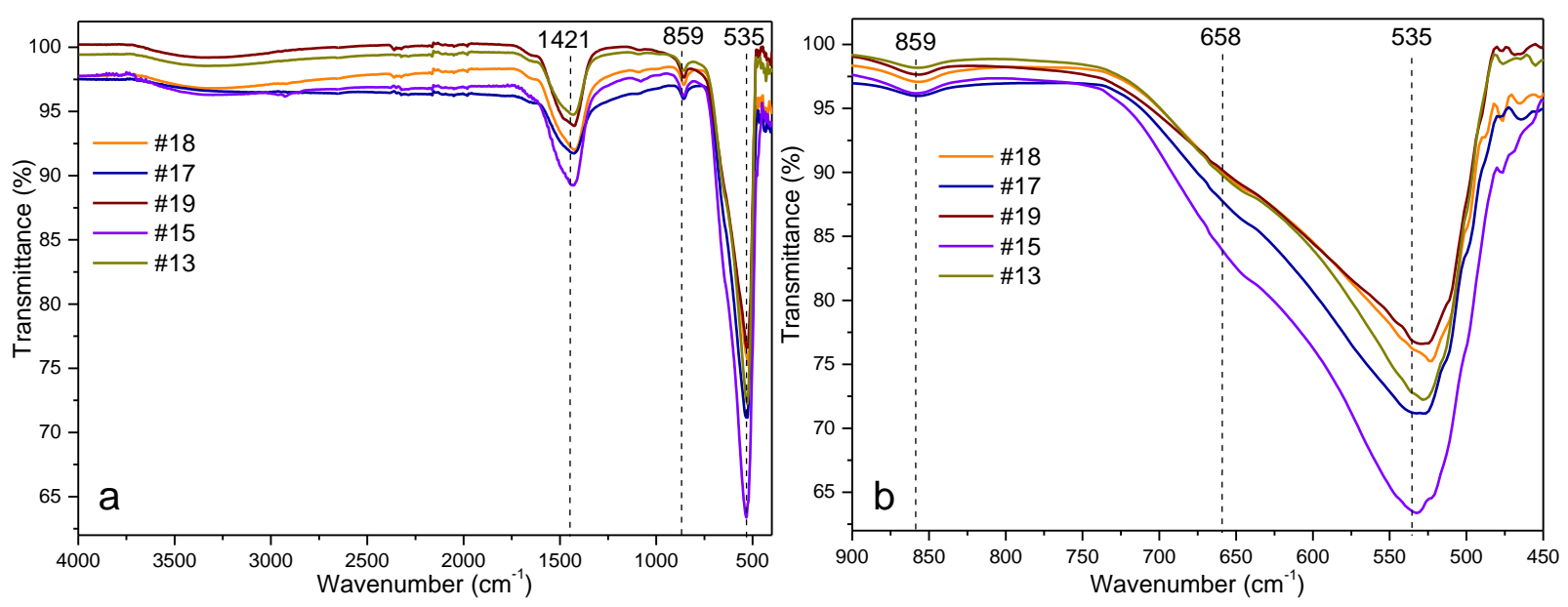

Fig. 10. IR bands of some NPs in the range of $4000-400 \mathrm{~cm}^{-1}$ (a), $900-450 \mathrm{~cm}^{-1}$ (b). The numbers of curves correspond to the numbers of NPs in Table 2.

The effects of the different collection zones on FT-IR spectra of the three couples of NPs are shown in Figures 11a and 11b. It was noted that NPs, collected in the same process, demonstrated, as a rule, above-mentioned features in the IR spectra at $1420 \mathrm{~cm}^{-1}$ and $535 \mathrm{~cm}^{-1}$ centered bands, at that, this phenomenon is much more various inside the first band (Figure 11a). It should be noted on the active role of some point defects on the NPs surface, which could act as traps of adventitious $\mathrm{CO}_{3}{ }^{2-}$ species, registered during the XPS studies. Similar behavior has been observed by aerial hydroxyl deposition on lowcoordinated sites at $3700 \mathrm{~cm}^{-1}$ bands [47].
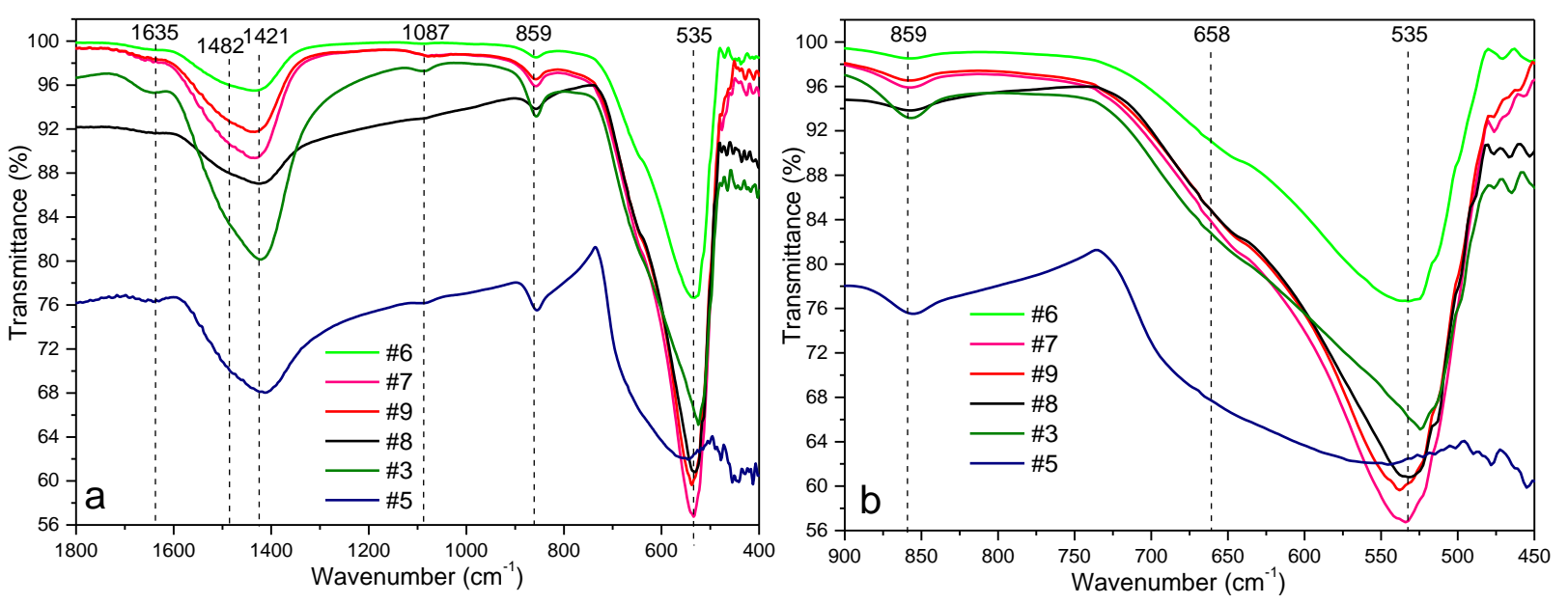

Fig. 11. Effect of the different collection zones on IR bands of NPs in the range of $1800-400 \mathrm{~cm}^{-1}$ (a), $900-450 \mathrm{~cm}^{-1}$ (b). The numbers of curves correspond to the numbers of NPs in Table 2.

\subsubsection{Raman spectra}

Since $\mathrm{MgO}$ has the $\mathrm{NaCl}$-type structure with inversion symmetry, first-order Raman scattering is forbidden in large bulk crystals and only second-order Raman spectrum has been 
observed [52]. Room-temperature Raman spectra of our NPs were recorded in the 100-1200 $\mathrm{cm}^{-}$ ${ }^{1}$ range. The first-order Raman spectra of the NPs revealed 7 vibrational bands centered around 275, 370, 448, 560, 960, 1080, and $1120 \mathrm{~cm}^{-1}$ (Figure 12). The Raman bands at $448 \mathrm{~cm}^{-1}$ and 290 $\mathrm{cm}^{-1}$ may coincide with the two prominent peaks predicted and observed for the $\mathrm{MgO}$ microcrystals [53, 54]. Accordingly, it was supposed, that the $290 \mathrm{~cm}^{-1}$ line was associated with a TA phonon at the energy zone boundary, whereas $448 \mathrm{~cm}^{-1}$ line with a TO phonon at the energy zone center. In addition, we supposed, that the Raman peak at $370 \mathrm{~cm}^{-1}$ corresponds to the stretching mode of the magnesium oxide (LA) and, therefore, was very sensitive to the presence of vacancies. This suggestion allows assigning the band at $960 \mathrm{~cm}^{-1}$ as a $\mathrm{LA}+\mathrm{LO}$ vibrational mode. The rather broad band composed of the line at $1080 \mathrm{~cm}^{-1}$ and accompanied by line at $1120 \mathrm{~cm}^{-1}$ was similar to those observed earlier $[54,55]$ ascribed to the surface phonon modes in a TO- LO phonon gap [56]. Similarly to the authors of [56], we discovered, that TA phonon- and TO phonon-related Raman lines were not clearly observed, and the Raman lines of the TO-LO phonon gap were significantly suppressed in the most of our NPs.

The larger specific surface area could provoke the intensity of vibrational modes to decreasing, due to the structural changes introduced by disorder and particle size reduction, because of that, the $\sigma_{\mathrm{s}}$ values of such NPs were lower. For NPs in the sequence \#\#13-9-6-11-19, the intensity of Raman bands is decreased, and most of the major Raman bands shifted towards the lower energy side. Despite the smallest particle size seen in this study, NPs \#19 had Raman peaks that were clearly pronounced, probably, because of the largest $y$ value. As it was seen from Figure 12 and Table 2, NPs with almost the same $y$ (\#6 and \#9), and close values of $S$ demonstrated similar Raman peaks positions and intensities, and their maximum magnetizations have only slightly differed.

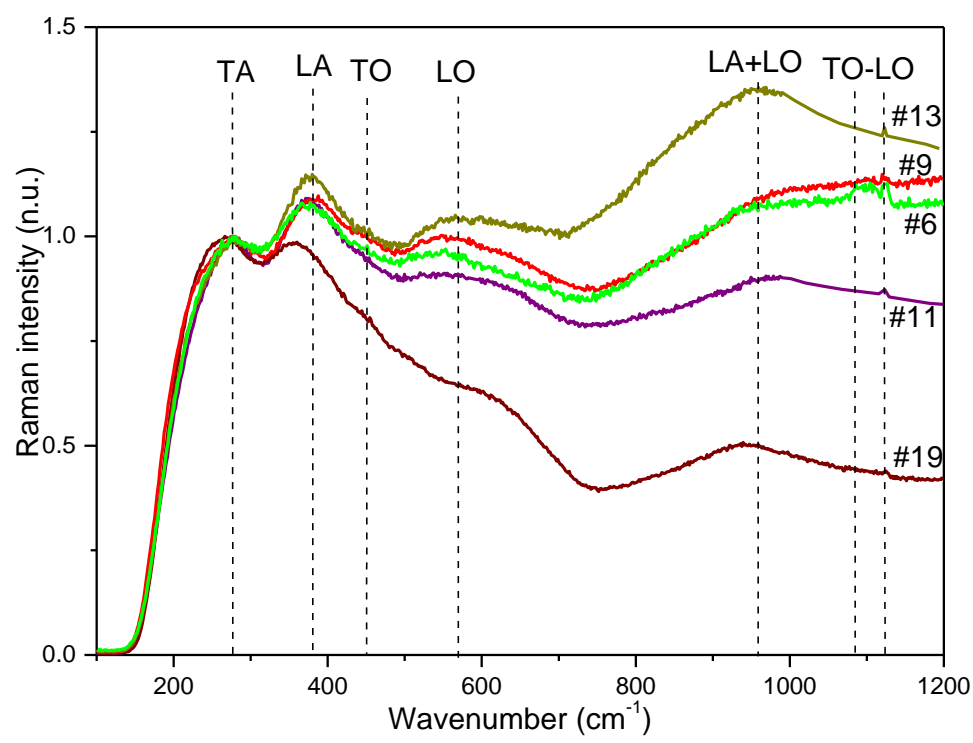

Fig. 12. Raman spectra of some NPs. The numbers of curves correspond to the numbers of NPs in 
Table 2.

Figure 13 demonstrated an effect of the different collection zones on the Raman spectra of NPs. For the two couples of NPs \#3, \#5 and \#17, \#18 the intensity of vibrational modes correlates with the maximum of $\sigma_{\mathrm{s}}$. Increase in intensities of the Raman spectra in the NPs, which were collected at the M-zones, has been accompanied by an enhancement in $\sigma_{\mathrm{s}}$. It was related to decrease in their perfectness degree, that is pointing out the predominant role of surface defects in the RTFM evolution of our NPs.

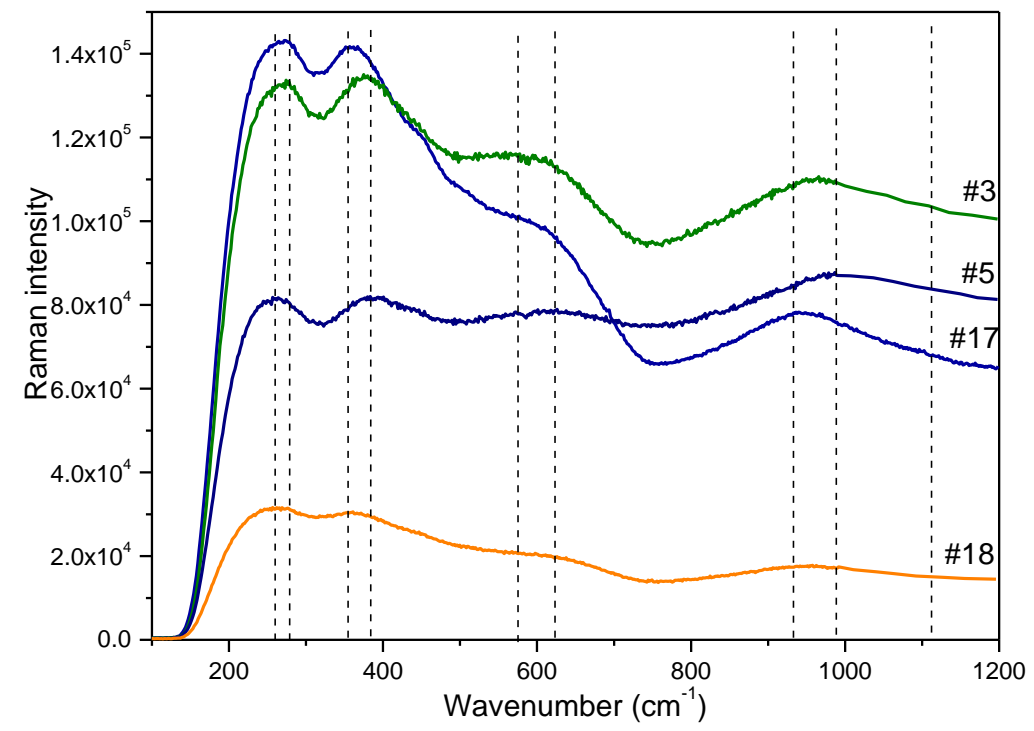

Fig. 13. Raman spectra of some NPs collected from the different zones. The numbers of curves correspond to the numbers of NPs in Table 2.

\subsection{XPS component analysis of the NPs}

$\mathrm{X}$-ray photoelectron spectroscopy was used to characterize the chemical composition of the different NPs. In Figure 14 the different peaks regions of the survey spectra of some NPs, identified by using CasaXPS v. 3.17 software [57], are presented. The peaks corresponding to Mg 1s, Mg 2s, Mg 2p, O 1s, C 1s and Ar 2p were clearly observed. The above-mentioned results indicate that the main species on the surface of $\mathrm{MgO}$ NPs were $\mathrm{Mg}, \mathrm{O}$, and $\mathrm{C}$. No obvious magnetic metal contaminations were discovered. Some differences in the element peak intensities among the spectra of our NPs were founded. The presence of carbon is attributed to the surface contamination, whereas argon is originating from the routine cleaning surface procedure, which takes place prior to the main XPS measurements [58]. 


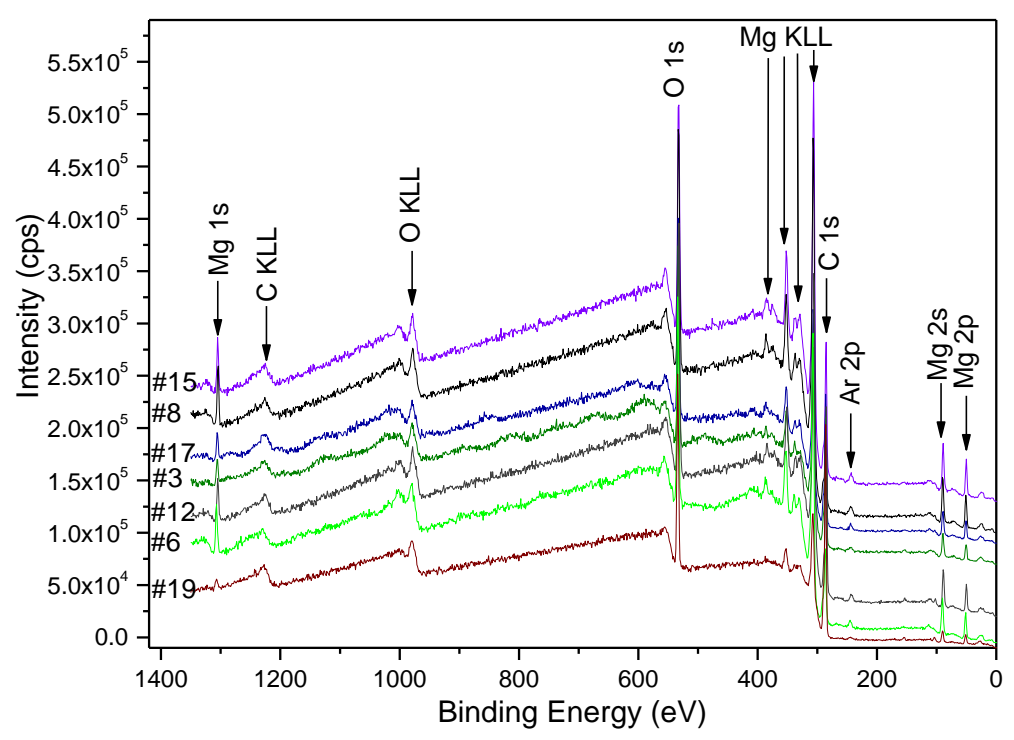

Fig. 14. Survey XPS spectra of some NPs. The numbers of curves correspond to the numbers of NPs in Table 2 . All the spectra were vertically shifted for clarity.

The XPS spectra from core regions of the three basic elements, belonging to the NPs \#8, \#9, and \#10, which were collected in the M-, C-, and T-zones, respectively, are shown in Figures 1517. The XPS peaks were fitted with the Origin 2015 software by using Gaussian profile function, including fixed XPS baseline mode in Shirley computation range method [57]. Determined values of binding energy (BE), full width at half maximum (FWHM), peak heights $\left(h_{\max }\right)$ and areas (area) of all the fitted components of some NPs were listed in Table S1 (Appendix A. Supplementary data).

From the high-resolution Mg 1s spectra (Figures 15a-c), we concluded that only one state of magnesium exists in our NPs. Figure 15a shows the XPS spectrum of Mg 1s core level for NPs \#8, which existed as $\mathrm{Mg}^{2+}$ with a binding energy of $1303.8 \mathrm{eV}$ [20]. For NPs, collected at C-and T-zones (Figures 15b-c), the Mg 1s XPS peak can be fitted into two symmetrical peaks. In the Figure $15 \mathrm{~b}$ for NPs, collected at C-zone, the lower binding energy peak, located at $1304 \mathrm{eV}$, corresponds to the $\mathrm{Mg}$ 1s core peak of $\mathrm{Mg}^{2+}$ bound to $\mathrm{O}^{2-}$, while the higher binding energy peak at $1305.1 \mathrm{eV}$ can attribute to formation of $\mathrm{Mg}(\mathrm{OH})_{2}$ at the surface of NPs due to the ambient atmosphere during XPS measurements [59]. In the Figure 15c, it may be seen deconvoluted $\mathrm{Mg}$ 1s XPS peak from NPs, collected at the nearest zone from the evaporator (T). As it may be seen from this Figure as well, positions of the above-mentioned components are shifted towards higher energies from NPs \#8 and \#9 peak positions to the $1306.1 \mathrm{eV}$ and $1307.4 \mathrm{eV}$, respectively. 

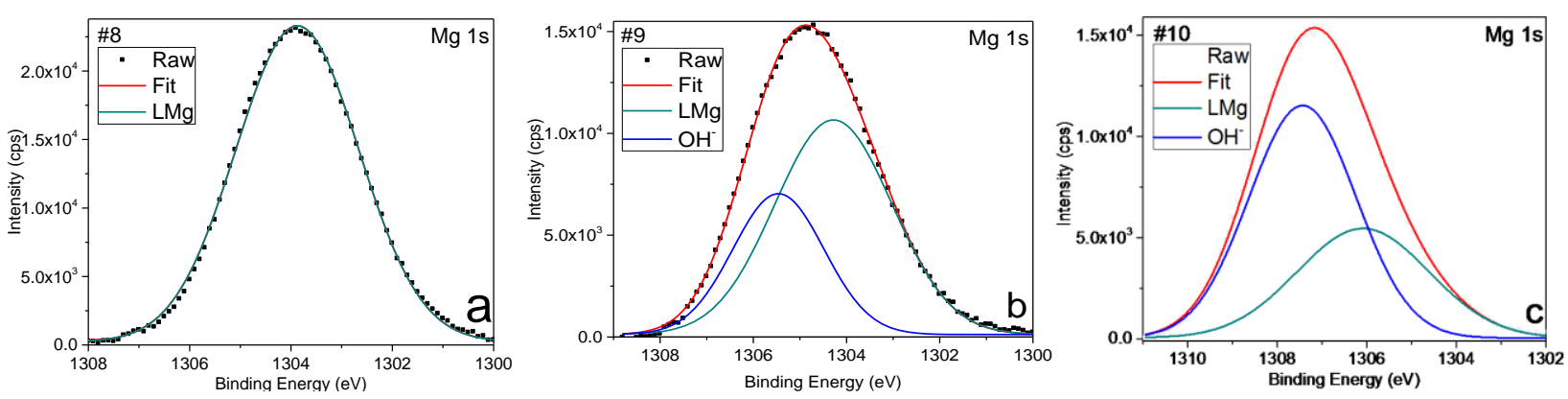

Fig. 15. High-resolution XPS spectra of NPs \#8 (a), \#9 (b), and \#10 (c) in the core level region Mg 1s. $\mathrm{LMg}$ - lattice magnesium, $\mathrm{OH}^{-}-\mathrm{Mg}(\mathrm{OH})_{2}$ components.

XPS data of the O 1s core level of the above-mentioned NPs are presented in Figures 16a-c. The broad and slightly asymmetric nature of the peak was suggested to be the multiple oxygen valences in our NPs. All the XPS peaks for the O 1s core level can be fitted in some symmetric Gaussian curves with the same FWHM for each component [60]. For the NPs \#8, the O 1s XPS peak can be fitted into two symmetrical peaks. The lower binding energy peak, located at 530.2 $\mathrm{eV}(\mathrm{Oa})$, was ascribed to the $\mathrm{O}$ 1s core level peak of $\mathrm{O}^{2-}$ bound to $\mathrm{Mg}^{2+}$ [20]. The higher binding energy peak at $532.3 \mathrm{eV}(\mathrm{Ob})$ was attributed to the near-surface oxygen $[17,59,61]$. Such peak structure seems to be characteristics for the $\mathrm{MgO}$ surface, which was observed in the NPs, synthesized under various conditions, where the low binding energy peak corresponds to the stoichiometric $\mathrm{MgO}$, whereas the higher binding energy peak corresponds to the $\mathrm{MgO}$ species with $\mathrm{Mg}$ vacancies [61].

For the NPs \#9 and \#10, the O 1s XPS peaks can be fitted into three symmetrical peaks. The highest binding energy peaks of the $\mathrm{O} 1 \mathrm{~s}$ core level for the NPs \#9 and \#10 appeared at $533.1 \mathrm{eV}$ and $534.2 \mathrm{eV}$, respectively, were ascribed to $\mathrm{OH}^{-}$in $\mathrm{Mg}(\mathrm{OH})_{2}$ [59], in agreement with the corresponding XPS peaks of core level Mg 1s of these NPs.
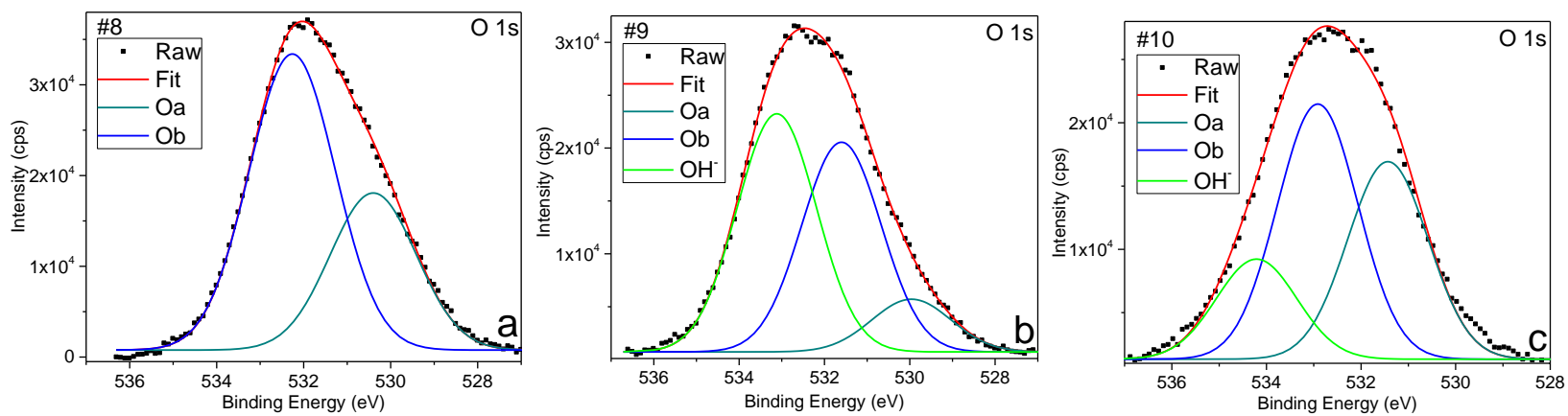

Fig. 16. High-resolution XPS spectra of the NPs \#8 (a), \#9 (b), and \#10 (c) in the core level region O 1s.

High-resolution C 1s spectra of the NPs \#\#8-10 were shown in Figures 17a-c in the energy range from $282 \mathrm{eV}$ to $293 \mathrm{eV}$. The main peak corresponds to the carbon contamination $(\mathrm{C}-\mathrm{C}$ 
bonds [62]), was observed at $284.8 \mathrm{eV}$ [63]. The second and third weak peaks were located at approx. $286.3 \mathrm{eV}$ and $288.6 \mathrm{eV}$ and were characteristics of the oxygen bound species with $\mathrm{C}-\mathrm{O}$ bonds, as well as $\mathrm{C}=\mathrm{O}$ bonds, respectively [64]. It is known that metal carbides may be inadvertently formed during argon sputtering of metal-containing oxides [63]. Because of that, the highest energy peak, probably, could be attributed to the hydrocarbonates of $\mathrm{Mg}$ (HC) [65], formed by above-mentioned cleaning procedure of samples operation in the ambient atmosphere of XPS apparatus.
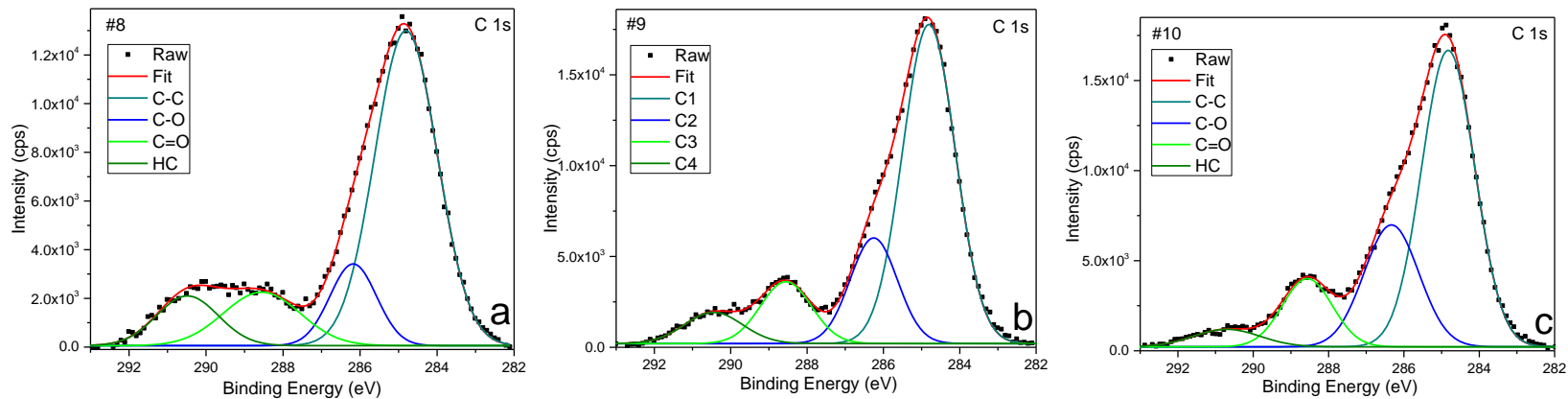

Fig. 17. High-resolution XPS spectra of the NPs \#8 (a), \#9 (b), and \#10 (c) in the core level region C 1s.

It is interesting the peak behavior in the Mg $2 \mathrm{p}$ core level region for the NPs \#\#8-10. As it is seen in Figure 18, for NPs, collected in the main zone, the intensity of the peak has its maximum value. It once more emphasizes the basic role of the surface crystal Mg sites in the NPs RTFM evolution. As it is known, that oxygen atoms could form interstitials $\left(O_{\mathrm{i}}\right)$ or replace the $\mathrm{Mg}$ lattice site and form the oxygen antisites $\left(O_{\mathrm{Mg}}\right)$ [59]. These species can break up the coupling between active $\mathrm{Mg}$ deficient defects $V_{\mathrm{Mg}}$. In Figure 19, the data for our NPs show that the progressive increase in FWHM of the peaks of Mg 2p component has been accompanied by an oscillating depression of the maximum magnetization. This behavior, probably, points to the breaking up the coupling between the active $\mathrm{Mg}$ defects with the formation of new types of these defects configurations, including due to a decrease in their total concentration. So, the larger concentration of $\mathrm{Mg}$ deficiency defects is, the stronger FM becomes [22, 26, 59, 66]. The ferromagnetic moment's enhancement with the increase in $V_{\mathrm{Mg}}$ concentration in the NPs is consistent with the results of the ab initio calculation for $\mathrm{MgO}$ [23]. 


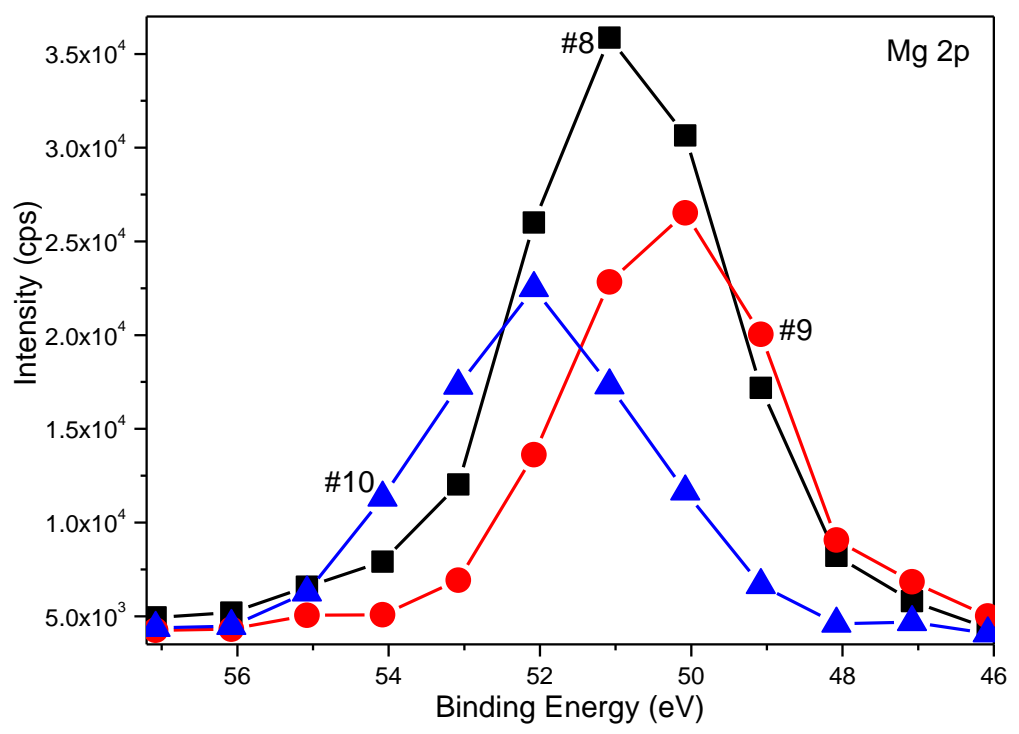

Fig. 18. Part of survey XPS spectra of the NPs \#8 (a), \#9 (b), and \#10 (c) in the core level region Mg 2p.

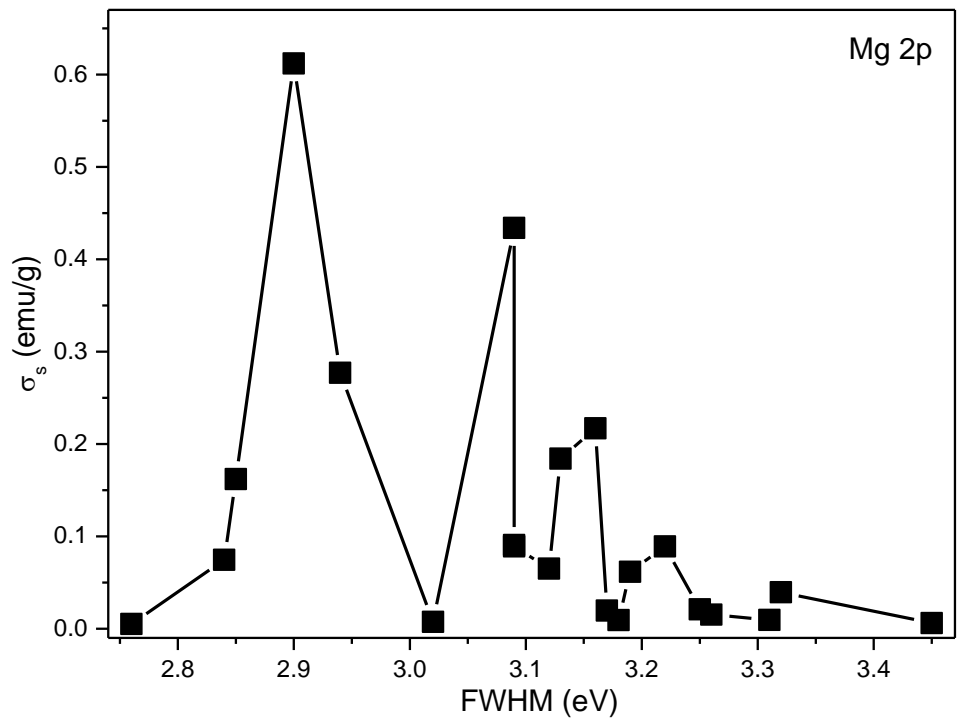

Fig. 19. The maximum magnetization of some NPs $v s$. FWHM of Mg $2 \mathrm{p}$ peak values.

It should be noted, that experimental results cannot be explained by assuming the existence only one-point defects. Therefore, in our study the magnetism should be interpreted with respect to the magnetic coupling, which was could induced by defect configurations with as one and/or double Mg vacancies (cf. Figure 7). The defects formation energies suggest, that two $\mathrm{Mg}$ vacancies prefer the next nearest sites to the other configurations, what has been theoretically predicted for the pure $\mathrm{MgO}$ [67].

\section{Conclusions}

Various $\mathrm{Mg} / \mathrm{MgO}$ aerosol-generated nanoparticles, ranging in the average particle sizes distributed from 30 up to $80 \mathrm{~nm}$, could be prepared by levitation-jet synthesis as a result of magnesium metal vapor condensation in an inert-gas flow under various process parameters, by 
using the different zones for the NPs collection. SEM, BET, XRD, UV-vis, FT-IR, Raman, and XPS studies of cubic, terraced, and spherical NPs demonstrate a predominant effect of the surface microstructure on their properties. All the synthesized materials were ferromagnetic at room temperature with the relatively high maximum magnetization of up to $0.65 \mathrm{emu} / \mathrm{g}$ and the coercive force of up to 140 Oe. The maximum magnetization of the NPs tends to grow with the increase in the value of specific surface area multiplied by oxide content in the form of two-peak function and accompanied by the increase in the Raman peaks intensities. XPS studies discovered an oscillation dependence of maximum magnetization from the $\mathrm{Mg} 2 \mathrm{p}$ state, suggesting that RTFM is possible to be existed due to the Mg-deficient defects on the surface of the NPs. These surface defects are the key factors, regulating the ferromagnetic ordering.

Determination of synthesis conditions of aerosol-generated NPs, favoring reproducibility of their high-quality magnetic properties, might be accepted as a starting point for the improvement of devices using spin polarization effect.

\section{Appendix A. Supplementary data}

Electronic Supplementary Information (ESI) related to this article may be found at http:// dx.doi.org/.

\section{References}

[1] F.-G. Kuang, S.-Y. Kang, Y.-Q. Xu, Z.-Z. Xiong, J.-F. Liao, H.-J. Yu, X.-K. Zhang, T.-Z. Sun, J. Cao, Effect of oxygen and magnesium vacancies on the $d^{0}$ magnetism of C-monodoped $\mathrm{MgO}$ using ab initio method, Journal of Alloys and Compounds, 712 (2017) 526-534.

[2] L.S. Panchakarla, Y. Sundarayya, S. Manjunatha, A. Sundaresan, C.N.R. Rao, On the Defect Origin of the Room-Temperature Magnetism Universally Exhibited by Metal-Oxide Nanoparticles, ChemPhysChem, 11 (2010) 1673-1679.

[3] S. Azzaza, M. El-Hilo, S. Narayanan, J. Judith Vijaya, N. Mamouni, A. Benyoussef, A. El Kenz, M. Bououdina, Structural, optical and magnetic characterizations of $\mathrm{Mn}$-doped $\mathrm{MgO}$ nanoparticles, Materials Chemistry and Physics, 143 (2014) 1500-1507.

[4] R.C. Whited, C.J. Flaten, W.C. Walker, Exciton thermoreflectance of $\mathrm{MgO}$ and $\mathrm{CaO}$, Solid State Communications, 13 (1973) 1903-1905.

[5] A. Khamkongkaeo, N. Mothaneeyachart, P. Sriwattana, T. Boonchuduang, T. Phetrattanarangsi, C. Thongchai, B. Sakkomolsri, A. Pimsawat, S. Daengsakul, S. Phumying, N. Chanlek, P. Kidkhunthod, B. Lohwongwatana, Ferromagnetism and diamagnetism behaviors of $\mathrm{MgO}$ synthesized via thermal decomposition method, Journal of Alloys and Compounds, 705 (2017) 668-674.

[6] I.G. Morozov, O.V. Belousova, D. Ortega, M.-K. Mafina, M.V. Kuznetcov, Structural, optical, XPS and magnetic properties of Zn particles capped by ZnO nanoparticles, Journal of Alloys and Compounds, 633 (2015) 237-245.

[7] A. Kumar, J. Kumar, S. Priya, Defect and adsorbate induced ferromagnetic spin-order in magnesium oxide nanocrystallites, Applied Physics Letters, 100 (2012) 192404.

[8] J. Hu, Z. Zhang, M. Zhao, H. Qin, M. Jiang, Room-temperature ferromagnetism in MgO nanocrystalline powders, Applied Physics Letters, 93 (2008) 192503.

[9] B. Choudhury, A. Choudhury, Microstructural, optical and magnetic properties study of nanocrystalline MgO, Materials Research Express, 1 (2014) 025026.

[10] K. Ali, J. Iqbal, T. Jana, N. Ahmad, I. Ahmad, D. Wan, Enhancement of microwaves absorption 
properties of $\mathrm{CuFe}_{2} \mathrm{O}_{4}$ magnetic nanoparticles embedded in $\mathrm{MgO}$ matrix, Journal of Alloys and Compounds, 696 (2017) 711-717.

[11] N. Kumar, D. Sanyal, A. Sundaresan, Defect induced ferromagnetism in MgO nanoparticles studied by optical and positron annihilation spectroscopy, Chemical Physics Letters, 477 (2009) 360-364.

[12] S. Nagar, O.D. Jayakumar, L. Belova, K.V. Rao, Room Temperature Ferromagnetic V-Doped MgO Nanoparticles, Materials Express, 2 (2012) 233-237.

[13] C.N. Rao, U.T. Nakate, R.J. Choudhary, S.N. Kale, Defect-induced magneto-optic properties of MgO nanoparticles realized as optical-fiber-based low-field magnetic sensor, Applied Physics Letters, 103 (2013) 151107.

[14] S. Phokha, J. Klinkaewnarong, S. Hunpratub, K. Boonserm, E. Swatsitang, S. Maensiri, Ferromagnetism in Fe-doped MgO nanoparticles, Journal of Materials Science: Materials in Electronics, 27 (2016) 33-39.

[15] J.I. Beltrán, C. Monty, L. Balcells, C. Martínez-Boubeta, Possible d0 ferromagnetism in MgO, Solid State Communications, 149 (2009) 1654-1657.

[16] B.M. Maoz, E. Tirosh, M. Bar Sadan, G. Markovich, Defect-induced magnetism in chemically synthesized nanoscale sheets of MgO, Physical Review B, 83 (2011) 161201.

[17] D. Mishra, B.P. Mandal, R. Mukherjee, R. Naik, G. Lawes, B. Nadgorny, Oxygen vacancy enhanced room temperature magnetism in Al-doped MgO nanoparticles, Applied Physics Letters, 102 (2013) 182404.

[18] L.-q. Qi, L.-h. Liu, S.-z. Feng, H.-y. Sun, R.-s. Han, Synthesis and magnetic properties of ceramic MgO porous film, Journal of the European Ceramic Society, 37 (2017) 4727-4731.

[19] F. Wang, Z. Pang, L. Lin, S. Fang, Y. Dai, S. Han, Magnetism in undoped MgO studied by density functional theory, Physical Review B, 80 (2009) 144424.

[20] J. Li, Y. Jiang, Y. Li, D. Yang, Y. Xu, M. Yan, Origin of room temperature ferromagnetism in MgO films, Applied Physics Letters, 102 (2013) 072406.

[21] S. Mahadeva, J. Fan, A. Biswas, K. Sreelatha, L. Belova, K. Rao, Magnetism of Amorphous and NanoCrystallized Dc-Sputter-Deposited MgO Thin Films, Nanomaterials, 3 (2013) 486.

[22] J. Guo, L. Wu, S. Ren, X. Kang, W. Chen, X. Zhao, Ultra-low voltage control of magnetic properties in amorphous MgO, Applied Physics Letters, 111 (2017) 192402.

[23] F. Gao, J. Hu, C. Yang, Y. Zheng, H. Qin, L. Sun, X. Kong, M. Jiang, First-principles study of magnetism driven by intrinsic defects in MgO, Solid State Communications, 149 (2009) 855-858.

[24] A. Droghetti, C.D. Pemmaraju, S. Sanvito, Polaronic distortion and vacancy-induced magnetism in MgO, Physical Review B, 81 (2010) 092403.

[25] B. Merabet, S. Kacimi, A. Mir, M. Azzouz, A. Zaoui, Vacancy effects on the electronic structure of MgO compound, Modern Physics Letters B, 29 (2015) 1550147.

[26] A. Khamkongkaeo, W. Klysubun, T. Boonchuduang, W. Sailuam, P. Sriwattana, T. Phetrattanarangsi, K. Srimongkon, B. Sakkomolsri, A. Pimsawat, S. Daengsakul, P. Kidkhunthod, A. Bootchanont, B.

Lohwongwatana, $\mathrm{X}$-ray absorption spectroscopy investigation of relationship between $\mathrm{Mg}$ vacancy and magnetic properties of MgO powder, Journal of Magnetism and Magnetic Materials, 460 (2018) 327333.

[27] N. Pathak, S.K. Gupta, C.L. Prajapat, S.K. Sharma, P.S. Ghosh, B. Kanrar, P.K. Pujari, R.M. Kadam, Defect induced ferromagnetism in $\mathrm{MgO}$ and its exceptional enhancement upon thermal annealing: a case of transformation of various defect states, Physical Chemistry Chemical Physics, 19 (2017) 1197511989.

[28] I.G. Morozov, O.V. Belousova, O.A. Belyakov, I.P. Parkin, S. Sathasivam, M.V. Kuznetcov, Titanium nitride room-temperature ferromagnetic nanoparticles, Journal of Alloys and Compounds, 675 (2016) 266-276.

[29] Y.G. Morozov, O.V. Belousova, M.V. Kuznetsov, D. Ortega, I.P. Parkin, Electric field-assisted levitation-jet aerosol synthesis of Ni/NiO nanoparticles, Journal of Materials Chemistry, 22 (2012) 11214-11223.

[30] I.G. Morozov, O.V. Belousova, S. Firth, I.P. Parkin, M.V. Kuznetcov, Levitation-jet synthesis of In-O nanoparticles with room-temperature ferromagnetic properties, Advanced Powder Technology, 28 (2017) 2065-2077.

[31] M.A. Garcia, E. Fernandez Pinel, J. de la Venta, A. Quesada, V. Bouzas, J.F. Fernández, J.J. Romero, 
M.S. Martín González, J.L. Costa-Krämer, Sources of experimental errors in the observation of nanoscale magnetism, Journal of Applied Physics, 105 (2009) 013925.

[32] S. Chae, H. Lee, P.V. Pikhitsa, C. Kim, S. Shin, D.H. Kim, M. Choi, Synthesis of terraced and spherical MgO nanoparticles using flame metal combustion, Powder Technology, 305 (2017) 132-140.

[33] R.N. Newman, J.F.B. Payne, The anomalous brightness of magnesium-Air flames, Combustion and Flame, 68 (1987) 31-41.

[34] S. Stankic, M. Cottura, D. Demaille, C. Noguera, J. Jupille, Nucleation and growth concepts applied to the formation of a stoichiometric compound in a gas phase: The case of $\mathrm{MgO}$ smoke, Journal of Crystal Growth, 329 (2011) 52-56.

[35] Q. Li, B. Ye, Y. Hao, J. Liu, W. Kong, B. Ye, Annealing temperature effects on the magnetic properties and induced defects in $\mathrm{C} / \mathrm{N} / \mathrm{O}$ implanted MgO, Nuclear Instruments and Methods in Physics Research Section B: Beam Interactions with Materials and Atoms, 297 (2013) 29-34.

[36] M.V. Kuznetsov, Y.G. Morozov, O.V. Belousova, D. Ortega, Ferromagnetic Zn/ZnO Nanoparticles, Inorg Mater, 50 (2014) 369-378.

[37] M.V. Kuznetcov, O.V. Belousova, D. Ortega, I.G. Morozov, Ferromagnetic nanoparticles in Sn-O system, Inorganic Materials, 50 (2014) 793-802.

[38] P. Esquinazi, W. Hergert, D. Spemann, A. Setzer, A. Ernst, Defect-Induced Magnetism in Solids, IEEE Transactions on Magnetics, 49 (2013) 4668-4674.

[39] P.V. Pikhitsa, C. Kim, S. Chae, S. Shin, S. Jung, M. Kitaura, S.-i. Kimura, K. Fukui, M. Choi, Two-band luminescence from an intrinsic defect in spherical and terraced $\mathrm{MgO}$ nanoparticles, Applied Physics Letters, 106 (2015) 183106.

[40] S.K. Moorthy, C.H. Ashok, K.V. Rao, C. Viswanathan, Synthesis and Characterization of MgO Nanoparticles by Neem Leaves through Green Method, Materials Today: Proceedings, 2 (2015) 43604368.

[41] S. Lacombe, H. Cardy, N. Soggiu, S. Blanc, J.L. Habib-Jiwan, J.P. Soumillion, Diffuse reflectance UVVisible spectroscopy for the qualitative and quantitative study of chromophores adsorbed or grafted on silica, Microporous and Mesoporous Materials, 46 (2001) 311-325.

[42] J. Tauc, Amorphous and liquid semiconductors, Springer Science \& Business Media, 2012.

[43] K. Kaviyarasu, A. Devarajan, Synthesis and characterization studies of cadmium doped MgO nanocrystals for optoelectronics application, Advances in Applied Science Research, 2 (2011) 131-138.

[44] P.K. Gour, S.D. Roy, Synthesis and Study of Magnesium Oxide and Cadmium Doped Magnesium Oxide Nanoparticles HCTL Open International Journal of Technology Innovations and Research (IJTIR) 16 (2015) 32 (31-36).

[45] M.W. Williams, E.T. Arakawa, Optical Properties of Single-Crystal Magnesium Oxide, Journal of Applied Physics, 38 (1967) 5272-5276.

[46] M.R. Bindhu, M. Umadevi, M. Kavin Micheal, M.V. Arasu, N. Abdullah Al-Dhabi, Structural, morphological and optical properties of $\mathrm{MgO}$ nanoparticles for antibacterial applications, Materials Letters, 166 (2016) 19-22.

[47] N.C.S. Selvam, R.T. Kumar, L.J. Kennedy, J.J. Vijaya, Comparative study of microwave and conventional methods for the preparation and optical properties of novel MgO-micro and nanostructures, Journal of Alloys and Compounds, 509 (2011) 9809-9815.

[48] S. Balamurugan, L. Ashna, P. Parthiban, Synthesis of Nanocrystalline MgO Particles by Combustion Followed by Annealing Method Using Hexamine as a Fuel, Journal of Nanotechnology, Article ID 841803 (2014) 6 pages.

[49] C.M. Janet, B. Viswanathan, R.P. Viswanath, T.K. Varadarajan, Characterization and Photoluminescence Properties of MgO Microtubes Synthesized from Hydromagnesite Flowers, J. Phys. Chem., 111 (2007) 10267-10272.

[50] P.B. Devaraja, D.N. Avadhani, S.C. Prashantha, H. Nagabhushana, S.C. Sharma, B.M. Nagabhushana, H.P. Nagaswarupa, Synthesis, structural and luminescence studies of magnesium oxide nanopowder, Spectrochimica Acta Part A: Molecular and Biomolecular Spectroscopy, 118 (2014) 847-851.

[51] S. Yousefi, B. Ghasemi, M. Tajally, A. Asghari, Optical properties of $\mathrm{MgO}$ and $\mathrm{Mg}(\mathrm{OH})_{2}$ nanostructures synthesized by a chemical precipitation method using impure brine, Journal of Alloys and Compounds, 711 (2017) 521-529.

[52] S. RSoniya, V.M. Nair, Synthesis and Characterization of Nanostructured $\mathrm{Mg}(\mathrm{OH})_{2}$ and $\mathrm{MgO}$, 
International Journal of Science and Research (IJSR), 5 (2016) 197-203.

[53] T.S. Chen, F.W. de Wette, L. Kleinman, D.G. Dempsey, Lattice dynamics and vibrational specific heat of MgO microcrystals, Physical Review B, 17 (1978) 844-851.

[54] K. Ishikawa, N. Fujima, H. Komura, First-order Raman scattering in MgO microcrystals, Journal of Applied Physics, 57 (1985) 973-975.

[55] H.K. Böckelmann, R.G. Schlecht, Raman scattering from microcrystals of MgO, Physical Review B, 10 (1974) 5225-5231.

[56] H.S. Kim, H.W. Kim, Fabrication and Raman Studies of $\mathrm{MgO} / \mathrm{SnO}_{2}$ Core-Shell Heteronanowires, Acta Physica Polonica A, 116 (2009) 58-61.

[57] http://www.casaxps.com/, (2018).

[58] M. Kapilashrami, H. Zhang, M. Fang, X. Li, X. Sun, K.V. Rao, L. Belova, Y. Luo, J. Guo, Electronic structure of room-temperature ferromagnetic $\mathrm{Mg}_{1-x} \mathrm{Fe}_{x} \mathrm{O}_{y}$ thin films, Applied Physics Letters, 101 (2012) 082411.

[59] J. Li, Y. Jiang, G. Bai, T. Ma, D. Yang, Y. Du, M. Yan, Room temperature ferromagnetism of amorphous MgO films prepared by pulsed laser deposition, Applied Physics A, 115 (2014) 997-1001. [60] https://kartyush.wordpress.com/, (2016).

[61] Y. Wu, X. Yang, J. Li, K.V. Rao, L. Belova, Solution processed room temperature ferromagnetic MgO thin films printed by inkjet technique, Materials Letters, 196 (2017) 388-391.

[62] Z. Jiang, D. Jiang, Z. Yan, D. Liu, K. Qian, J. Xie, A new visible light active multifunctional ternary composite based on $\mathrm{TiO}_{2}-\mathrm{In}_{2} \mathrm{O}_{3}$ nanocrystals heterojunction decorated porous graphitic carbon nitride for photocatalytic treatment of hazardous pollutant and $\mathrm{H}_{2}$ evolution, Applied Catalysis $\mathrm{B}$ :

Environmental, 170-171 (2015) 195-205.

[63] https://xpssimplified.com/elements/carbon.php, (2018).

[64] Z. Jin, W. Duan, W. Duan, B. Liu, X. Chen, F. Yang, J. Guo, Indium doped and carbon modified P25 nanocomposites with high visible-light sensitivity for the photocatalytic degradation of organic dyes, Applied Catalysis A: General, 517 (2016) 129-140.

[65] A.V. Shchukarev, D.V. Korolkov, XPS Study of group IA carbonates, Central European Journal of Chemistry, 2 (2004) 347-362.

[66] K. Mukes, X. Jun, K.V. Rao, B. Lyuba, C. Elin, F. Mats, Experimental evidence for ferromagnetism at room temperature in MgO thin films, Journal of Physics: Condensed Matter, 22 (2010) 345004.

[67] F.-G. Kuang, S.-Y. Kang, X.-Y. Kuang, Q.-F. Chen, An ab initio study on the electronic and magnetic properties of MgO with intrinsic defects, RSC Advances, 4 (2014) 51366-51373. 


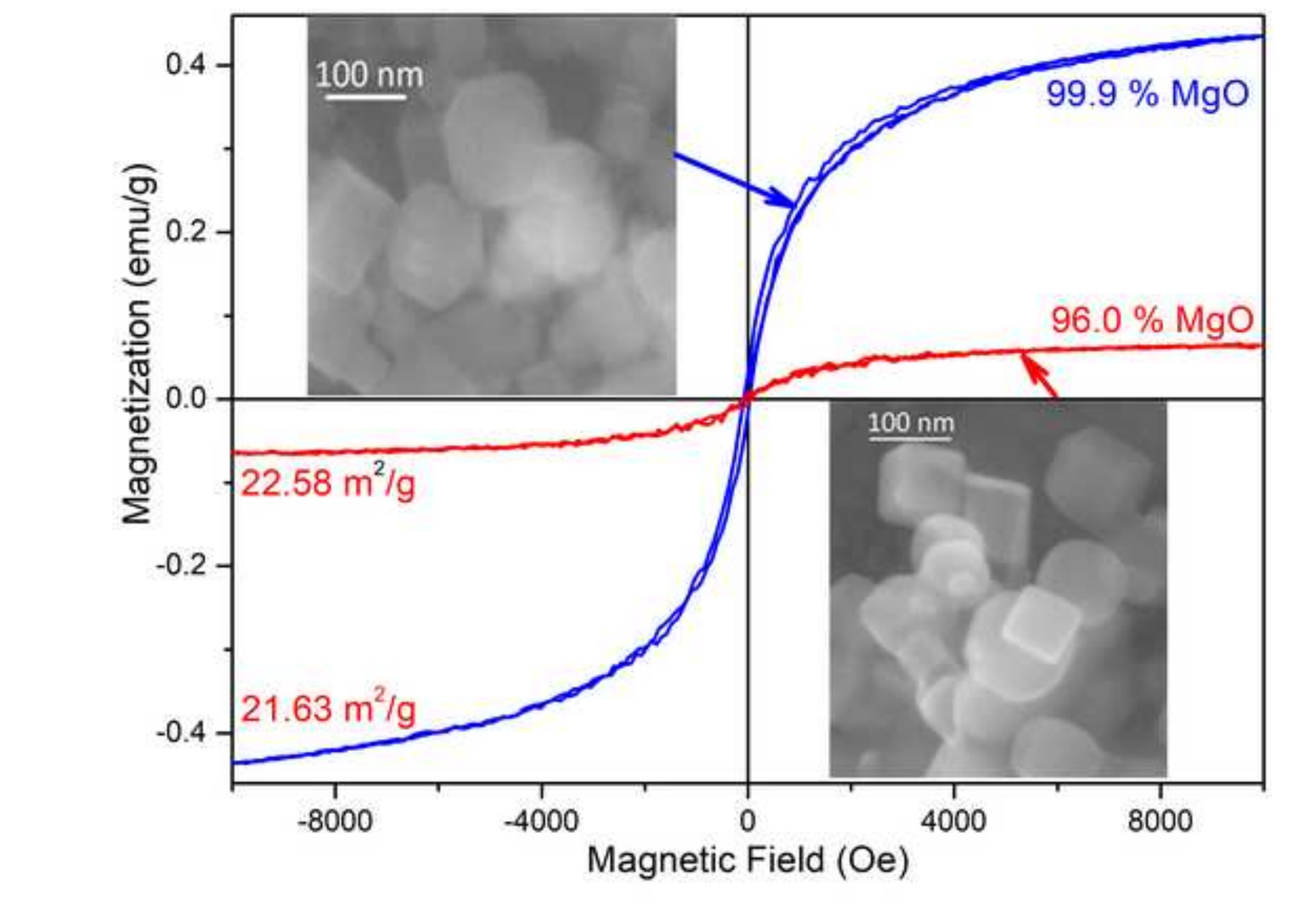

)

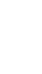
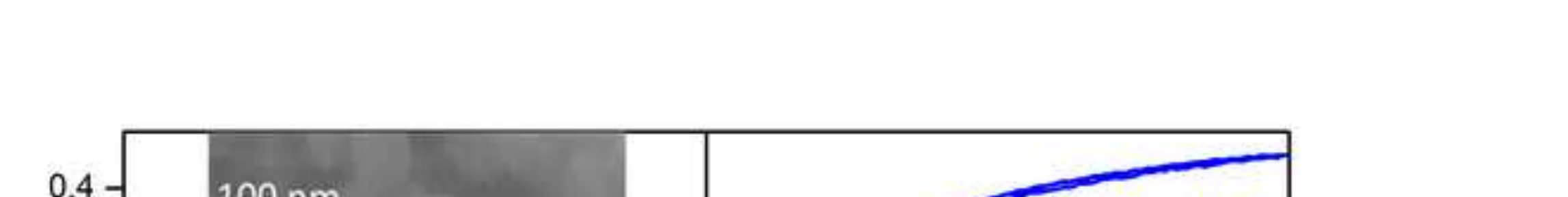

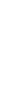


- Levitation-jet synthesis of Mg-O nanoparticles (NPs) at different conditions

- Cubic, terraced, and spherical NPs in average particle sizes from 30 up to $80 \mathrm{~nm}$

- RT ferromagnetism (RTFM) in the NPs with maximum magnetization up to 0.65 emu/g

- Dependence of the magnetization on specific surface area multiplied by MgO content

- Oscillating quenching dependence of the maximum magnetization on $\mathrm{Mg} 2 \mathrm{p}$ peak width 
Table 1. Experimental observation of RTFM in undoped Mg-O NPs.

\begin{tabular}{|c|c|c|c|}
\hline Fabrication method & $\begin{array}{l}\text { Average particle } \\
\text { size, nm }\end{array}$ & $\begin{array}{l}\text { Maximum RT } \\
\text { magnetization, memu/g }\end{array}$ & Refs. \\
\hline \multirow[t]{2}{*}{ Sol-gel } & $6-23$ & 13 & [7] \\
\hline & 24,52 & 33 & {$[8]$} \\
\hline \multirow[t]{6}{*}{ Wet-chemical technology } & 12 & 2.6 & [3] \\
\hline & 13 & 70 & [9] \\
\hline & $17,21,25$ & 8.3 & [2] \\
\hline & $20-30$ & 50 & {$[10]$} \\
\hline & $22,28,32$ & 2 & {$[11]$} \\
\hline & 35 & 14 & {$[12]$} \\
\hline Microwave-assisted co-precipitation & 20 & 25 & {$[13]$} \\
\hline Thermal decomposition of $\mathrm{Mg}(\mathrm{OH})_{2}$ & 50 (clustered) & 2 & {$[6]$} \\
\hline Polymer pyrolysis & 25 & 35 & {$[5]$} \\
\hline $\begin{array}{l}\text { Vaporization-condensation in a glass balloon under } \\
\text { reduced pressure }\end{array}$ & 15 & 13 & {$[14]$} \\
\hline
\end{tabular}


Table 2. Main properties of the Mg-O NPs. $S$ - specific surface area obtained from BET measurements; $\langle d\rangle-$ mean particle size obtained from SEM micrographs; $y-\mathrm{MgO}$ content and $a-\mathrm{MgO}$ lattice parameter obtained from XRD data; $\sigma_{\mathrm{s}}$ - maximum specific magnetization (VSM, RT, $10 \mathrm{kOe}$ ).

\begin{tabular}{|c|c|c|c|c|c|c|c|c|c|}
\hline \multirow{2}{*}{$\begin{array}{l}\text { Sample } \\
\text { IDs }\end{array}$} & \multicolumn{3}{|c|}{ Synthesis conditions } & \multirow{2}{*}{$\begin{array}{l}\text { NPs } \\
\text { collection } \\
\text { zone }\end{array}$} & \multirow{2}{*}{$\begin{array}{l}<\mathrm{d}> \\
\mathrm{nm}\end{array}$} & \multirow[t]{2}{*}{$S, \mathrm{~m}^{2} / \mathrm{g}$} & \multirow[t]{2}{*}{$y$, at. $\%$} & \multirow[t]{2}{*}{$a, \mathrm{~nm}$} & \multirow{2}{*}{$\begin{array}{l}\sigma_{\mathrm{s}}, \\
\text { memu/g }\end{array}$} \\
\hline & $\begin{array}{l}\mathrm{Mg}, \\
\mathrm{g} / \mathrm{h}\end{array}$ & $\begin{array}{l}\mathrm{Ar}, \\
\mathrm{l} / \mathrm{h}\end{array}$ & $\begin{array}{l}\text { Air, } \\
1 / h\end{array}$ & & & & & & \\
\hline$\# 1$ & 8 & 53 & 28 & $\mathrm{M}$ & 42 & $14.57 \pm 0.18$ & 100 & 0.42168 & 650 \\
\hline$\# 2$ & 8 & 53 & 28 & $\mathrm{~T}$ & - & $15.06 \pm 0.34$ & 68.1 & 0.42186 & 7.4 \\
\hline$\# 3$ & 12 & 53 & 14 & $\mathrm{M}$ & 37 & $15.81 \pm 0.52$ & 70.1 & 0.42010 & 217 \\
\hline$\# 4$ & 12 & 53 & 14 & $\mathrm{C}$ & 33 & $16.09 \pm 0.44$ & 66.0 & 0.42047 & 108 \\
\hline$\# 5$ & 12 & 53 & 14 & $\mathrm{~T}$ & 30 & $16.29 \pm 0.58$ & 42.5 & 0.42088 & 9.5 \\
\hline$\# 6$ & 8 & 68 & 55 & $\mathrm{C}$ & - & $21.22 \pm 0.38$ & 99.7 & - & 90.5 \\
\hline$\# 7$ & 8 & 68 & 55 & $\mathrm{~T}$ & - & $22.11 \pm 0.34$ & 99.2 & - & 9.3 \\
\hline$\# 8$ & 6 & 68 & 55 & $\mathrm{M}$ & 80 & $21.63 \pm 0.45$ & 99.9 & 0.42108 & 430 \\
\hline$\# 9$ & 6 & 68 & 55 & $\mathrm{C}$ & 74 & $22.58 \pm 0.36$ & 96.0 & 0.42096 & 65 \\
\hline$\# 10$ & 6 & 68 & 55 & $\mathrm{~T}$ & 59 & $24.01 \pm 0.24$ & 94.3 & 0.42138 & 6 \\
\hline$\# 11$ & 6 & 85 & 40 & $\mathrm{M}$ & - & $24.17 \pm 0.41$ & 99.8 & - & 184 \\
\hline$\# 12$ & 6 & 53 & 30 & $\mathrm{M}$ & - & $22.77 \pm 1.45$ & 99.9 & - & 162 \\
\hline$\# 13$ & 8 & 85 & 50 & M & 66 & $25.26 \pm 0.08$ & 99.6 & 0.42102 & 75 \\
\hline$\# 14$ & 8 & 85 & 50 & $\mathrm{~T}$ & 60 & $26.89 \pm 0.31$ & 99.3 & 0.42104 & 16 \\
\hline$\# 15$ & 6 & 53 & 14 & $\mathrm{M}$ & 47 & $30.07 \pm 0.99$ & 99.9 & 0.42068 & 610 \\
\hline$\# 16$ & 6 & 53 & 14 & $\mathrm{~T}$ & 45 & $32.52 \pm 0.61$ & 99.1 & 0.42099 & 175 \\
\hline$\# 17$ & 6 & 150 & 55 & $\mathrm{M}$ & 55 & $32.59 \pm 0.23$ & 98.0 & 0.42010 & 280 \\
\hline$\# 18$ & 6 & 150 & 55 & $\mathrm{~T}$ & 52 & $34.69 \pm 0.62$ & 96.2 & 0.42040 & 62 \\
\hline$\# 19$ & 6 & 300 & 40 & $\mathrm{M}$ & 37 & $62.16 \pm 0.51$ & 100 & 0.42074 & 42 \\
\hline$\# 20$ & 6 & 300 & 40 & $\mathrm{~T}$ & 35 & $66.24 \pm 0.56$ & 91.7 & 0.42081 & 41 \\
\hline
\end{tabular}


Click here to download high resolution image

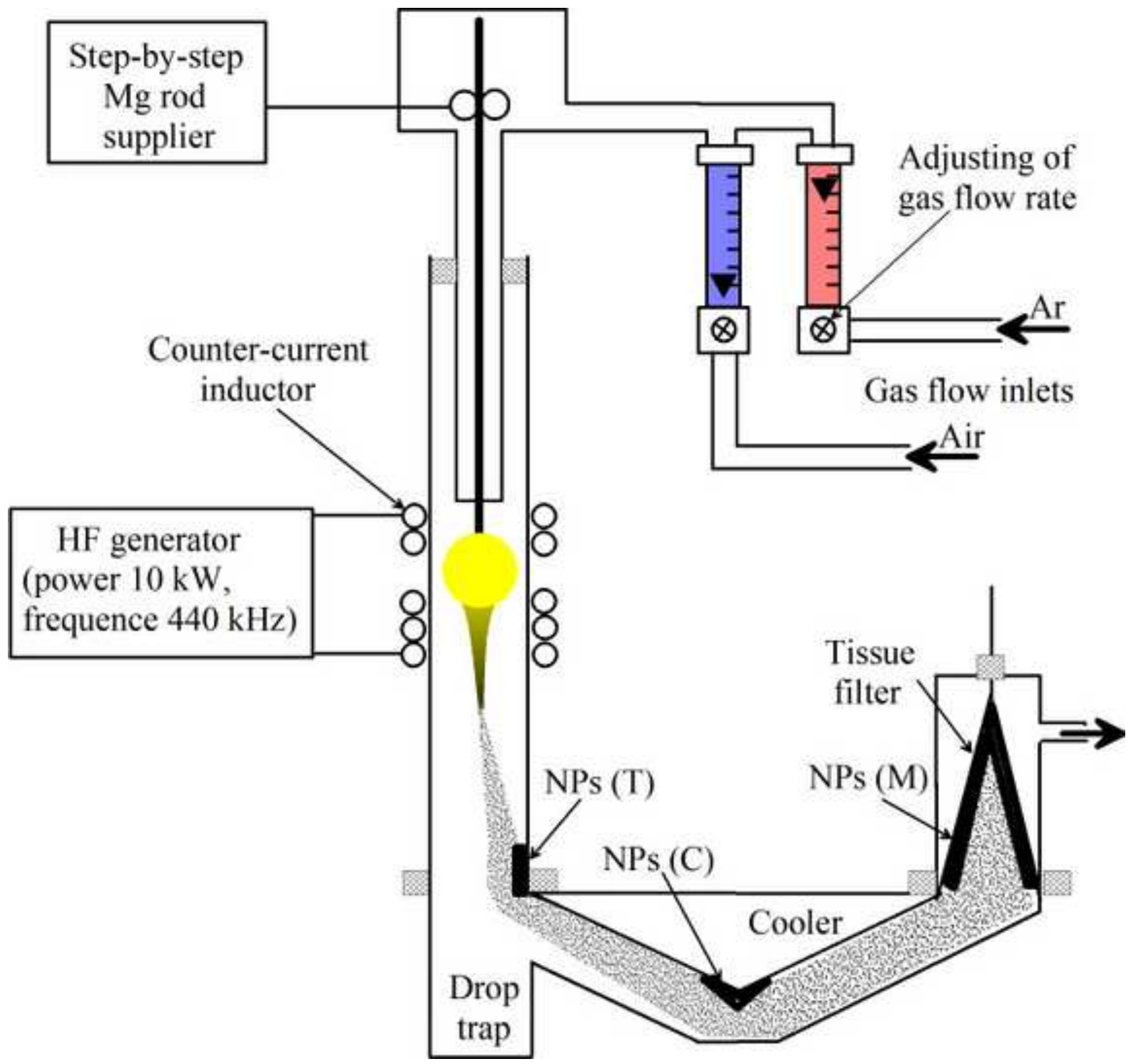




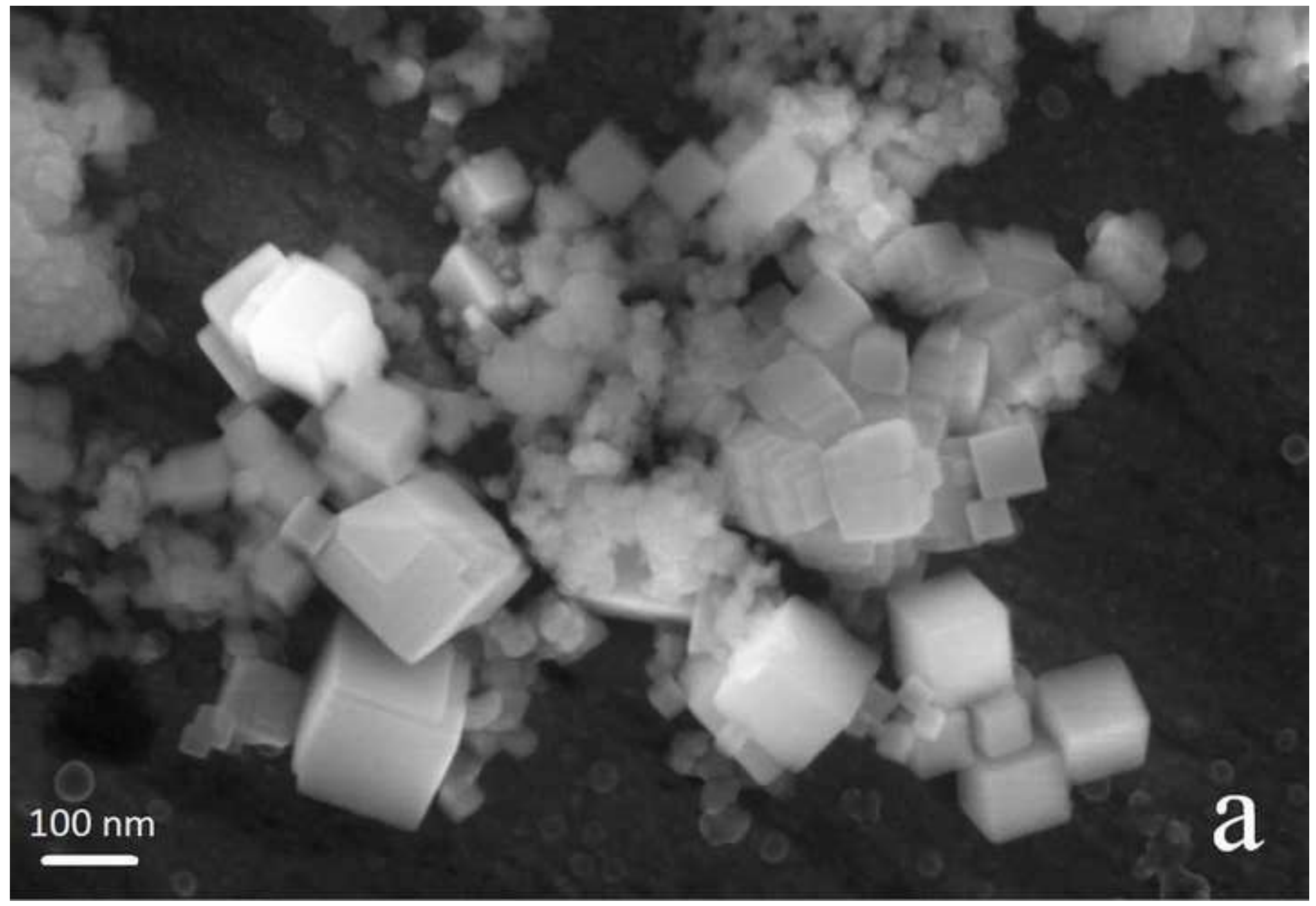


Figure3a
Click here to download high resolution image

\section{$100 \mathrm{~nm}$}
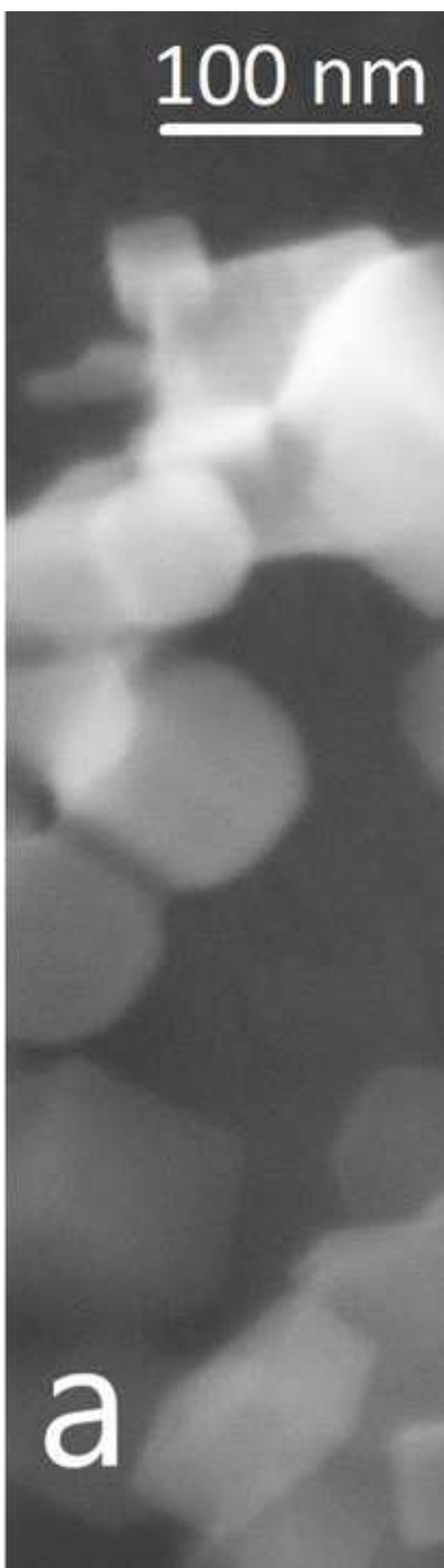


\section{Figure3b}

Click here to download high resolution image

\section{$100 \mathrm{~nm}$}

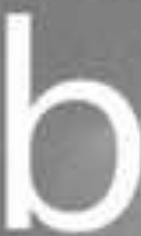




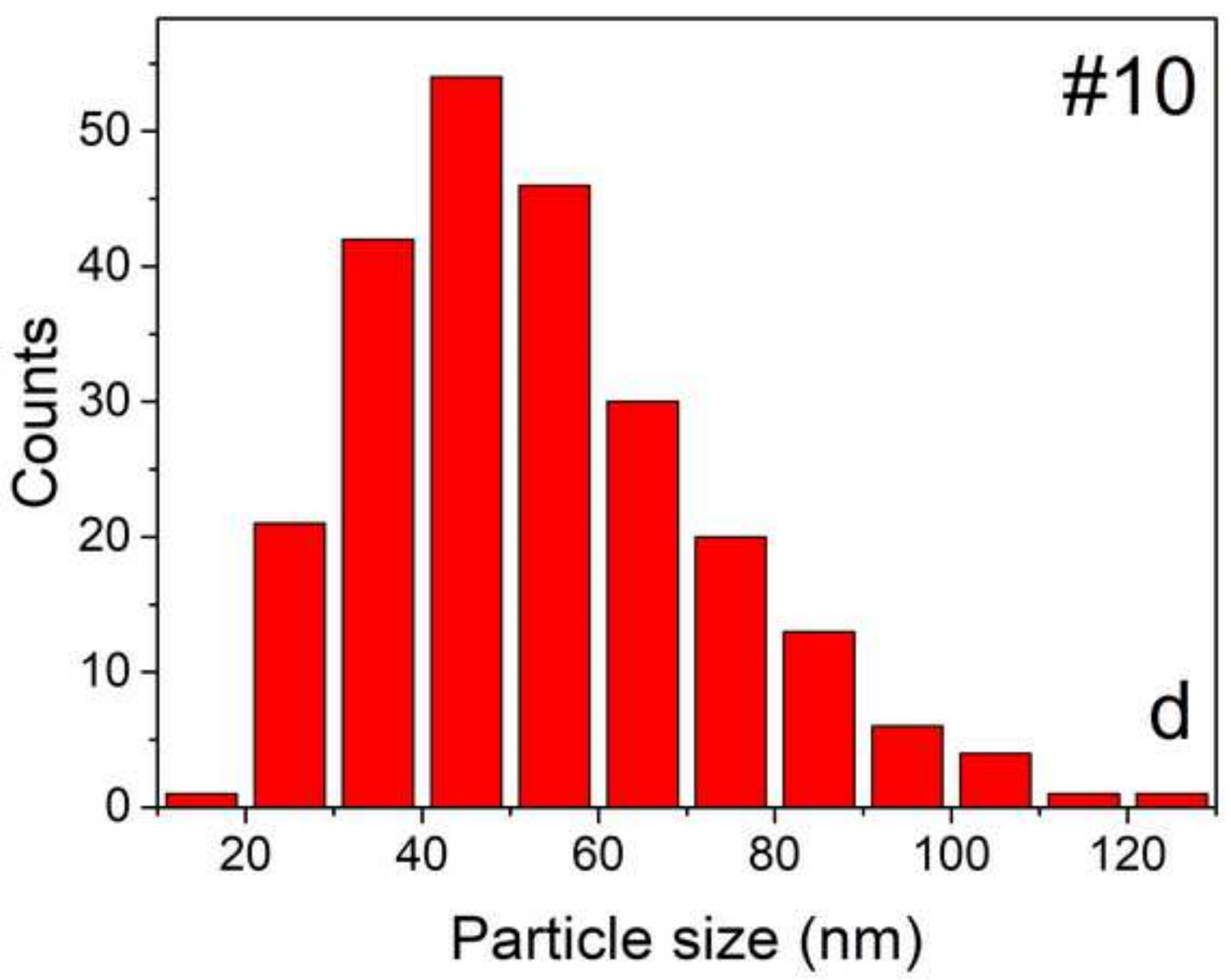




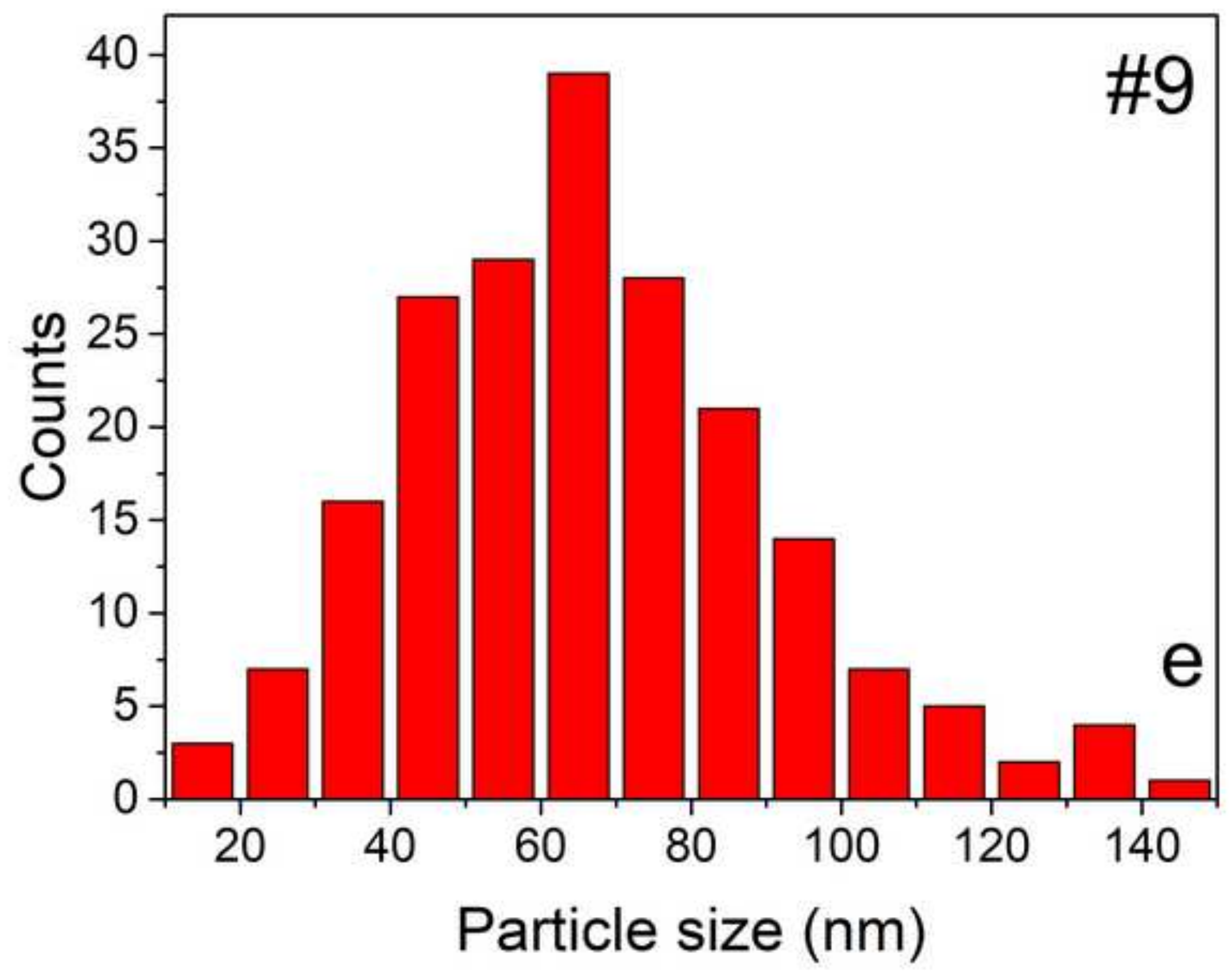




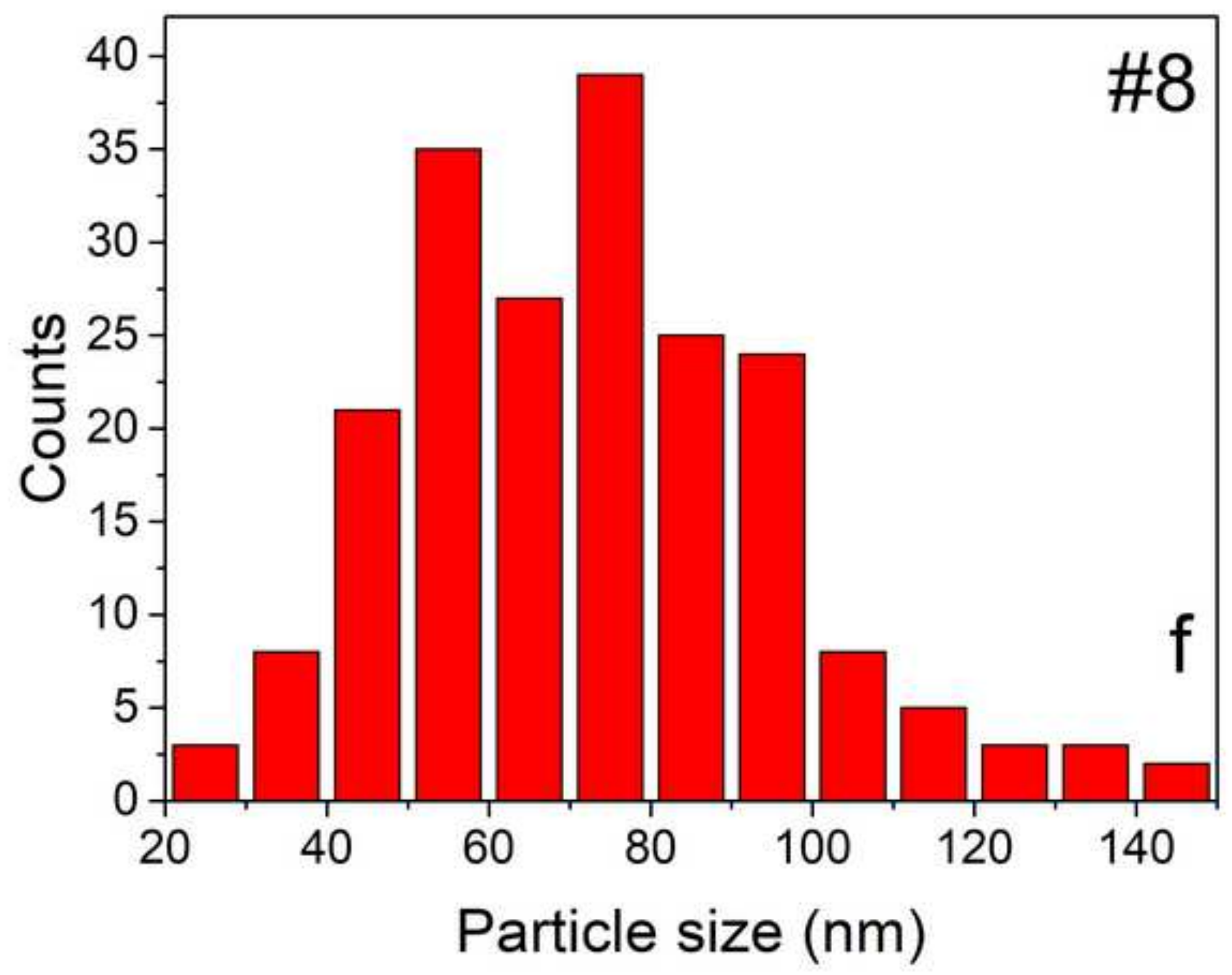




\section{Figure}

Click here to download high resolution image

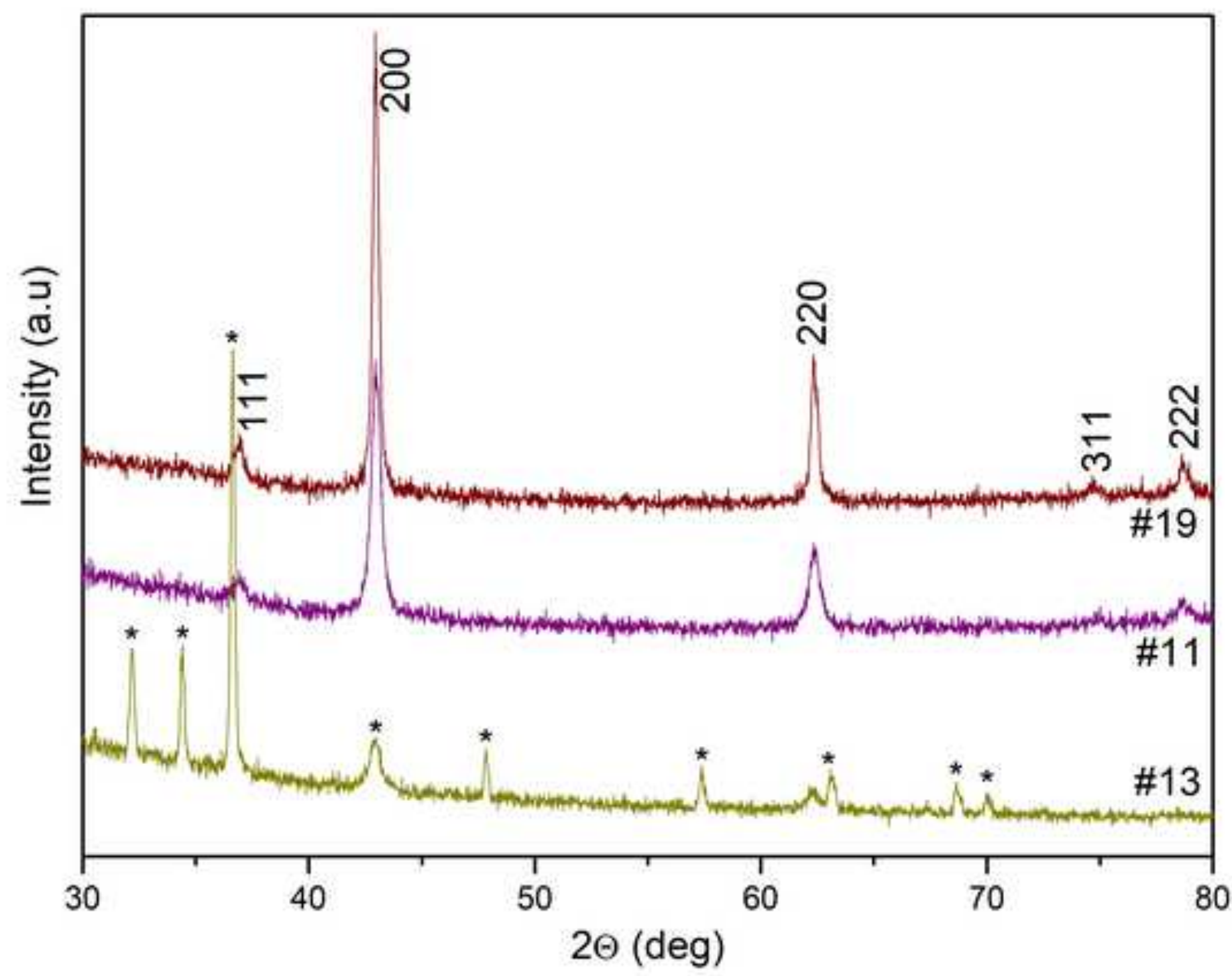


Click here to download high resolution image

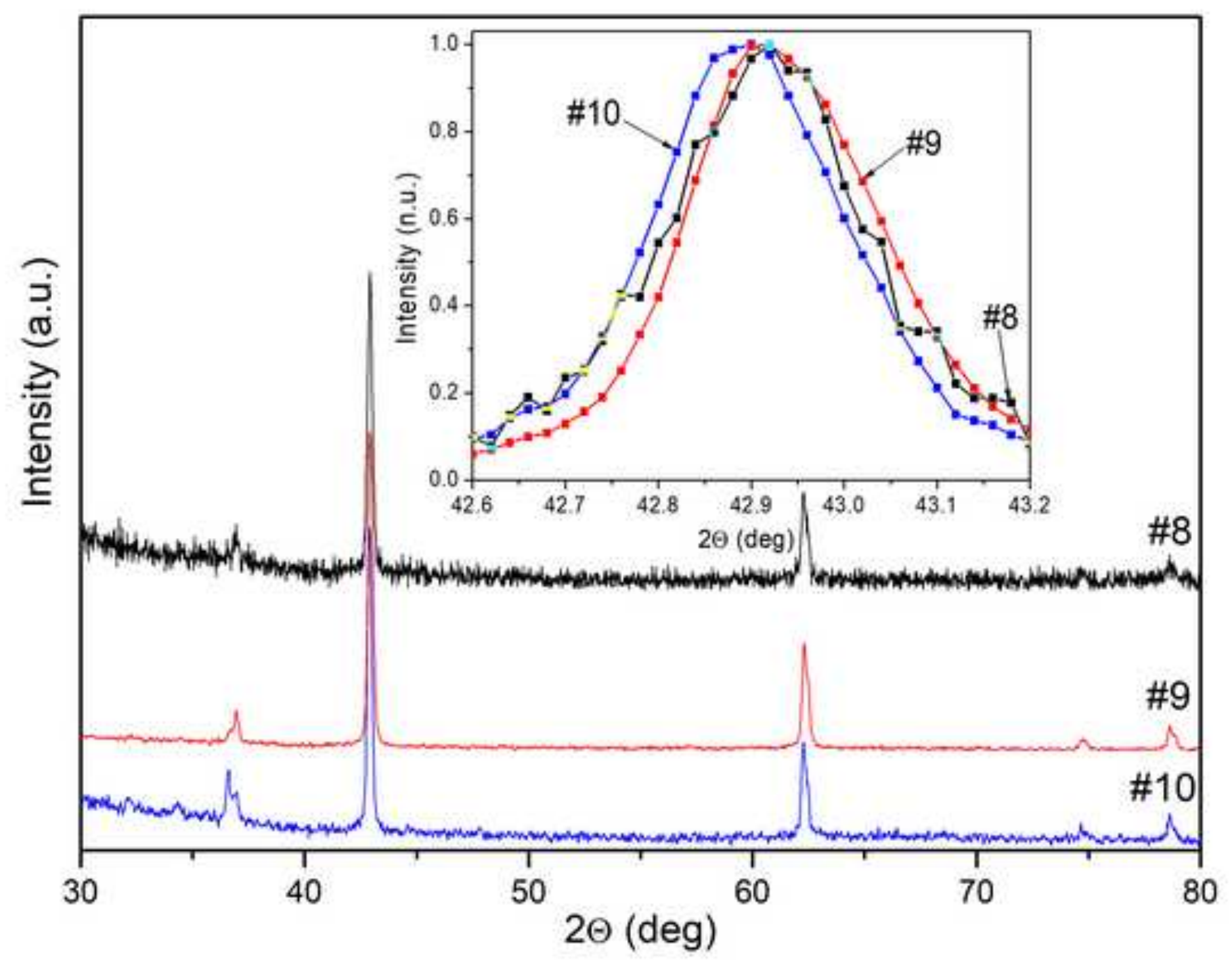




\section{Figure6

Click here to download high resolution image

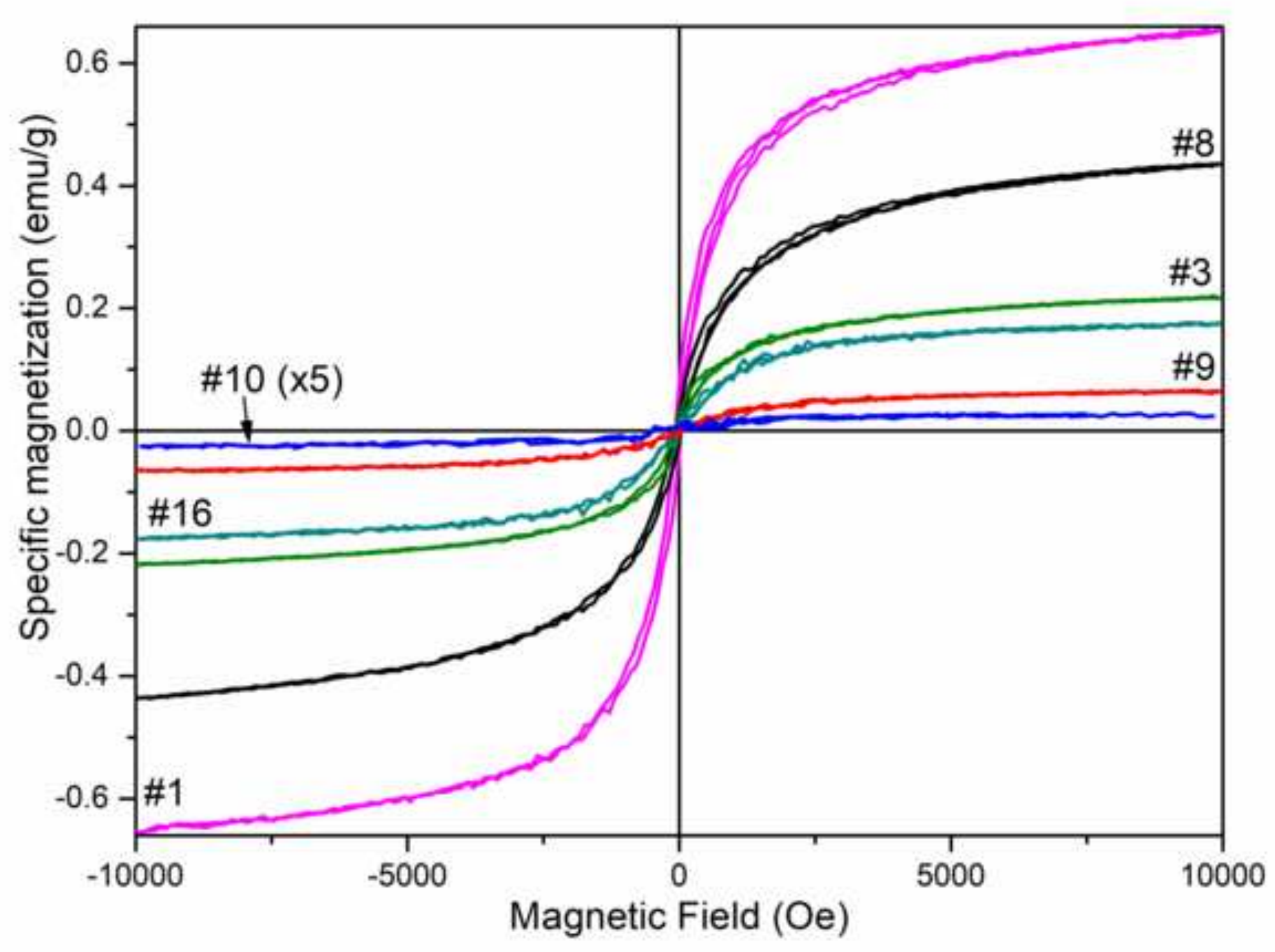

Click here to download high resolution image 


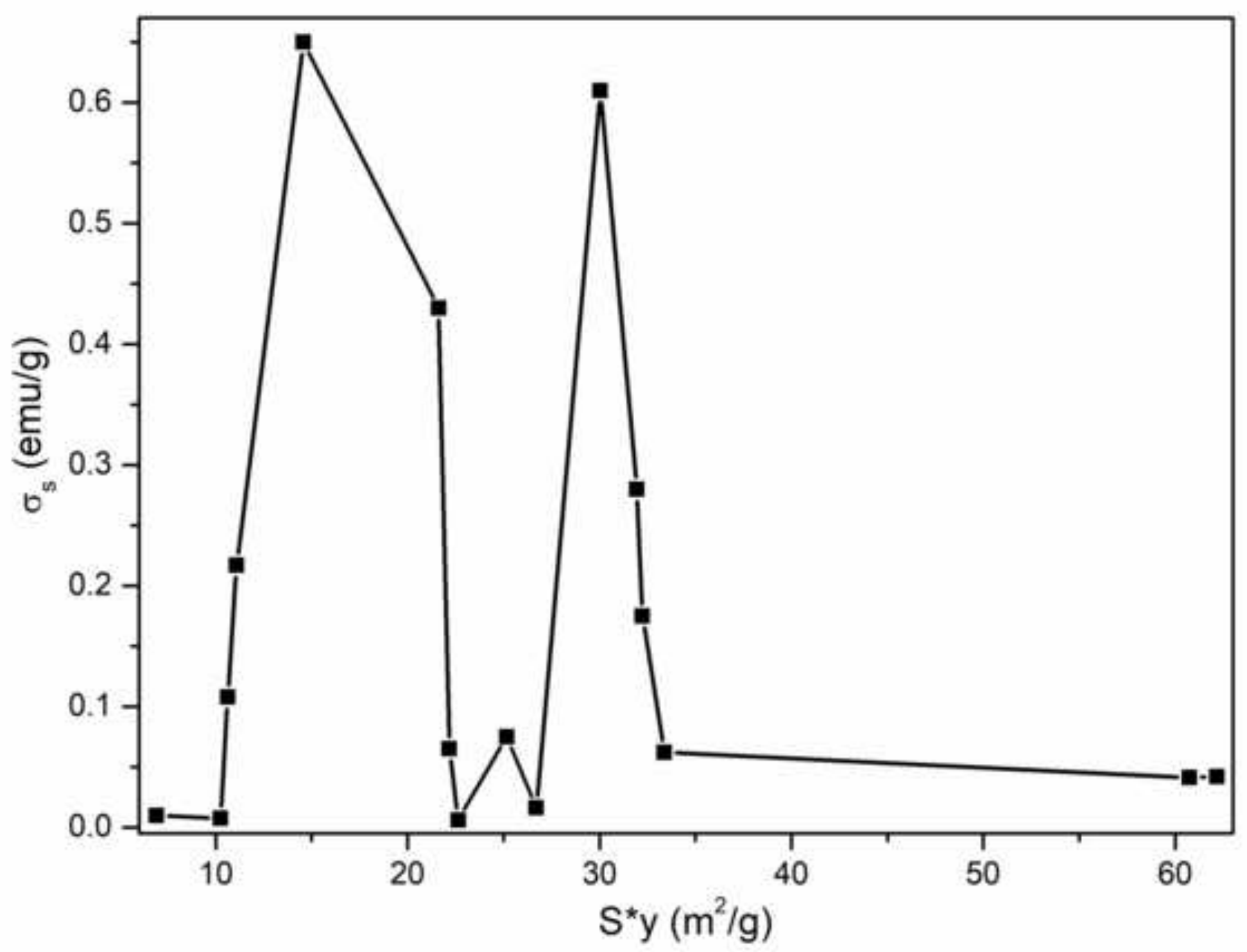




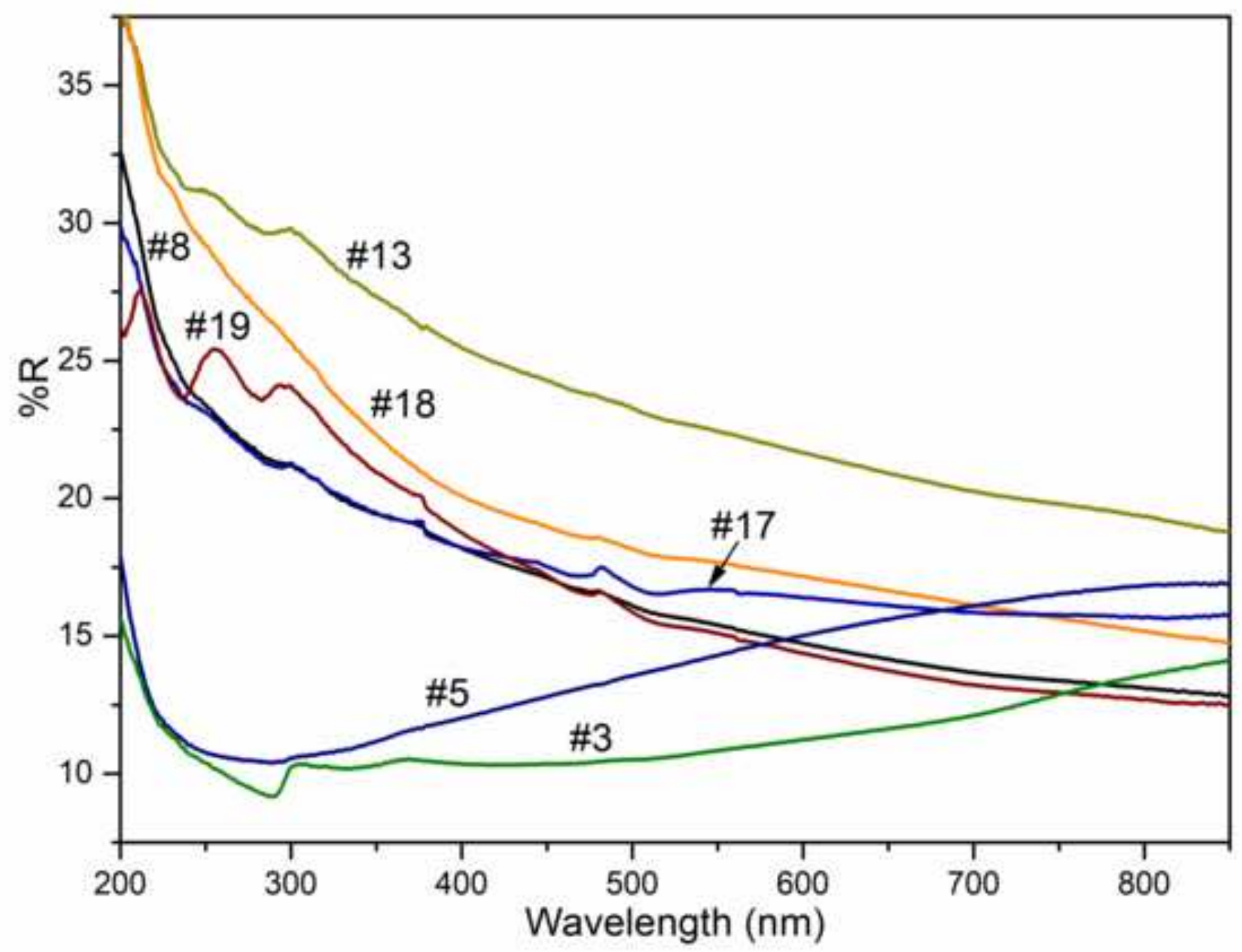




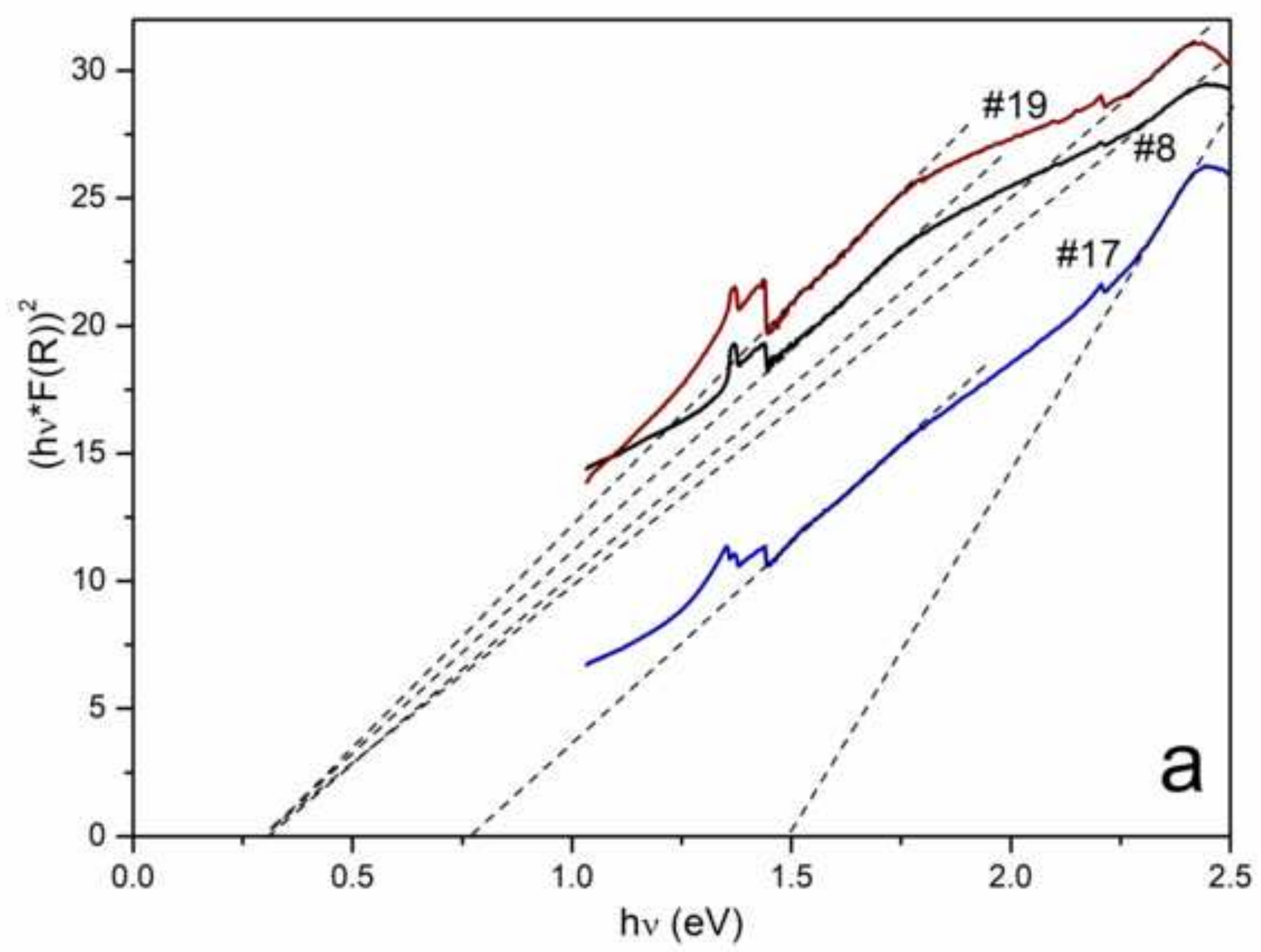


Click here to download high resolution image

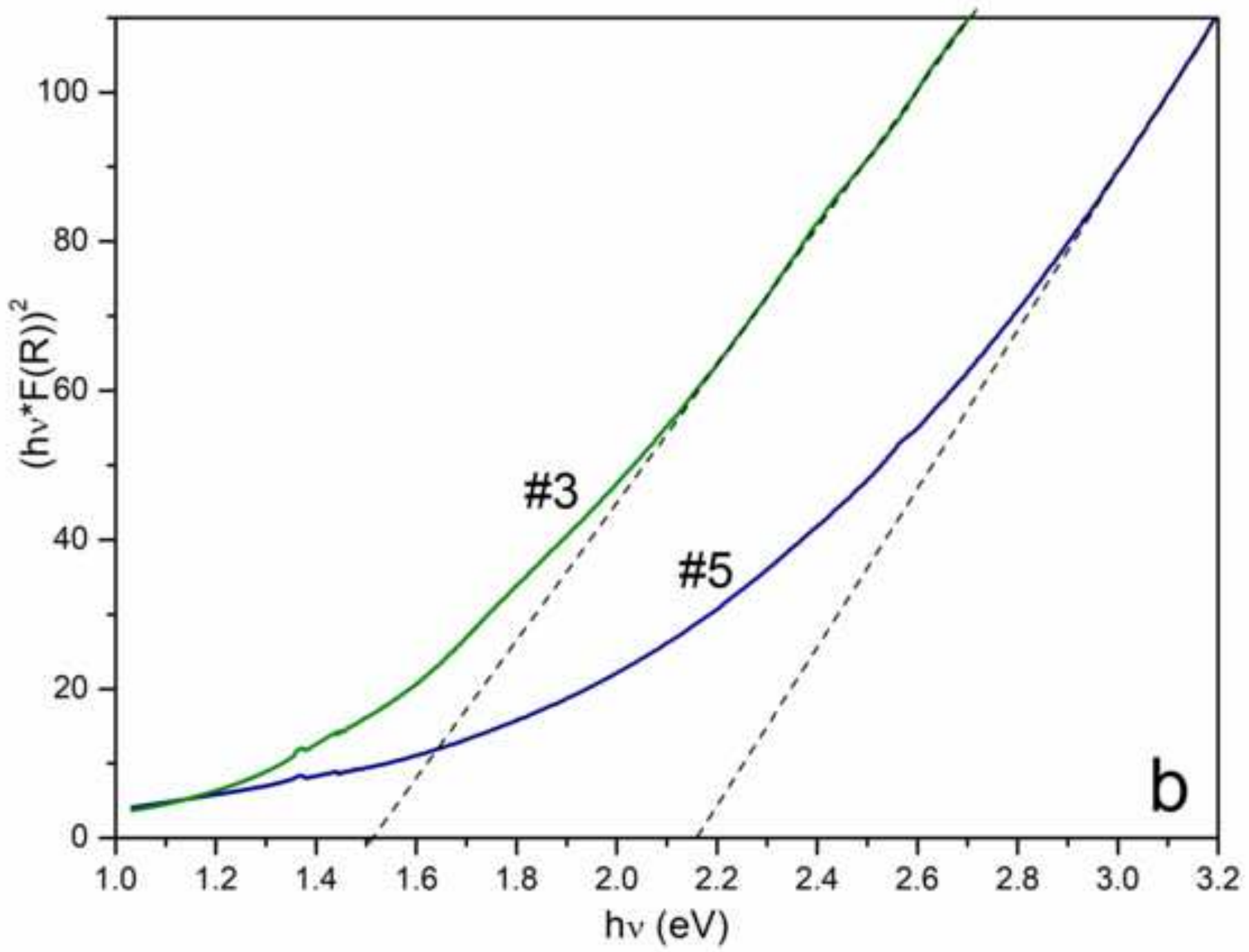




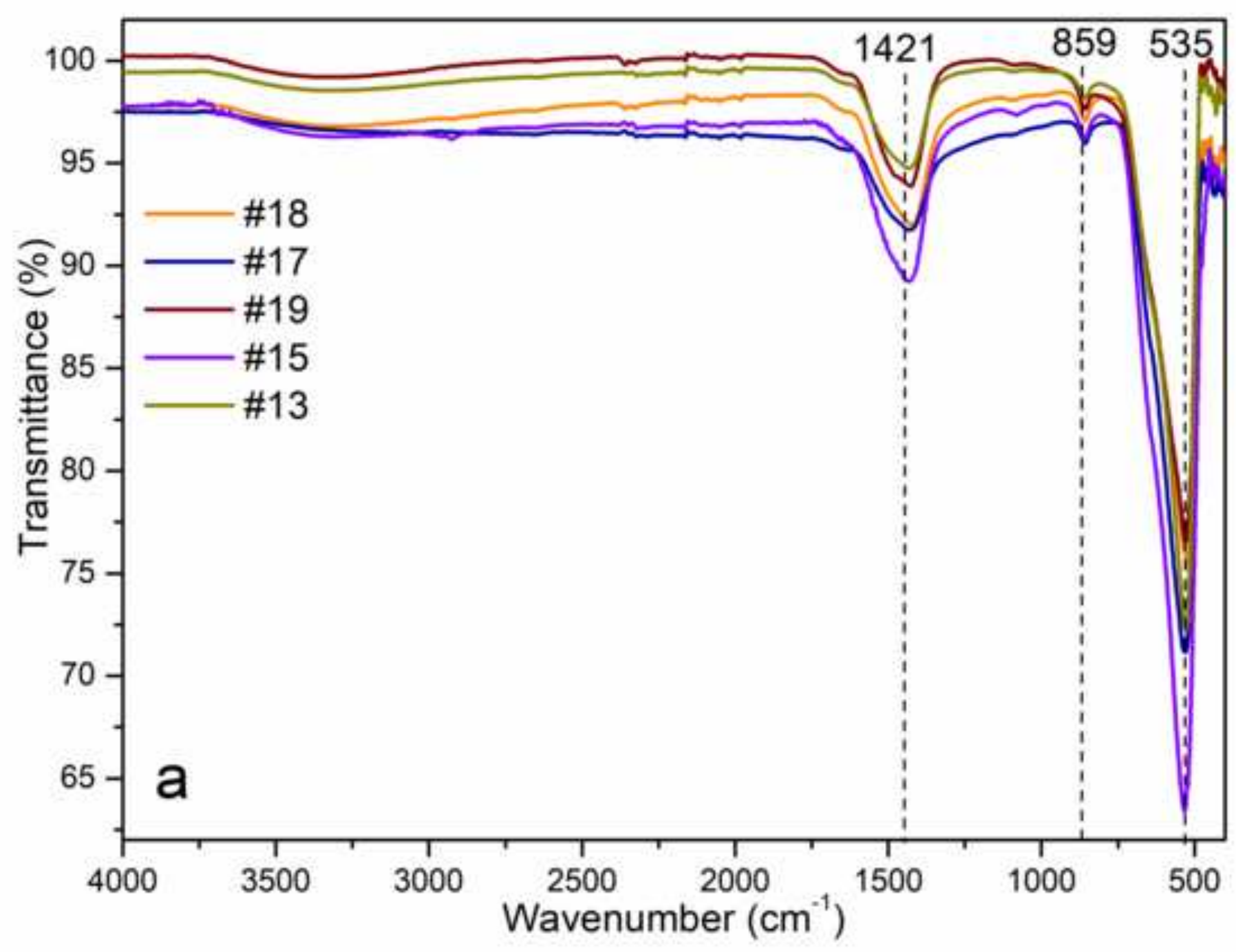




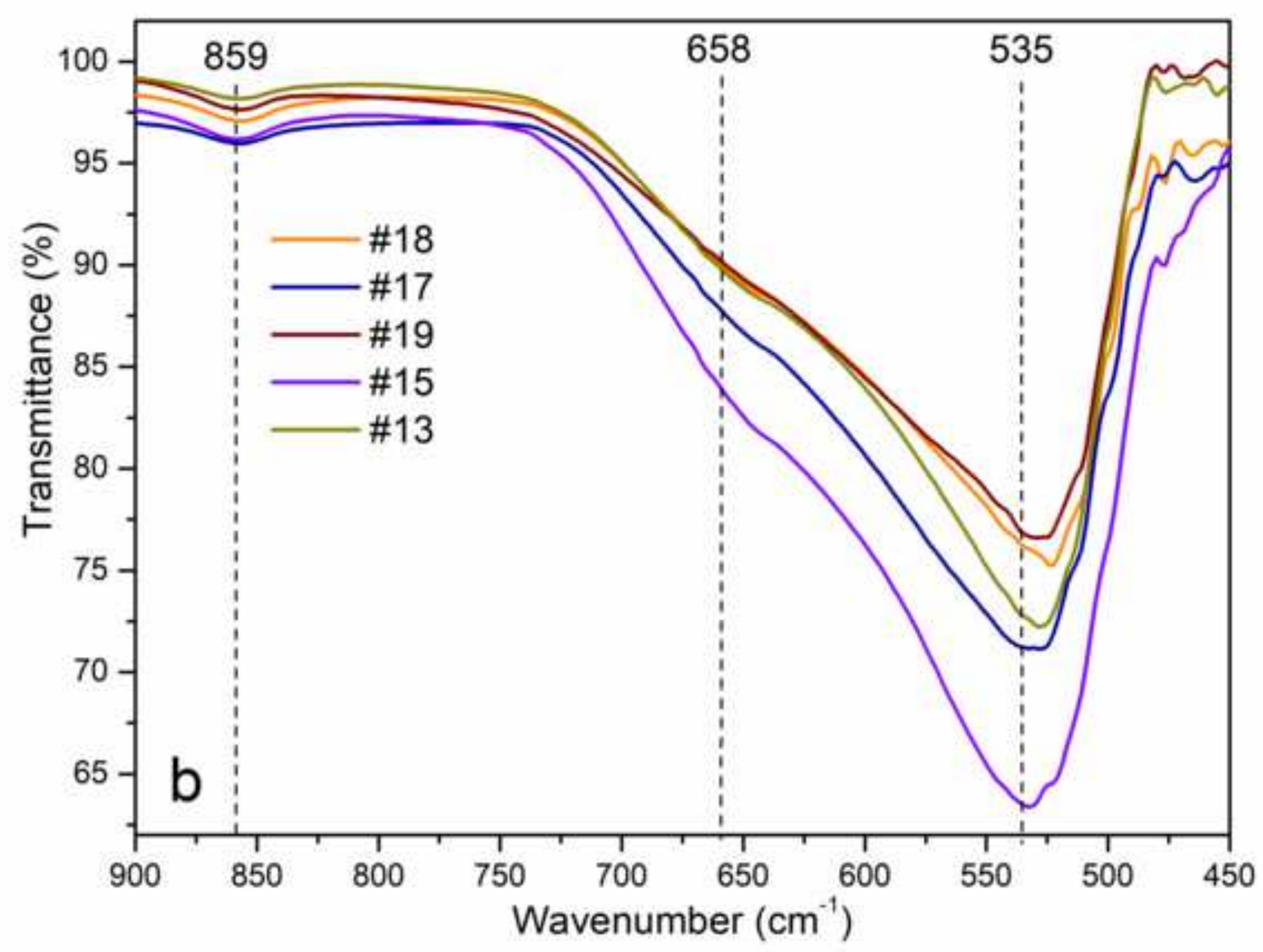




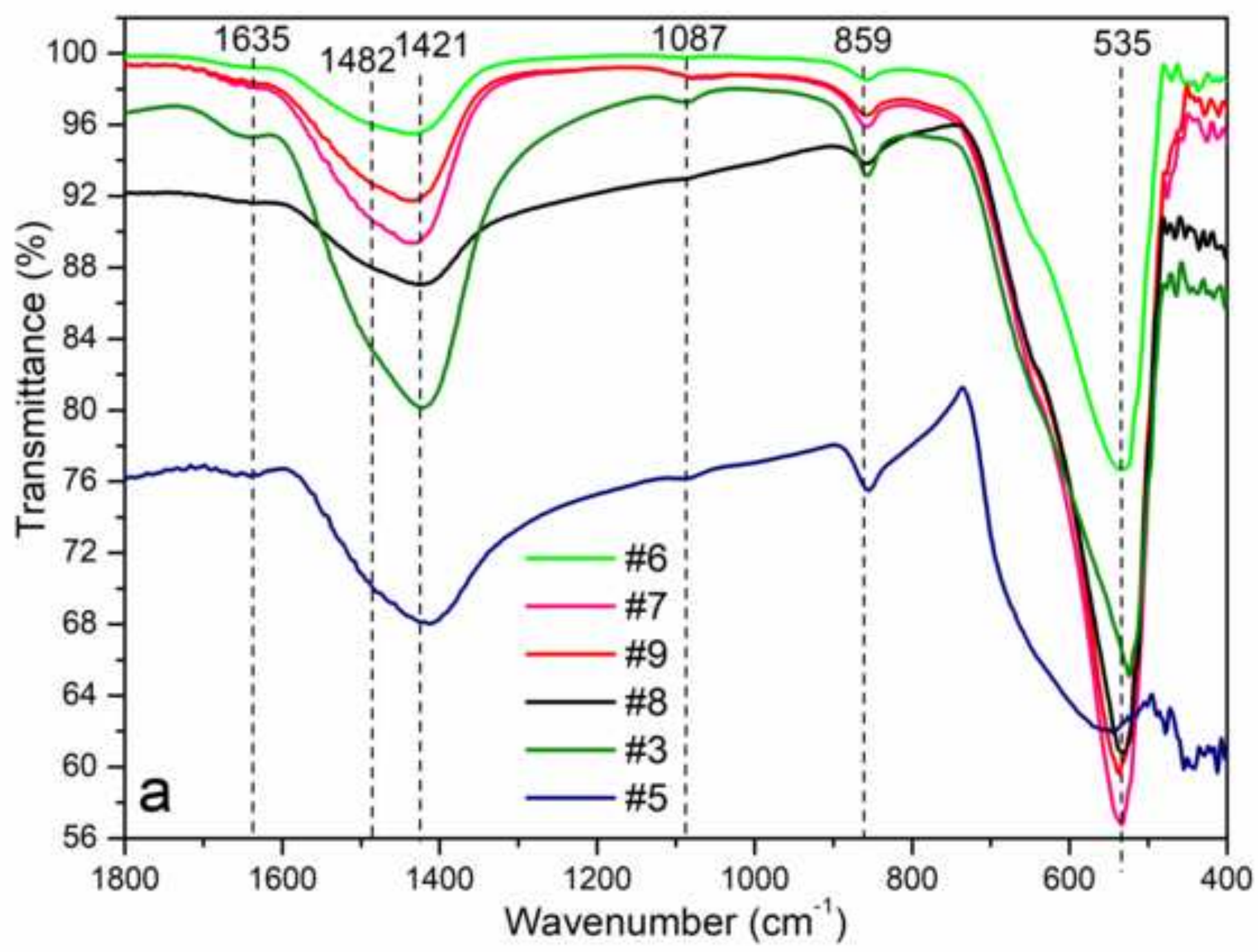




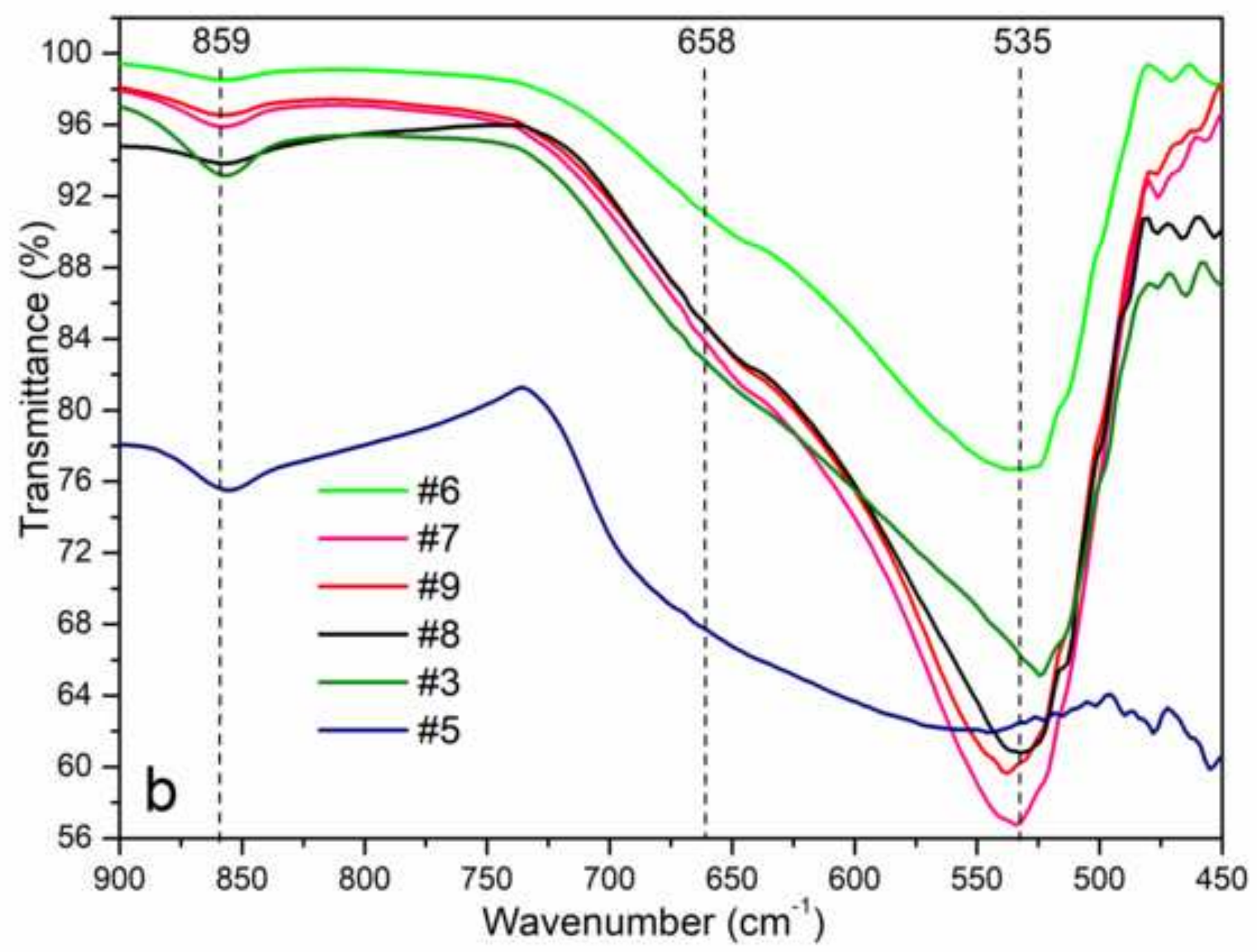


Click here to download high resolution image

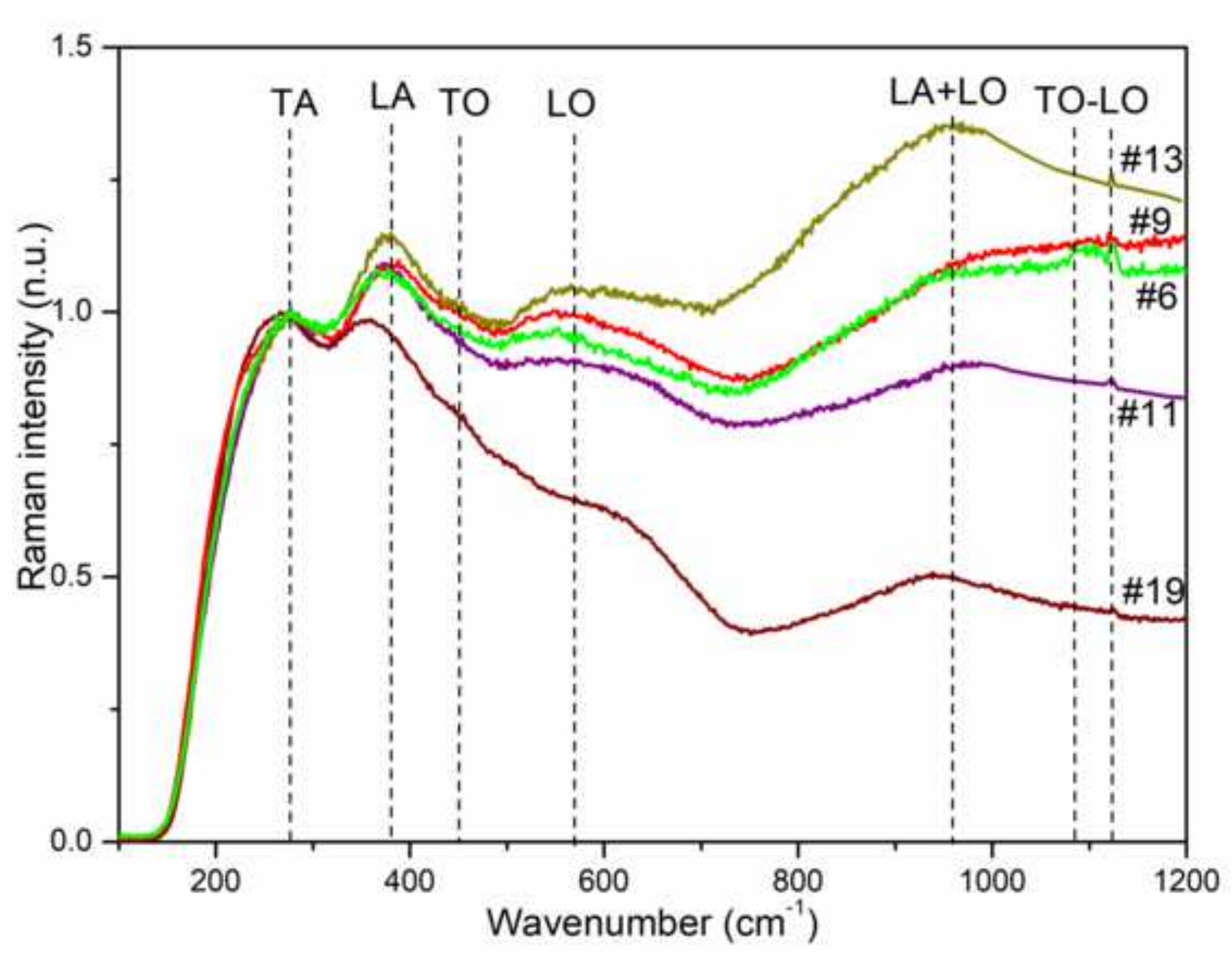

. 


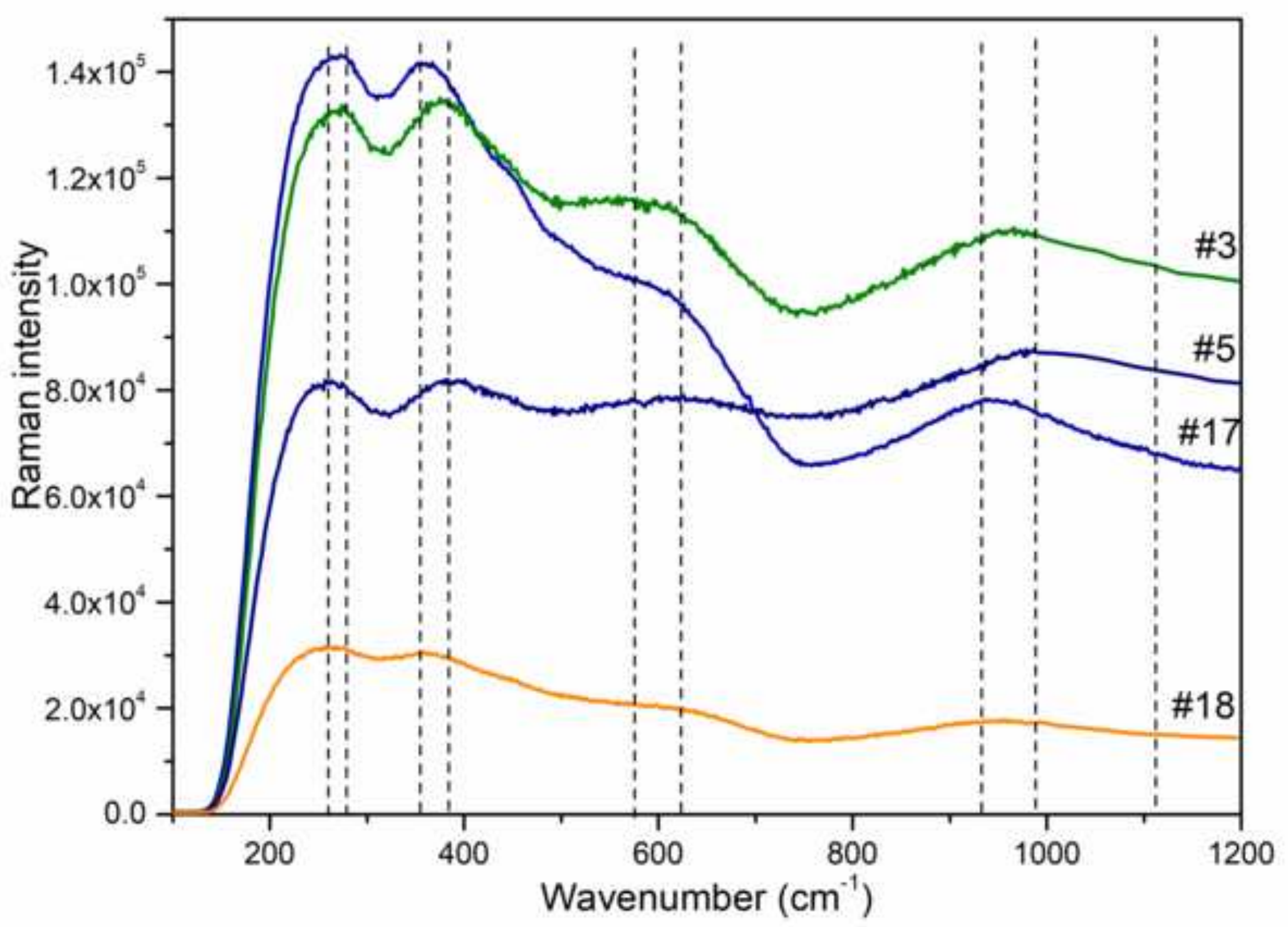




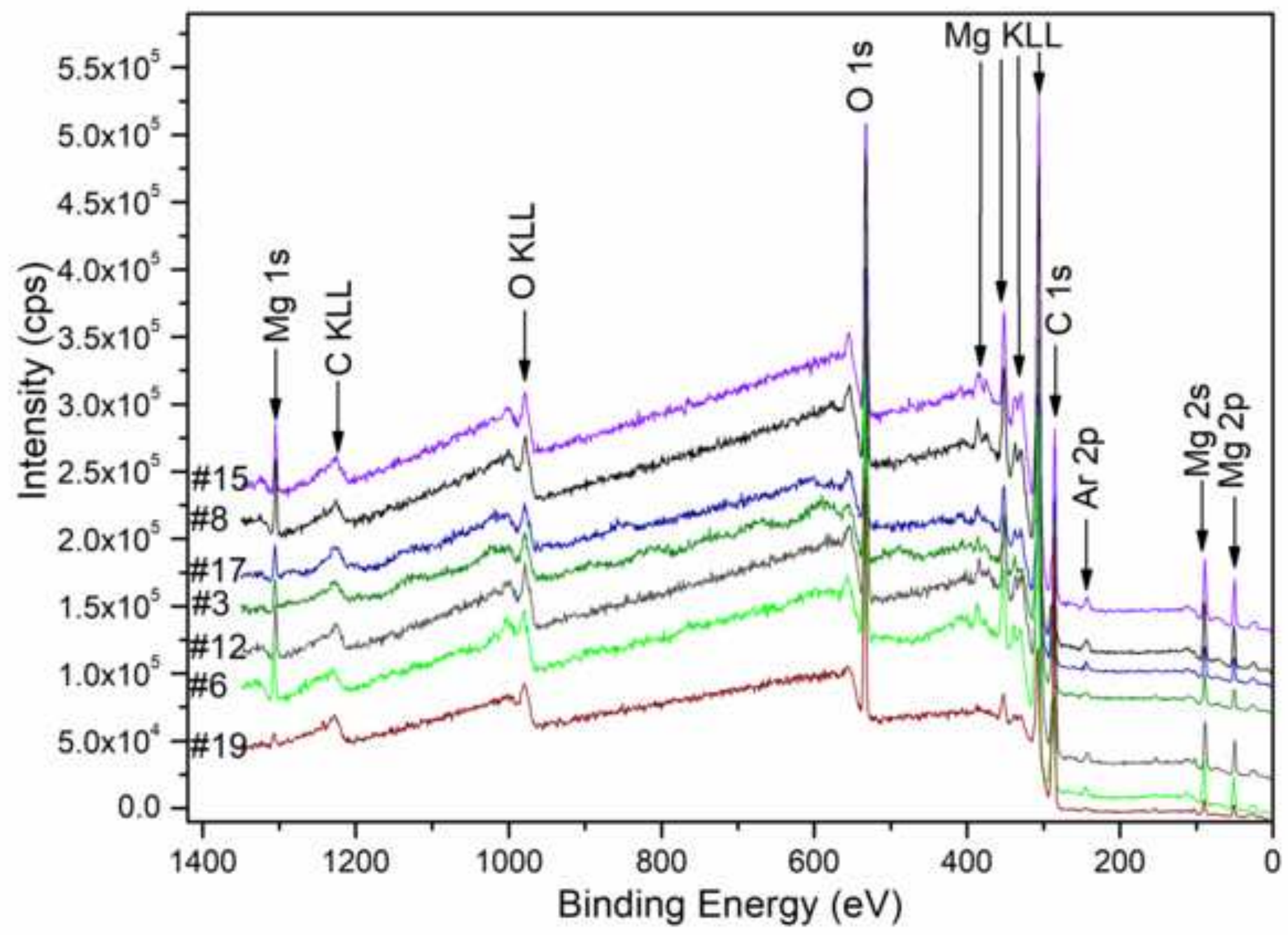




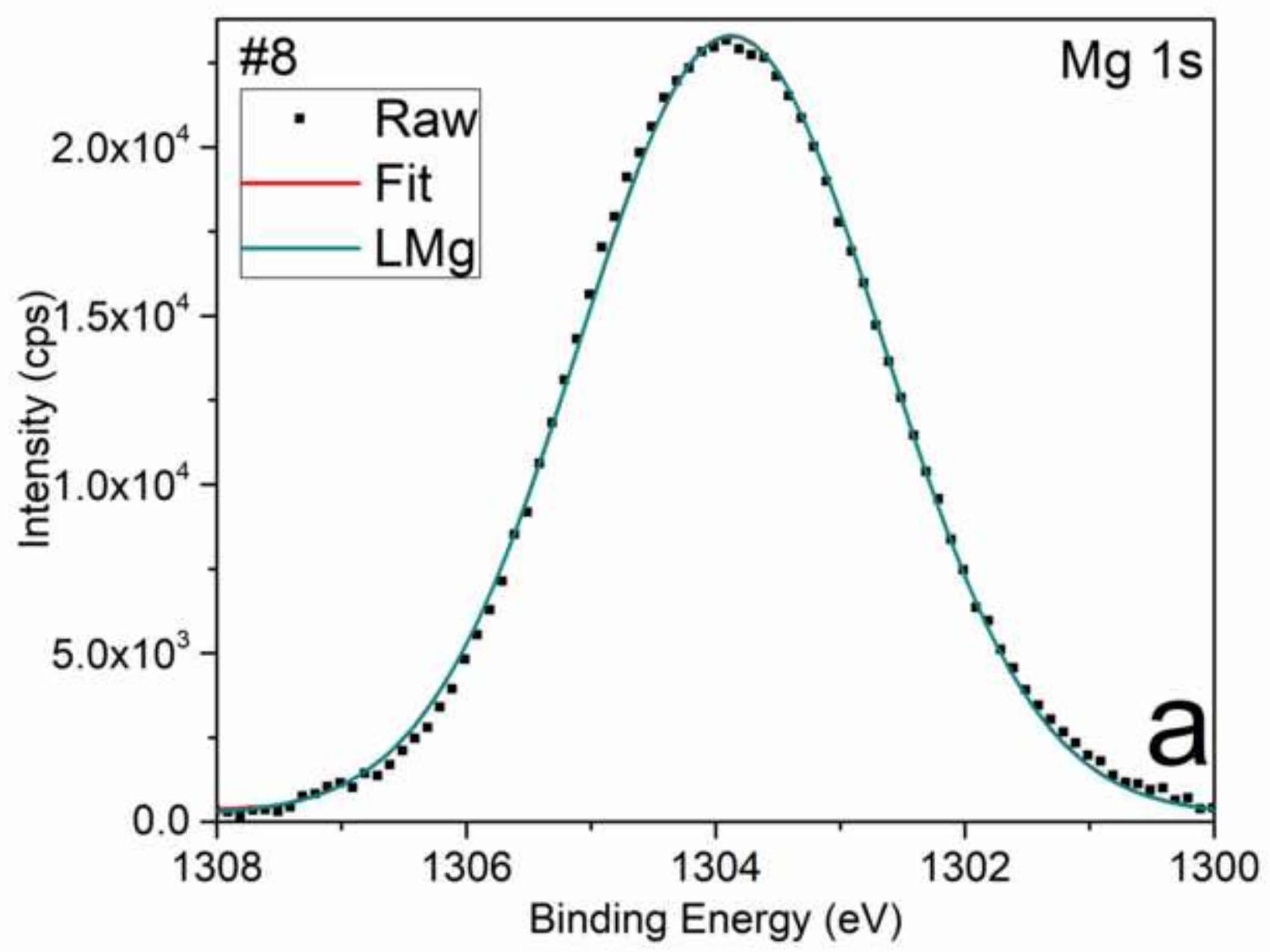




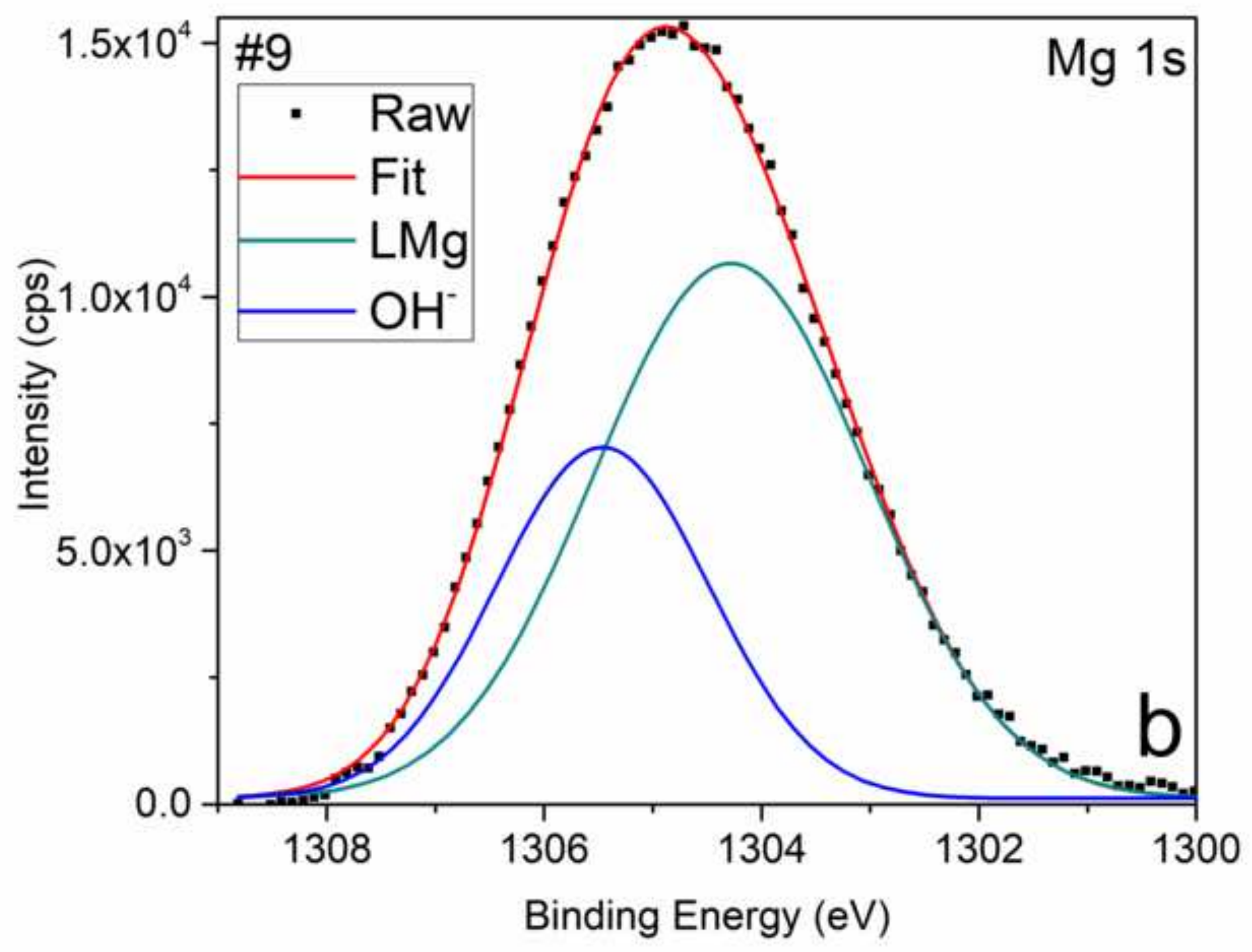




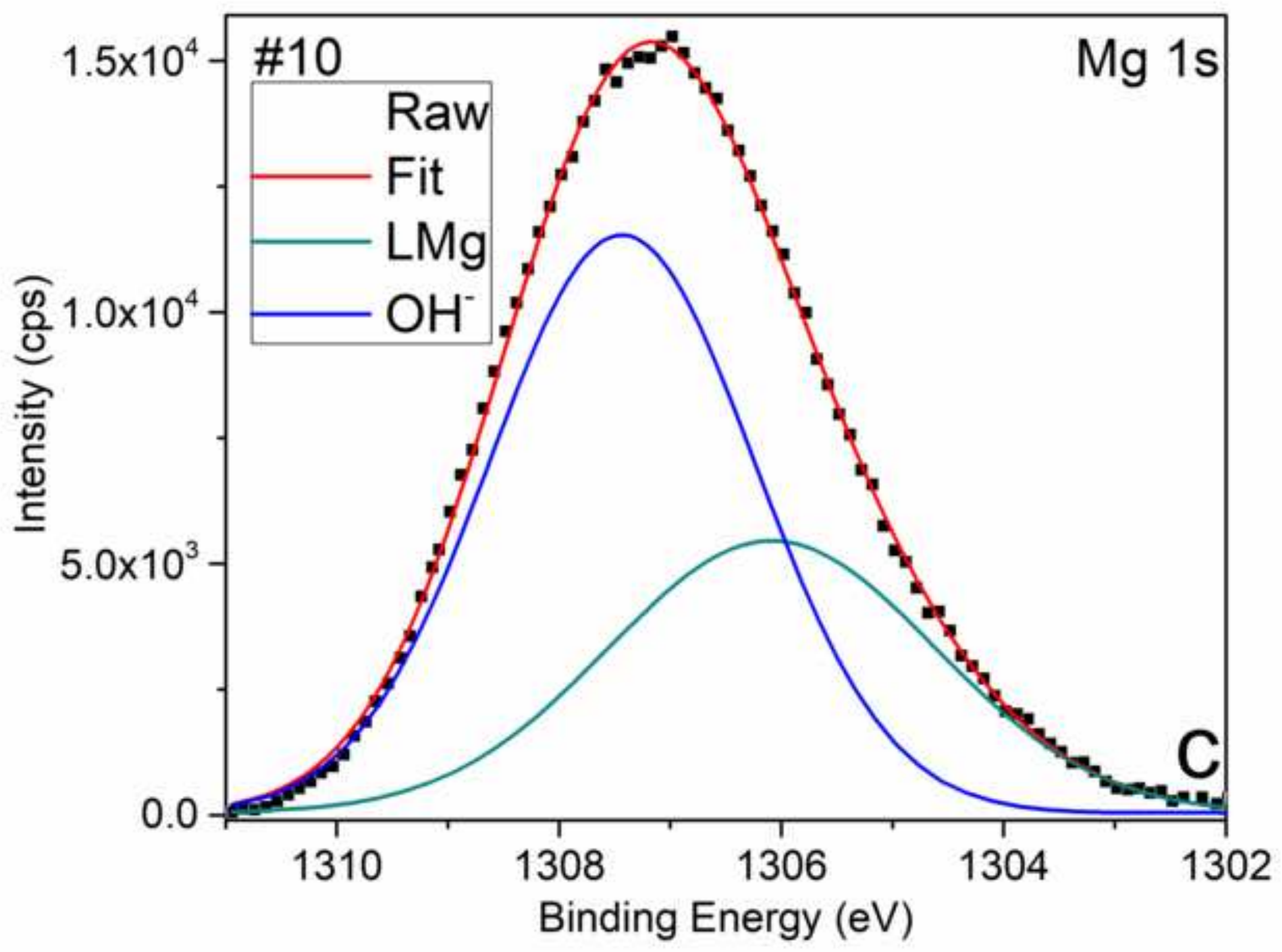




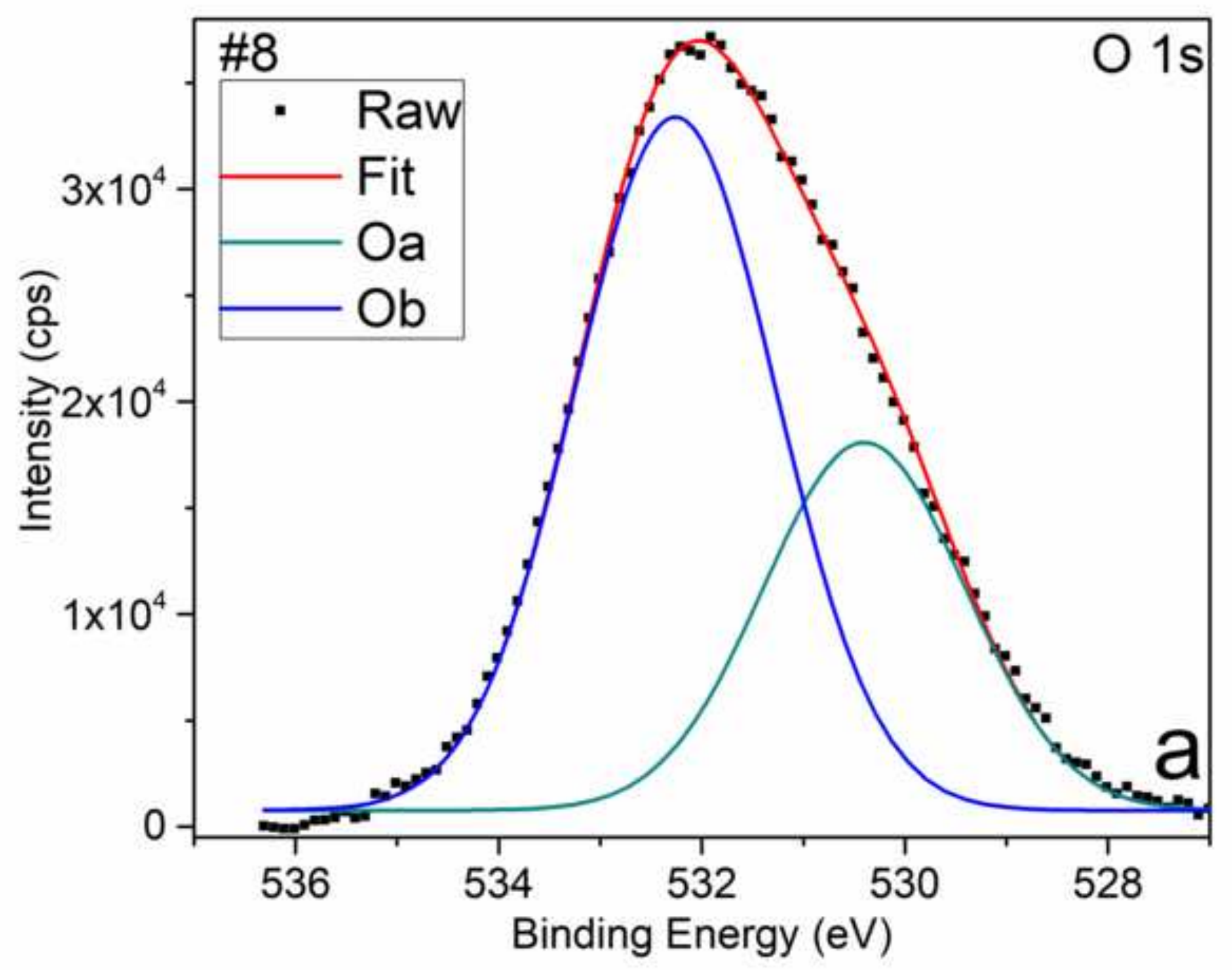




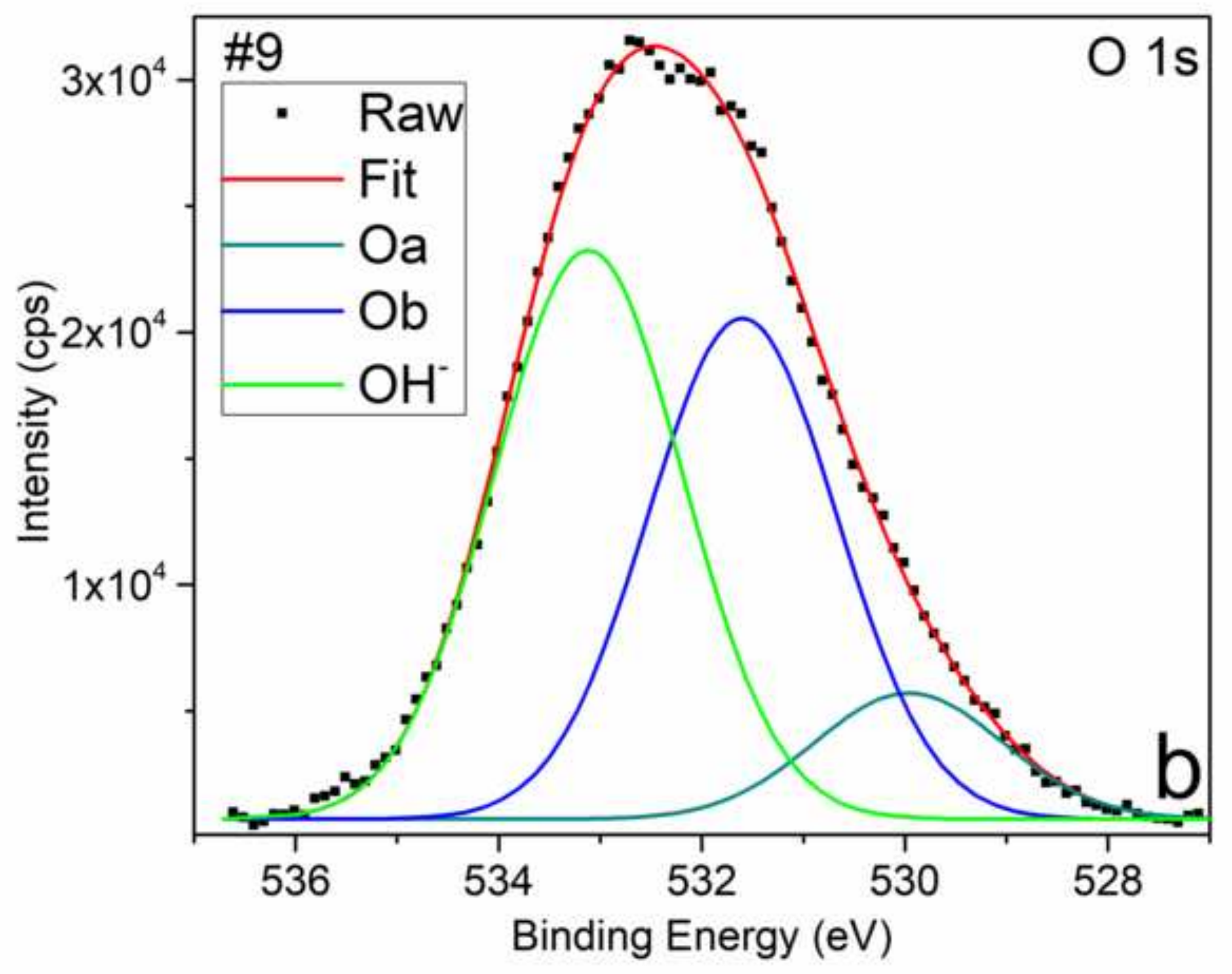




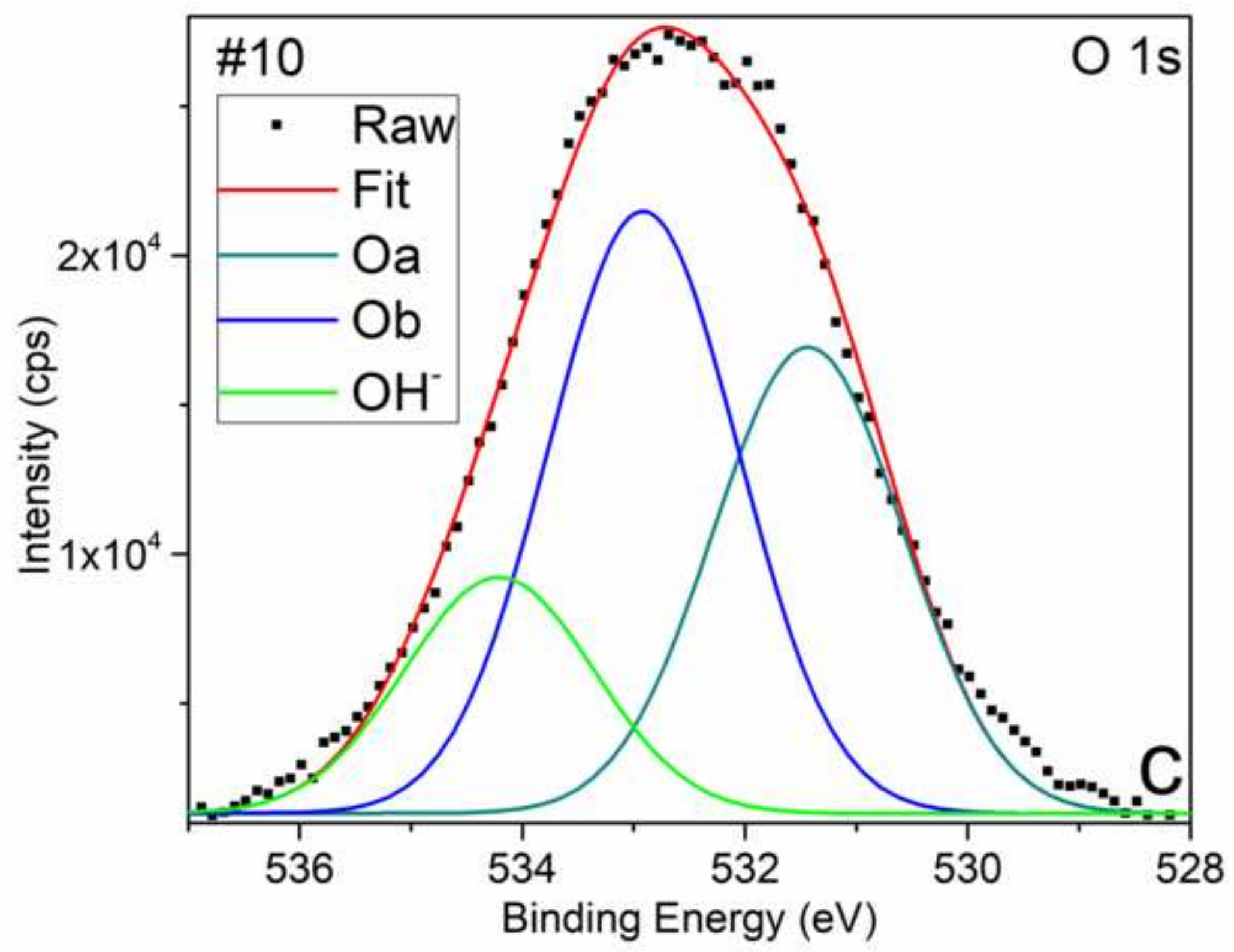




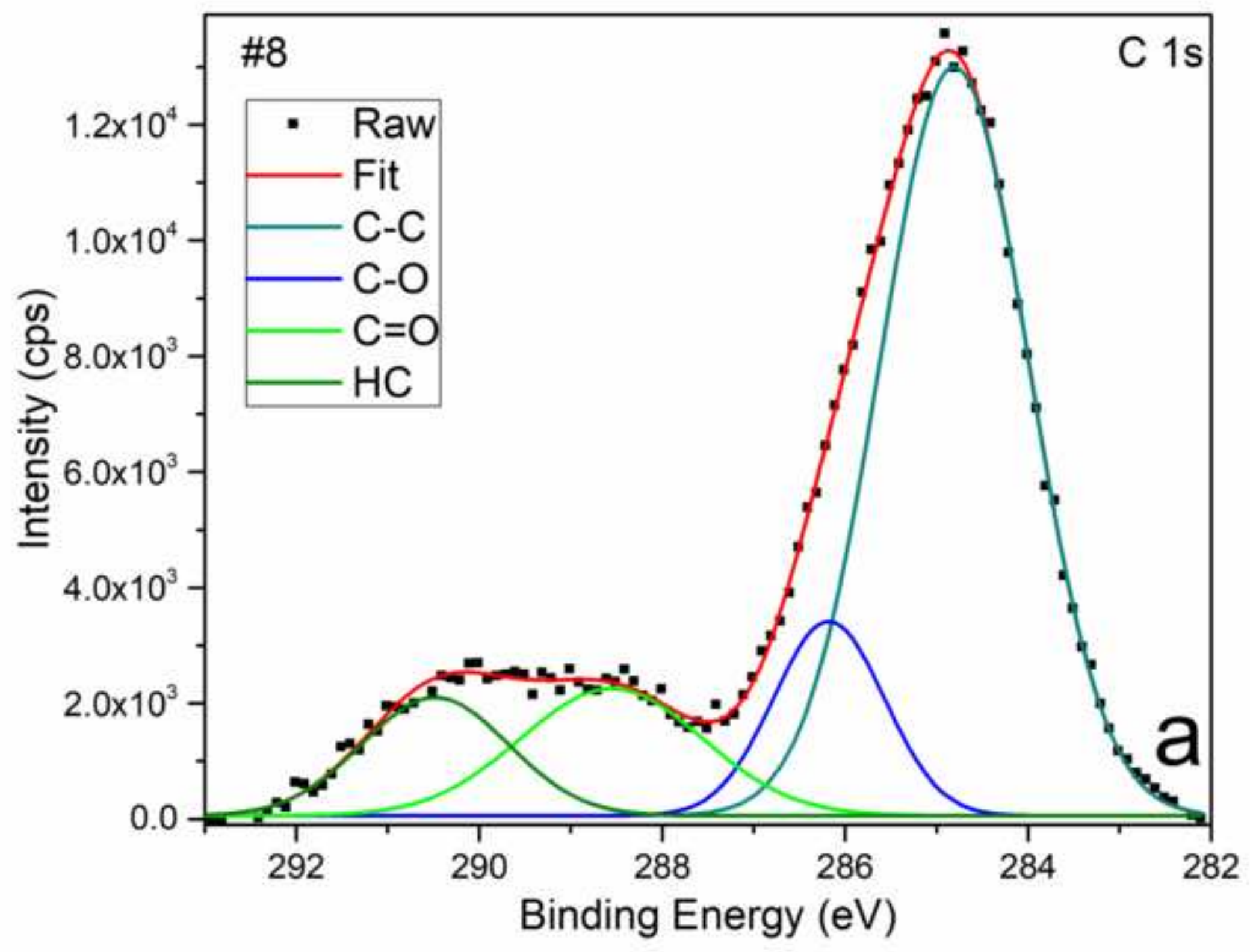




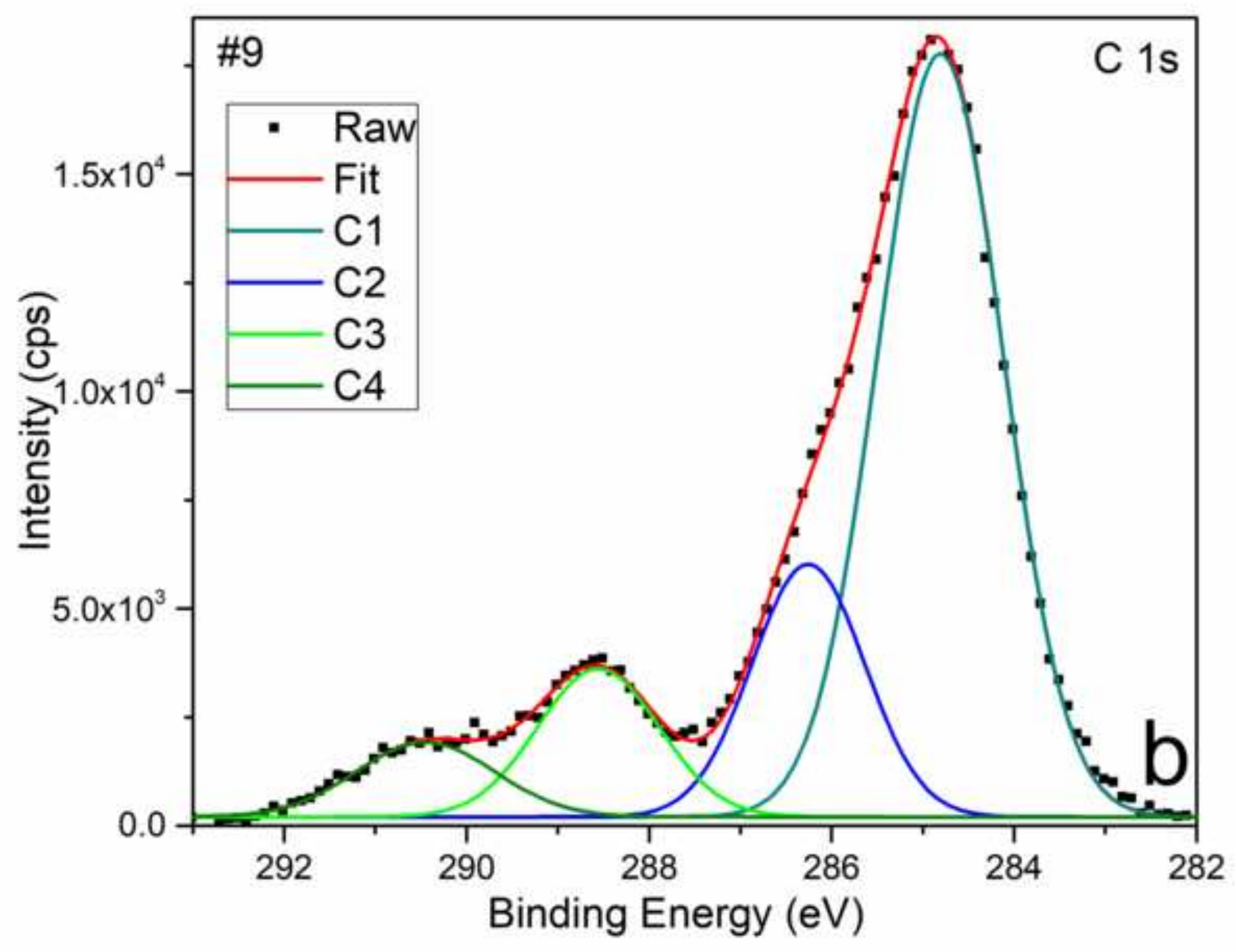




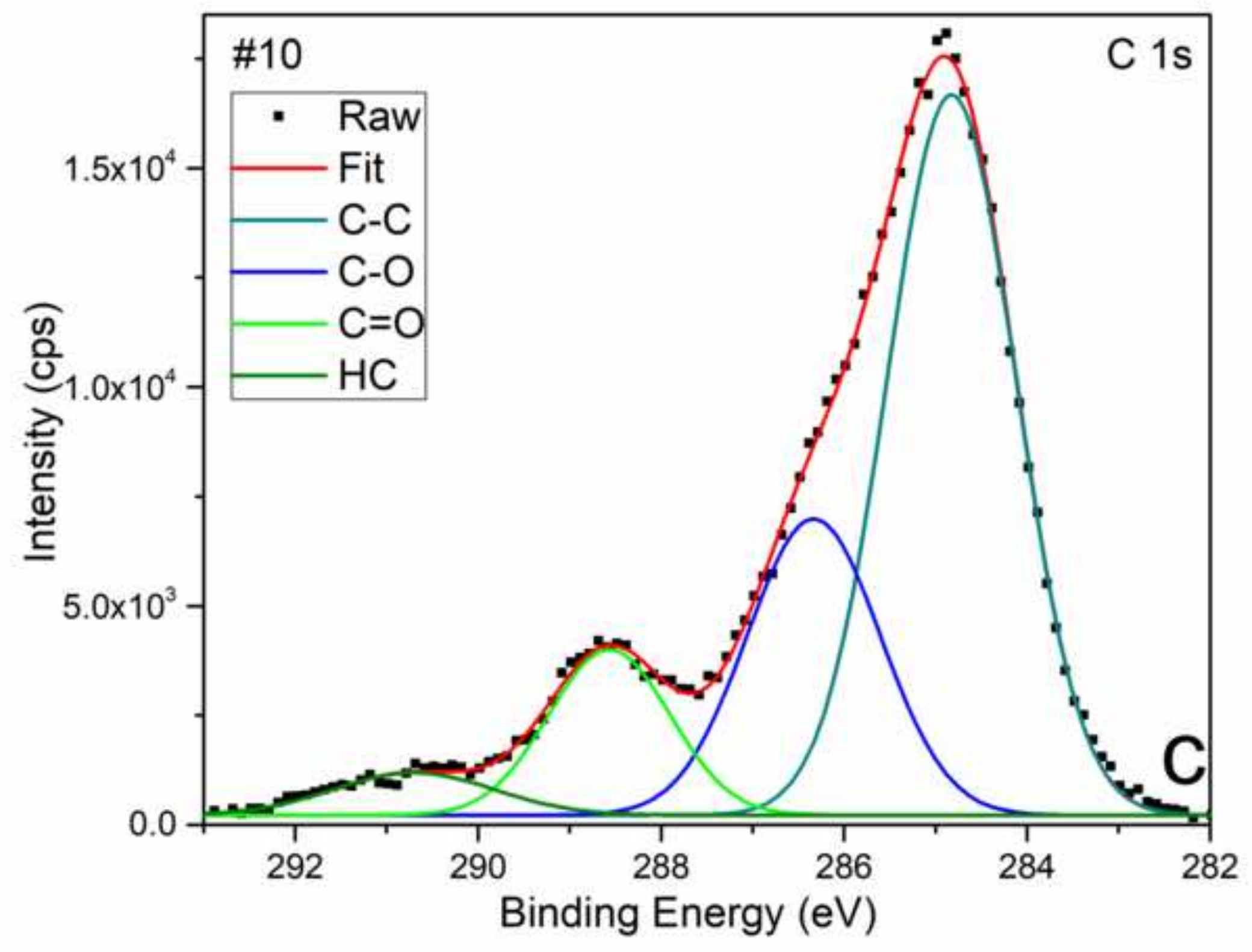




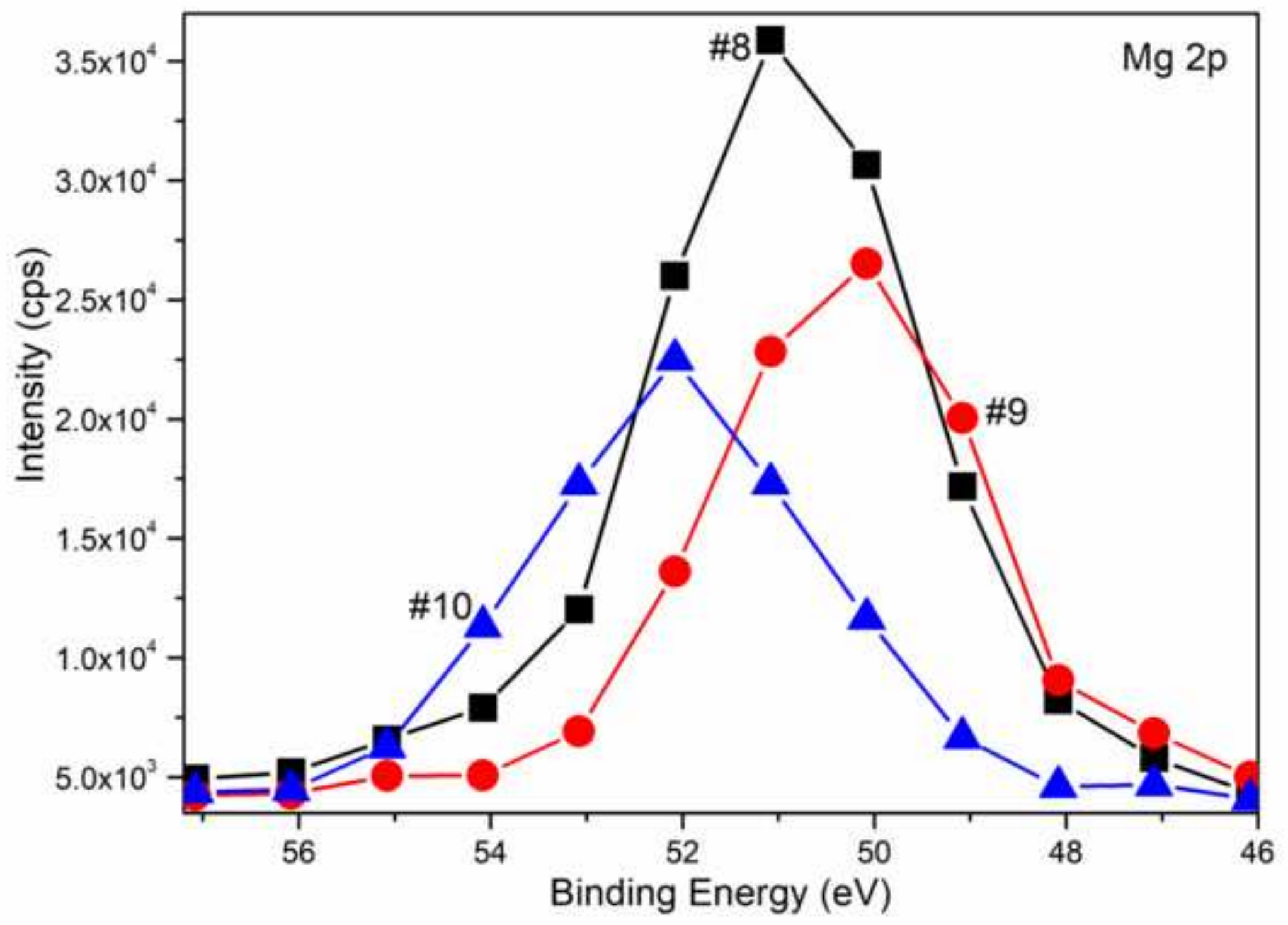




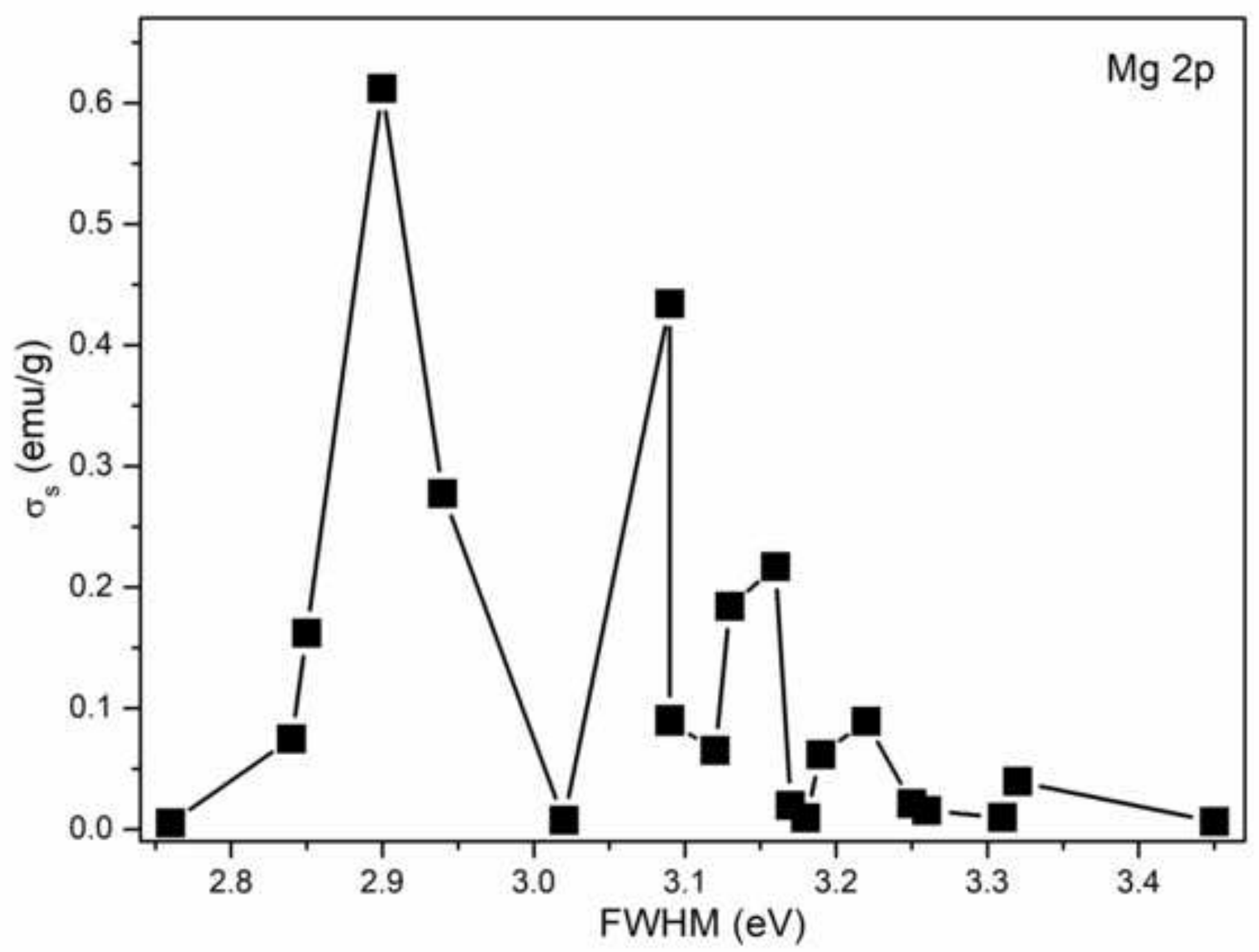


Supplementary Material for on-line publication only
Click here to download Supplementary Material for c

Click here to download Supplementary Material for on-line publication only: Supplementary Material.pdf 